\title{
The intermolecular Pictet-Spengler condensation with chiral carbonyl derivatives in the stereoselective syntheses of optically- active isoquinoline and indole alkaloids
}

\author{
Enrique L. Larghi, Marcela Amongero, Andrea B. J. Bracca, and Teodoro S. Kaufman* \\ Instituto de Química Orgánica de Síntesis (CONICET-UNR) and Facultad de Ciencias \\ Bioquímicas y Farmacéuticas, Universidad Nacional de Rosario, Suipacha 531 S2002LRK \\ Rosario, República Argentina \\ E-mail: tkaufman@fbioyf.unr.edu.ar
}

Dedicated to Dr. Rosa M. de Lederkremer on occasion of her $70^{\text {th }}$ anniversary

\begin{abstract}
The stereoselective Pictet-Spengler synthesis is one of the currently most important synthetic methodologies for the preparation of polysubstituted optically active tetrahydroisoquinolines and tetrahydro- $\beta$-carboline derivatives functionalized on $\mathrm{C}-1$. The intermolecular Pictet-Spengler condensation with chiral carbonyl derivatives constitutes an interesting and useful approach towards this goal, as summarized in this review. Strategies covered, which were developed during the last 15 years, include the intermolecular Pictet-Spengler reaction with the use of carbonyl derivatives tethered to removable chiral auxiliaries and the cyclocondensation of $\beta$ arylethylamines with chiral carbonyl components. Brief mention is also made to the occurrence of asymmetric $\beta$-carbolines in foodstuffs.
\end{abstract}

Keywords: Pictet-Spengler condensation, asymmetric synthesis, chiral aldehydes, optically active heterocycles, natural products

\section{Contents}

1. Introduction

2. The Pictet-Spengler condensation with chiral carbonyl compounds

3. Occurrence of chiral $\beta$-carbolines in food

4. Intermolecular condensation with aldehydes tethered to a chiral auxiliary

5. Intermolecular condensation with optically active aldehydes

5.1 Carbohydrates and derivatives

5.2 Use of aldehydes and derivatives prepared from aminoacids 


\subsubsection{Alanine}

5.2.2 Aspartic acid

5.2.3 Cysteine

5.2.4 Glutamic acid

5.2.5 Phenylalanine

5.2.6 Proline

5.2.7 Threonine

5.2.8 Tyrosine

5.3 Asymmetric cyclopropanation of enol ethers

5.4 Use of structurally complex non-carbohydrate naturally occurring aldehydes

5.4.1 Ircinal A and the synthesis of the manzamines

5.4.2 Condensation of secologanin with naturally occurring amines and derivatives

5.5 Use of structurally complex synthetic carbonyls

5.6 Quinic acid as a source of chirality

6. Concluding remarks

\section{Introduction}

The Pictet-Spengler condensation ${ }^{1}$ is one of the most important strategies available to the modern chemist for the synthesis of isoquinoline and indole alkaloids. It was discovered in 1911 by Amé Pictet and Theodor Spengler, ${ }^{2}$ when these scientists isolated 1-methyl-1,2,3,4tetrahydroisoquinoline (3) from the cyclocondensation of $\beta$-phenethylamine (1) with formaldehyde dimethyl acetal (2) in the presence of hydrochloric acid. ${ }^{3}$ The reaction was later modified to accept other $\beta$-phenethylamines such as $N$-alkyl, $N$-acyl and $N$-sulfonyl derivatives, proceeding via iminium, $N$-alkyliminium, $N$-acyliminium or $N$-sulfonyliminium ion formation, respectively (4) and subsequent intramolecular electrophilic substitution, as depicted in Scheme 1.

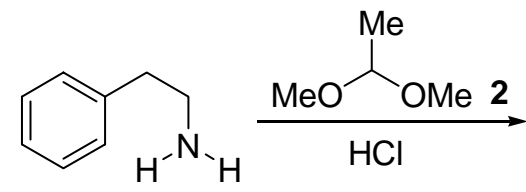

1

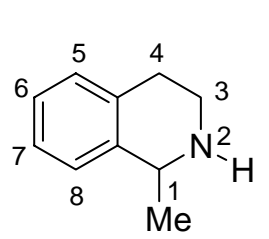

3

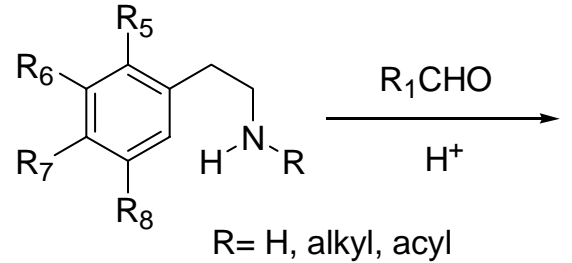

$\mathrm{R}=\mathrm{H}$, alkyl, acyl

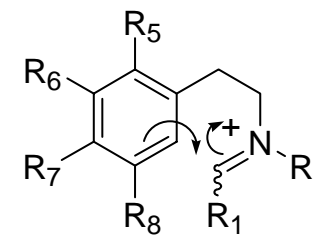

4<smiles>[R6]c1c([R8])c([R5])c2c(c1[R6])CCN([R])C2[R]</smiles>

\section{Scheme 1}


During almost two decades after its discovery, the original version of this transformation was employed exclusively for the synthesis of tetrahydroisoquinoline (THIQ) derivatives; however, in 1928 Tatsui prepared 1-methyl-1,2,3,4-tetrahydro- $\beta$-carboline (6) from tryptamine (5), demonstrating that the reaction could efficiently yield tetrahydro- $\beta$-carbolines (THBC), ${ }^{4}$ as shown in Scheme 2.

The mechanism of the Pictet-Spengler condensation to form THBC is characterized by the formation of an iminium intermediate (7) after the acid catalyzed reaction of a tryptamine derivative and an aldehyde (Scheme 2). However, unlike the synthesis of THIQ, this iminium ion may be attacked intramolecularly by the electrons of the pyrrole ring, either from C-2 or C-3.

Employing isotopic labeling, Bailey proved that the spiro-indolenine 8, which is formed after attack from the indole $\mathrm{C}-3$ position, may be a reaction intermediate, ${ }^{5}$ despite MNDO calculation results which have indicated that the rearrangement from 8 to intermediate $\mathbf{9}$ is energetically unfavorable. ${ }^{6}$ An alternative pathway, consisting in the direct attack from the $\mathrm{C}-2$ position $(\mathbf{7} \rightarrow \mathbf{9})$, is considered by many authors as the most plausible key step in the Pictet-Spengler condensation mechanism.

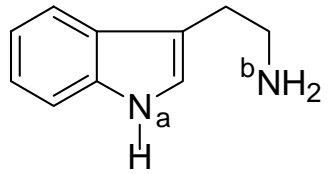

5

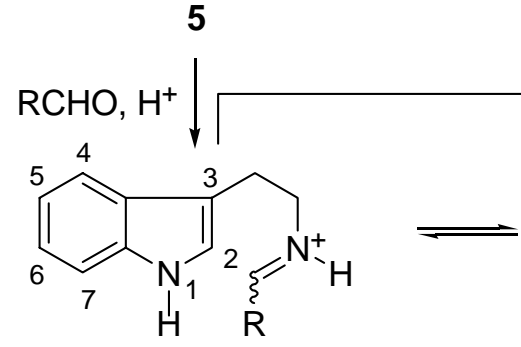

7

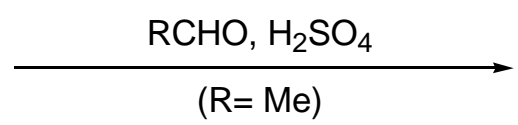

$(\mathrm{R}=\mathrm{Me})$

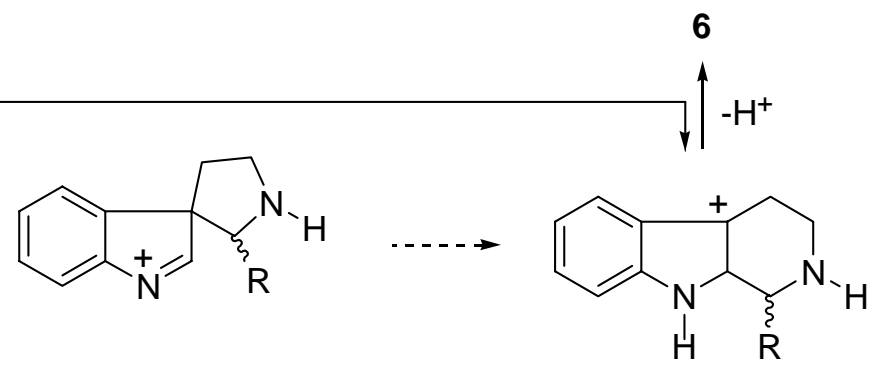

8

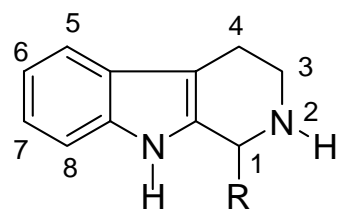

6

9

\section{Scheme 2}

Masked aldehydes (acetals, enol ethers, halomethyl methyl ethers, hemiaminals, $\alpha$ aminonitriles, $\alpha$-halo- $\alpha$-phenylthio-, $\alpha$-halo- $\alpha$-phenylseleno- derivatives, etc.) or aldehyde surrogates can be used in place of aldehydes, ${ }^{7}$ ketones can also be employed, intramolecular versions of the reaction for THIQ as well as for THBC are known, ${ }^{8}$ and the reaction has been carried out on solid supports. ${ }^{9}$

Almost a century-old reaction, the Pictet-Spengler condensation is now established as one of the most powerful methods for the construction of both THBC and THIQ frameworks; besides, other heterocyclic compounds have been synthesized employing the same strategy ${ }^{10}$ and the related oxa-Pictet-Spengler condensation provides a convenient and widely used entry to isochromans. $^{11}$ 
A host of naturally occurring indole and isoquinoline alkaloids, with a wide range of important biological activities, including pharmaceutically useful properties, have been synthesized employing this reaction. Interestingly, however, despite that the transformation was first discovered and applied in the field of THIQ, current literature citations regarding the application of the Pictet-Spengler condensation for the synthesis of heterocycles mostly relate to the preparation of THBC derivatives.

The Pictet-Spengler reaction also takes place under enzymatic catalysis and it has been demonstrated that the key step for the biogenesis of monoterpene indole alkaloids consists in the Pictet-Spengler condensation of tryptamine with secologanin to afford strictosidine; ${ }^{12}$ analogously $R$-salsolinol synthase catalyzes the reaction of dopamine with acetaldehyde forming the $R$-salsolinol in brain. ${ }^{13}$ The reaction also takes place when tryptophan is employed as substrate $^{14}$ and recent studies have demonstrated the wide presence of Pictet-Spengler condensation products in foodstuff. ${ }^{15}$ In addition, it has been proposed that the formation of the so-called "mammalian alkaloids" as $R$-salsolinol, produced during conditions such as aberrant metabolism in alcoholism, phenylketonuria, L-Dopa chemotherapy of Parkinson's disease and mental diseases such as schizophrenia may take place through Pictet-Spengler condensations. ${ }^{16}$

The interest of chemists in the total synthesis of isoquinoline and indole alkaloids is of long date, mainly because these natural products are structurally complex and interesting or exhibit biological properties of high value. The antitumor properties ${ }^{17}$ of some vinca alkaloids such as vincristine and vinblastine are still of clinical significance and the cardiovascular effects of reserpine and ajmaline have long been known, ${ }^{18}$ being reserpine still in pharmaceutical use. Other indole alkaloids exhibit antiparasitary activity, ${ }^{19}$ as well as monoaminooxidase inhibiting activity $^{20}$ and some THBC have shown to display anxiogenic, convulsant, proconvulsant, somnolytic and other CNS-related properties by binding or interacting with key entities, such as the $\mathrm{GABA}_{\mathrm{A}}$ receptor ion channel. ${ }^{21}$

On the other hand, complex isoquinoline alkaloids, such as the saframycins, the ecteinascidins $^{22}$ and related compounds ${ }^{23}$ have evidenced potentially useful activity as antitumor antibiotics and synthetic compounds such as HR22C16 exhibit cell-division inhibitory activity. ${ }^{24}$ Most of the syntheses or synthetic attempts towards these compounds involved Pictet-Spengler cyclizations.

Since the end of the 1980s, the stereoselective synthesis of complex isoquinoline alkaloids has been a field of increasing interest in synthetic organic chemistry ${ }^{25}$ as reflected in the spectrum of published strategies that report highly stereoselective syntheses of THIQ and THBC with different substitution patterns at the heterocyclic ring system. Most of these publications have paid special attention to the 1 -substituted derivatives, ${ }^{26}$ which are diverse, relatively abundant in nature and have demonstrated to be extremely useful intermediates for the preparation of a wide range of other related alkaloids.

The literature records multiple approaches to the asymmetric synthesis of 1-substituted THIQ and THBC derivatives employing the Pictet-Spengler strategy. These include the use of 1,4chirality transfer, ${ }^{27} 1,3$-chirality transfer, ${ }^{28}$ removable chiral auxiliaries bound to the nitrogen $\left(\mathrm{N}_{\mathrm{b}}\right.$ 
in case of THBC), ${ }^{29}$ as well as chiral Lewis acids and other compounds as catalysts. ${ }^{30}$

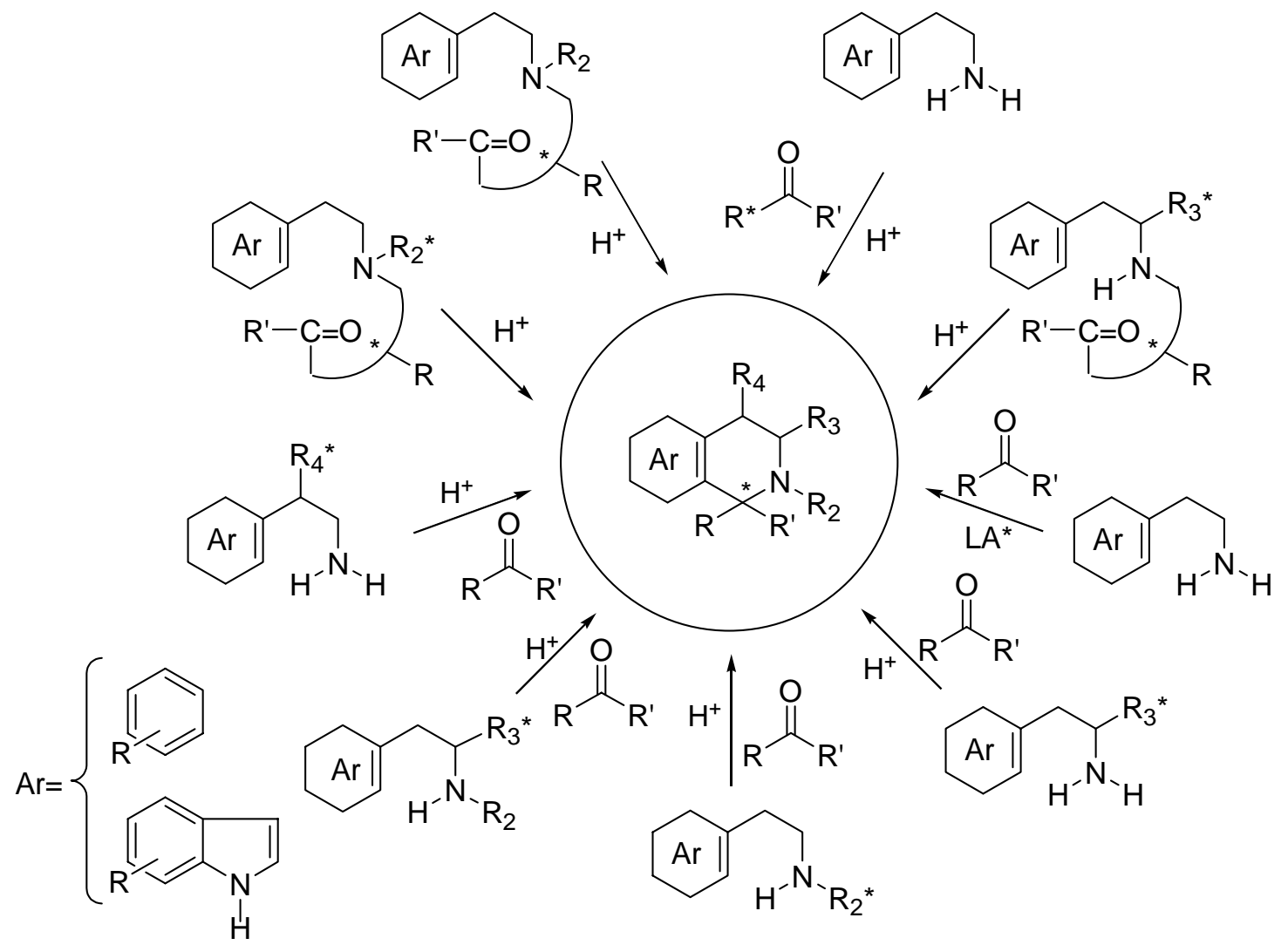

Scheme 3

In addition, optically active aldehydes and ketones ${ }^{31}$ as well as intramolecular versions where optically active aldehydes or their precursors are tethered to the amino group of $\beta$ phenethylamine or tryptamine derivatives ${ }^{32}$ have found wide use, part of these being the subject of this review. Other recorded syntheses include combinations of the above strategies, ${ }^{33}$ as summarized in Scheme 3.

\section{The Pictet-Spengler condensation with chiral carbonyl compounds}

The major key point in the development of an asymmetric Pictet-Spengler reaction is an efficient generation of an asymmetric iminium intermediate. The possibility for enantioselective synthesis of THIQ from $\beta$-phenethylamine or 3,4-dimethoxy-phenylalanine (DOPA) instead of using the readily available aminoacids phenylalanine or tyrosine, is hindered by the absence of the stereodirecting effect of the carboxy group, which operates through 1,3-chirality transfer. The same effect is operative during the stereoselective elaboration THBC derived from tryptamine instead of tryptophan or its esters.

Therefore, the use of chiral carbonyl components in the intermolecular Pictet-Spengler 
condensation is a valuable strategy for obtaining chiral iminium intermediates and achieving chirality transfer from the optically active reagent to the newly generated C-1 stereocenter. This strategy, which is a permanently active field of research, entails a diastereoselective synthesis.

Among the numerous attractive syntheses described in the recent literature, this work will cover only those approaches in which the carbonyl component is optically active, although not always the only source of chirality. ${ }^{34}$ In addition, despite many interesting intramolecular transformations have been carried out employing either vinylogous carbonyls ${ }^{35}$ or chiral carbonyls and their synthetic equivalents (not always aldehydes) ${ }^{36}$ tethered to the nitrogen atom of the $\beta$-arylethylamine precursor, ${ }^{37}$ only intermolecular Pictet-Spengler syntheses will be discussed.

Synthetic strategies reported in the literature have been divided in those employing carbonyls attached to a removable chiral auxiliary and those in which at least one of the asymmetric centers present in the chiral carbonyl moiety forms part of the desired final product.

Among the former, optically active carbonyl components employed to date comprise those making use of sulfur chirality (sulfoxides), as well as that found in naturally occurring cyclohexyl derivatives such as menthol and bicyclics like camphor. The aminoacid-derived aldehydes have also been taken into account.

Ideally, these chiral auxiliaries require not only ready availability and affordable costs, but also appropriate and efficient methods for their removal once the Pictet-Spengler reaction has been carried out, without affecting the optical integrity of the newly generated stereogenic center and, preferably, the accessibility of both enantiomers of the optically active moiety. These simple requirements seriously restrict the number of potentially useful candidates amenable for use, and constitute a strong driving force behind the development of new compounds, since all of the known and proven chiral auxiliaries have both advantages and drawbacks, and the ideal chiral auxiliary has not been discovered yet.

The intermolecular condensation strategies, which employ chiral carbonyls, have been divided according to the source or mode of preparation of these optically active moieties. The use of carbohydrates, aminoacids and quinic acid or their derivatives as sources of chiral materials is discussed, as well as asymmetric reactions leading to optically active carbonyls, such as chiral cyclopropanation. A couple of sections are also dedicated each to the use of complex synthetic as well as naturally occurring aldehydes, such as secologanin and ircinal A, as components in the Pictet-Spengler cyclocondensation.

\section{Occurrence of optically active $\beta$-carbolines in food}

Aldohexoses react with tryptophan (10), furnishing carbohydrate-derived tetrahydro- $\beta$-carboline3 -carboxylic acids (12) and $\beta$-carbolines (13), as shown in Scheme 4. Diem and Herderich ${ }^{38}$ have detected novel glyco-tetrahydro- $\beta$-carboline-3-carboxylic acids in model reactions of tryptophan with hexoses and pentoses, as well as in food samples (soy sauce, fish sauce, ketchup, and in 
alcoholic beverages such as beer, wine and sherry) in the $\mu \mathrm{g} / \mathrm{L}$ to $\mathrm{mg} / \mathrm{L}$ range, Herraiz and Galisteo found that the cis/trans ratio of THBC formed was different in grape juice, pineapple juice and tomato juice, the trans isomer prevailing only in the latter, while Rönner and coworkers $^{39}$ investigated the oxidative decarboxylation of 1-(D-gluco- 1,2,3,4,5-penta hydroxypentyl)-1,2,3,4-tetrahydro- $\beta$-carboline-3-carboxylic acid which resulted in formation of 1 -(D-gluco-1,2,3,4,5-pentahydroxypentyl)- $\beta$-carboline $(\mathbf{1 1} \rightarrow \mathbf{1 2})$.

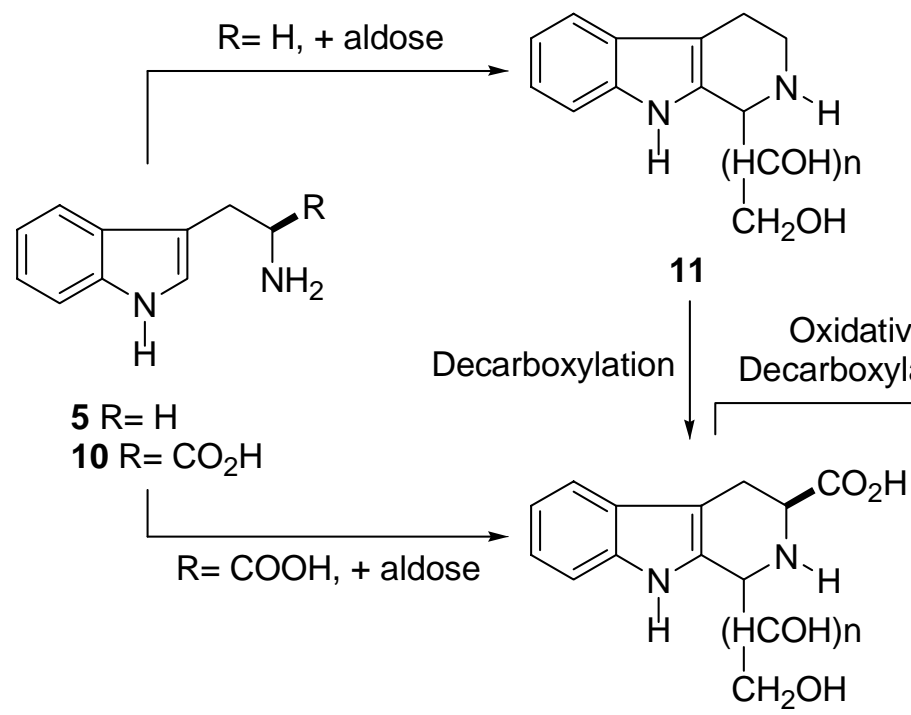

12

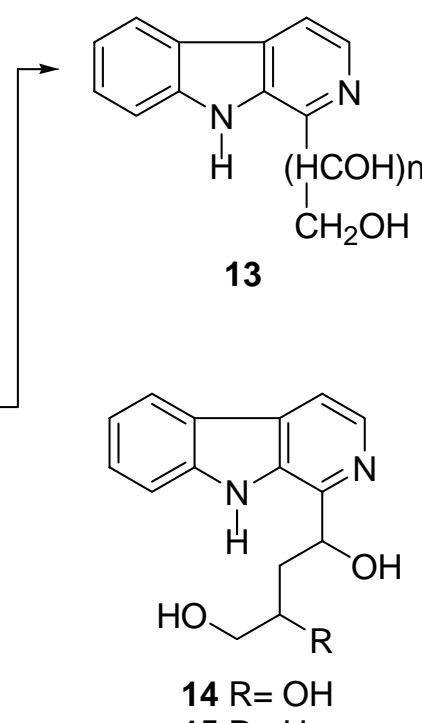

$15 \mathrm{R}=\mathrm{H}$

\section{Scheme 4}

In addition, Wang and co-workers identified 1-(1,3,4-trihydroxybutyl)- $\beta$-carboline (14) and 1 -(1,4-dihydroxy butyl)- $\beta$-carboline (15) in model reactions of tryptophan with xylose ${ }^{40}$ and the group of Herderich has recently identified numerous hexose- and pentose-derived $\beta$-carbolines in food samples ${ }^{41}$ and studied the formation pathway of these novel alkaloids. ${ }^{42}$

According to Wang, the formation of compounds 14 and 15 from tryptophan and xylose, involves a sequence including Pictet-Spengler condensation, oxidative decarboxylation, tautomerization, and dehydrogenation steps, a mechanism in which isomerization of the sugarderived side chain at C-1' is essential. The use of glucose as model sugar allowed confirmation of the side chain isomerization feature. These compounds may be acting as antioxidants.

\section{Intermolecular condensation with aldehydes tethered to a removable chiral auxiliary}

The use of the stereogenic sulfur center of a chiral sulfoxide to achieve stereocontrol in the elaboration of optically active compounds has been widely demonstrated and the sulfinyl group is currently an important tool in auxiliary-induced asymmetric synthesis. ${ }^{43}$

The effectiveness of this moiety is due to the steric as well as the stereoelectronic differences existing between the four different substituents of the sulfur atom, which are able to differentiate 
the diastereotopic faces of the proximal reaction center. Other influential factors contributing to the wide use of sulfoxides are their high configurational stability, the availability of an important number of efficient synthetic methods to obtain homochiral sulfoxides and procedures for their removal under mild conditions, as well as their synthetic versatility. ${ }^{44}$

The cyclization of vinyl sulfinyl derivatives leading to THIQ or THBC derivatives reported to date through the tandem Michael addition-acid induced cyclization reaction sequences ${ }^{45}$ can be regarded as special cases of the Pictet Spengler reaction in which the aromatic part conclude the heterocyclic ring closure initiated by Michael addition. ${ }^{46}$ These strategies complement alkaloid syntheses in which the vinyl sulfinyl moiety is attached to the aromatic ring, suffering stereoselective ring closure by Michael addition of the ethylamino nitrogen onto the double bond. $^{47}$

The group of Lee ${ }^{48}$ prepared chiral acetylenic sulfoxides $21 \mathbf{a}$ and $\mathbf{2 1 b}$ by reaction of trimethylsilylacetylenyl magnesium bromide with chiral menthyl sulfinates $\mathbf{1 8}$ and 19, through the intermediacy of $\mathbf{2 0 a}$ and 20b. Andersen synthesis was employed for the elaboration of (-)menthyl-p-toluenesulfinate (18), and the Sharpless' procedure ${ }^{49}$ was used for the preparation of (-)-menthyl 2-nitrobenzene sulfinate, both from natural menthol (16) and sulfonyl chlorides 17a and $\mathbf{1 7 b}$, as depicted in Scheme 5.<smiles>CC(C)C1CC[C@@H](C)C[C@H]1O</smiles>

16
$17 a$ or $17 b$,

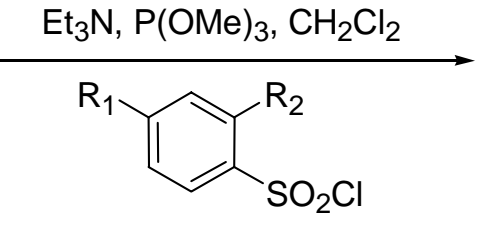

17a Ar: $\mathrm{R}_{1}=\mathrm{Me}, \mathrm{R}_{2}=\mathrm{H}$

17b Ar: $R_{1}=H, R_{2}=N_{2}$

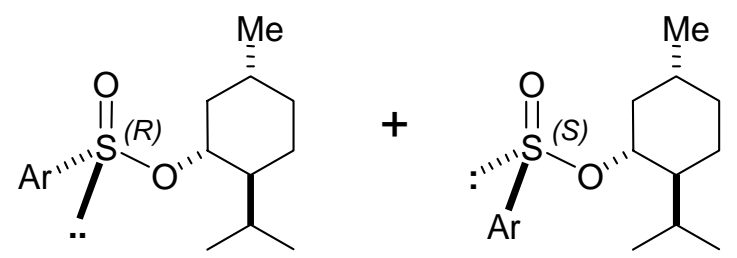

18 Ar: $\mathrm{R}_{1}=\mathrm{Me}, \mathrm{R}_{2}=\mathrm{H}$

19 Ar: $\mathrm{R}_{1}=\mathrm{H}, \mathrm{R}_{2}=\mathrm{NO}_{2}$

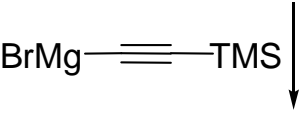

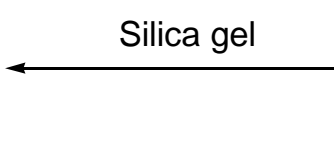

21a Ar: $R_{1}=M e, R_{2}=H$

21b Ar: $R_{1}=H, R_{2}=N_{2}$

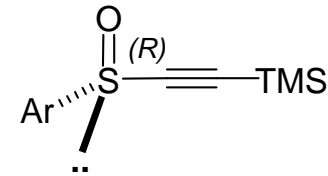

20a Ar: $R_{1}=M e, R_{2}=H$

20b Ar: $R_{1}=H, R_{2}=N_{2}$

\section{Scheme 5}

Then, the acetylenic sulfoxides were submitted to a Michael addition with 3,4dimethoxyphenethylamine (22), furnishing vinyl sulfoxides 23, which were cyclized in chloroform under TFA catalysis (Scheme 6). Several factors affecting the yield and diastereomeric ratio were detected. The type of acid and the temperature were found to be important, with the transformation having its best performance in the presence of TFA at $0^{\circ} \mathrm{C}$. 
Table 1. Diastereoselective cyclization of vinyl sulfoxides 23 to THIQ 25 in $\mathrm{CHCl}_{3}$

\begin{tabular}{cccccc}
\hline Entry $\mathrm{N}^{\mathbf{0}}$ & $\mathrm{Ar}$ & Acid & Temp $\left({ }^{\circ} \mathrm{C}\right)$ & $\mathbf{2 5 a} / \mathbf{2 5 b}$ & Yield (\%) \\
\hline 1 & $2-\mathrm{NO}_{2}-\mathrm{C}_{6} \mathrm{H}_{4}$ & TFA & -20 & - & - \\
2 & $2-\mathrm{NO}_{2}-\mathrm{C}_{6} \mathrm{H}_{4}$ & TFA & 0 & $100: 0$ & 65 \\
3 & $2-\mathrm{NO}_{2}-\mathrm{C}_{6} \mathrm{H}_{4}$ & TFA & $\mathrm{RT}$ & $100: 0$ & 35 \\
4 & $2-\mathrm{NO}_{2}-\mathrm{C}_{6} \mathrm{H}_{4}$ & $\mathrm{BF}_{3} \cdot \mathrm{Et} \mathrm{H}_{2} \mathrm{O}$ & 0 & $100: 0$ & 20 \\
5 & $4-\mathrm{Me}_{-} \mathrm{C}_{6} \mathrm{H}_{4}$ & TFA & 0 & $67: 33$ & 45 \\
\hline
\end{tabular}

On the other hand, the substituent on the benzene ring of the starting aryl sulfoxide influenced the optical course of the cyclization; when para-toluenesulfinate was employed, a 2:1 mixture of diastereomers 25a and 25b $\left(\mathrm{Ar}=4-\mathrm{Me}-\mathrm{C}_{6} \mathrm{H}_{4}\right)$ was realized; however, when the nitroderivative was used, exclusive formation of 25a $\left(\mathrm{Ar}=2-\mathrm{NO}_{2}-\mathrm{C}_{6} \mathrm{H}_{4}\right)$ was observed, as consigned in Table 1.

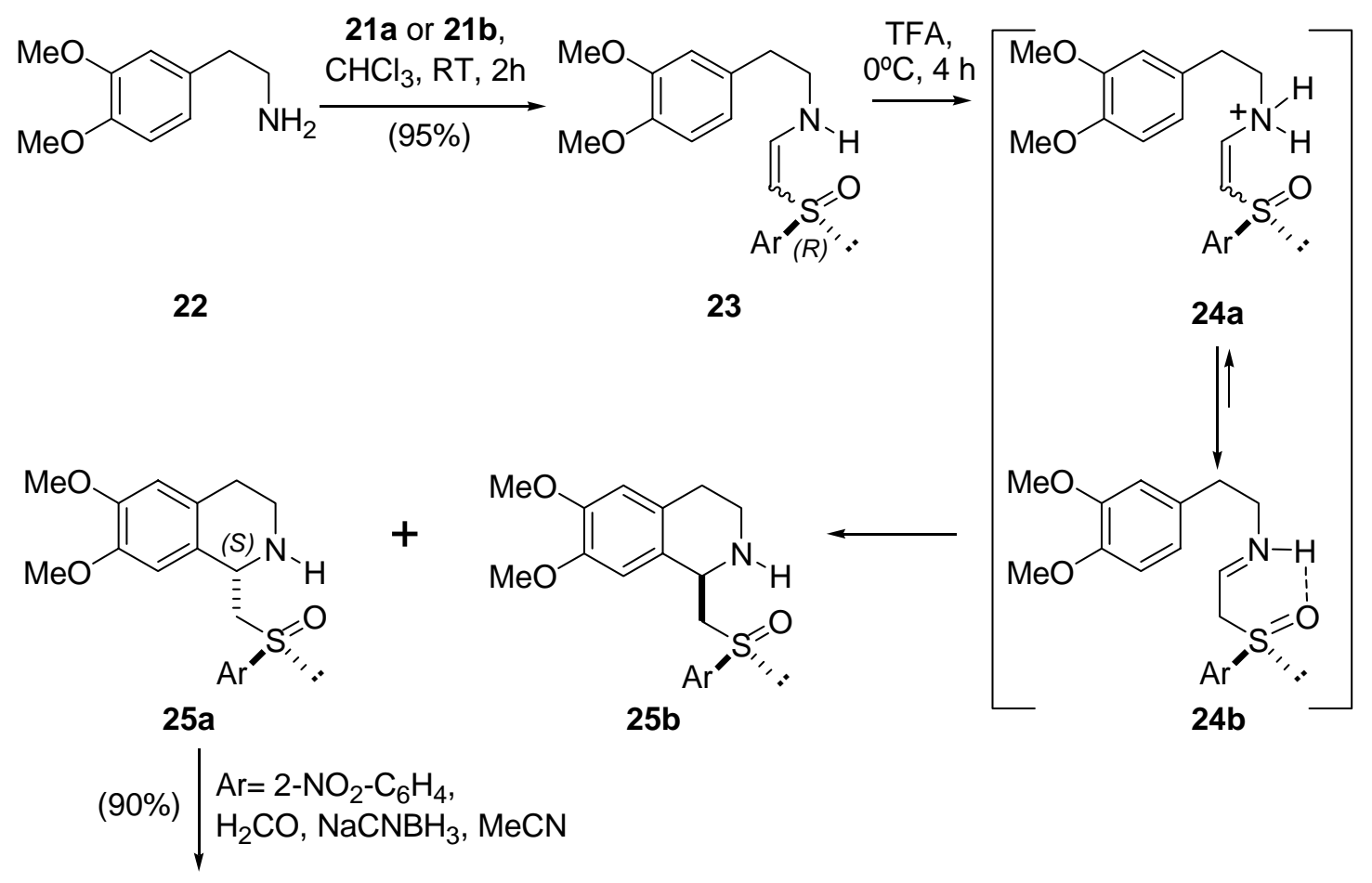<smiles>COc1cc2c(cc1OC)[C@H](C[SH](C)(C)=[18O])N(C)CC2</smiles><smiles>CCO[C@H](C)O[Mg]</smiles>

\section{Scheme 6}


These effects of the substituents on the diastereoselectivity was rationalized assuming that under the influence of the acid, the protonated amine 24a and the enamine $24 \mathbf{b}$ are in equilibrium, with the latter as the predominant species. A hydrogen bond could be formed under these conditions, leading to a six-member ring intermediate, which locks the conformation of the molecule.

The higher diastereoselectivity observed with the nitro derivative, was assigned to the differential stability of the transition states; these involve hydrogen bond stabilization of the cyclizing intermediate by the presence of the electron withdrawing substituent in close proximity to the sulfoxide.

To complete the synthesis, sulfoxide $\mathbf{2 5 a}$ was reductively $\mathrm{N}$-methylated under conventional conditions and then desulfurized with Raney nickel in water-saturated ether, yielding $R-(+)-$ carnegine [(+)-27]. Interestingly enough, the resulting $\mathbf{2 6}$ is analogous to a THIQ accessed by a slightly different route by the group of Pyne. ${ }^{50}$

An interesting feature of this sequence disclosed by the same group (Scheme 7$)^{51}$ is that employing $N$-methyl-3,4-dimethoxy- $\beta$-phenethylamine (28) as starting amine and nitroderivative 21b as chiral sulfoxide. Cyclization of intermediate vinylsulfoxide 29 proceeds with reverse diastereoselectivity, furnishing a 1.8:1 mixture of diastereomers in favor of $\mathbf{3 0 b}$, less polar than its congener 30a. Raney nickel desulfurization of the chiral auxiliary in the major diastereomer, as above, provided $S$-(-)-carnegine (S-27), being this a complementary and more convergent way of accessing the natural product.

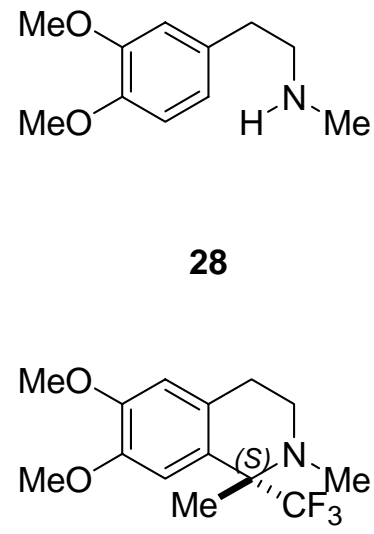

31

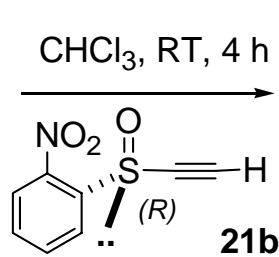

21b<smiles>COc1ccc(CCN(C)/C=C\[SH](=O)=O)cc1OC</smiles>

29<smiles>[3H][Te][SH](C)(C)=O</smiles>

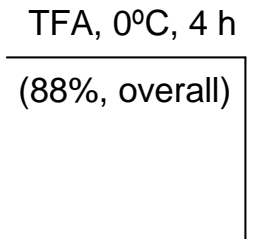

(88\%, overall)

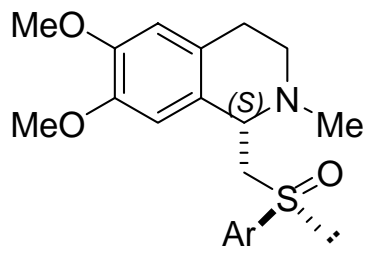

$30 a$

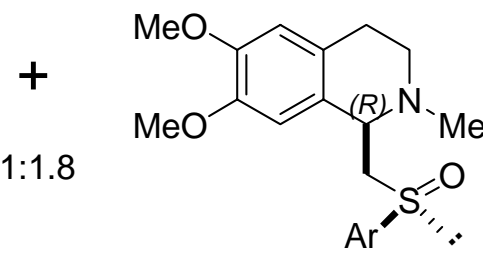

$30 \mathrm{~b}$

\section{Scheme 7}

Notably enough, an extension of this cyclization reaction involving a stabilized sulfinylimine intermediate was recently employed for the elaboration of 1-trifluoromethyl carnegine $(S$ 31). ${ }^{52}$

Singh and coworkers reported that simple oxazinanes can be employed as carbonyl equivalents to synthesize otherwise inaccessible 1,3-disubstituted THBCs in a highly 
diastereoselective manner. ${ }^{53}$ As an application of these findings the group developed optically active oxazinanes as chiral carbonyl equivalents with a possibility of C-2 elaboration. Singh also demonstrated their effective use in asymmetric synthesis of THBCs and related systems and also a convenient extension of Meyer's approach ${ }^{54}$ for the synthesis of new, stereochemically homogenous chiral oxazines. The usefulness of the latter as two carbon synthons for enantio- and diastereselective synthesis of THBC, convertible into congeners of yohimbine alkaloids, was also studied (Scheme 8).<smiles>CC(C)C1CC[C@@H](C)C[C@H]1OS(C)(=O)=O</smiles>

18<smiles>CC1=NC(C)(C)CC(C)O1</smiles>

32

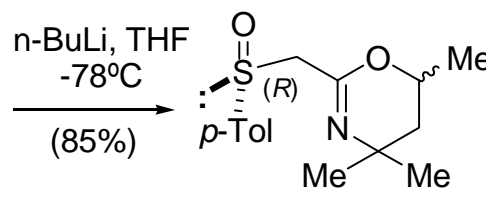

33

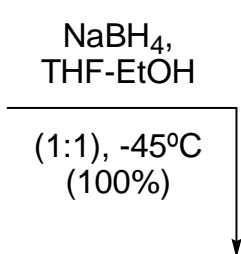<smiles>CC1CC(C)(C)N(C)[C@H](CS(=O)(=O)O)O1</smiles>

$5 \mathrm{R}=\mathrm{R}_{1}=\mathrm{H}$

35a R $=\mathrm{H}, \mathrm{R}_{1}=4-\mathrm{OMe}-\mathrm{C}_{6} \mathrm{H}_{4}-\mathrm{CH}_{2}$

35b $\mathrm{R}=\mathrm{CO}_{2} \mathrm{Me}, \mathrm{R}_{1}=\mathrm{H}$

35c R $=\mathrm{CO}_{2} \mathrm{CHMe}_{2}, \mathrm{R}_{1}=\mathrm{H}$

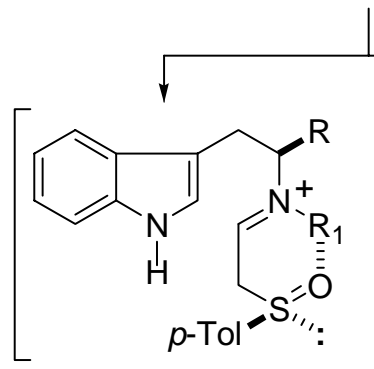

$36 a$

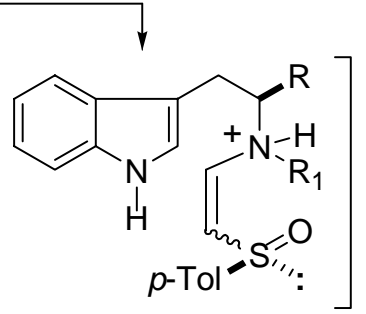

$36 b$

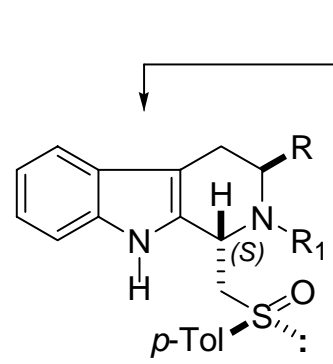

37a $\mathrm{R}=\mathrm{R}_{1}=\mathrm{H}$

37b $\mathrm{R}=\mathrm{CO}_{2} \mathrm{Me}, \mathrm{R}_{1}=\mathrm{H}$

37c $\mathrm{R}=\mathrm{CO}_{2} \mathrm{CHMe}_{2}, \mathrm{R}_{1}=\mathrm{H}$

37d R= H, R $=4-\mathrm{OMe}-\mathrm{C}_{6} \mathrm{H}_{4}-\mathrm{CH}_{2}$ 38a $R=R_{1}=H$

38b $\mathrm{R}=\mathrm{CO}_{2} \mathrm{Me}, \mathrm{R}_{1}=\mathrm{H}$

38c $\mathrm{R}=\mathrm{CO}_{2} \mathrm{CHMe}_{2}, \mathrm{R}_{1}=\mathrm{H}$

38d $\mathrm{R}=\mathrm{H}, \mathrm{R}_{1}=4-\mathrm{OMe}-\mathrm{C}_{6} \mathrm{H}_{4}-\mathrm{CH}_{2}$

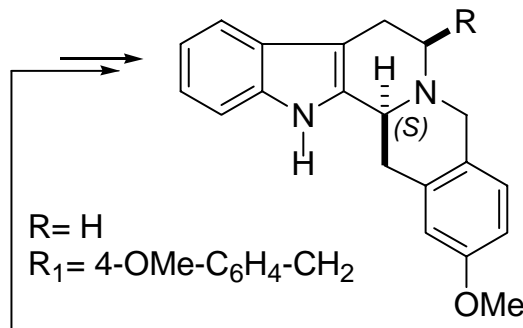

39

Raney nickel,

$\mathrm{EtOH}$, reflux

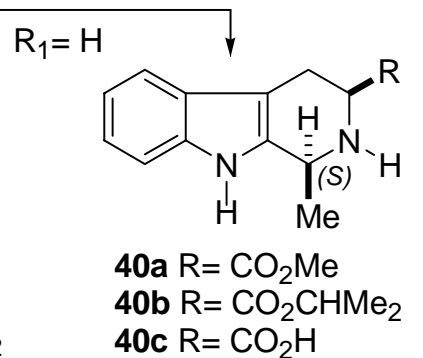

\section{Scheme 8}


Reaction of metallated 2,4,4,6-tetramethyl-5,6-dihydro-(4H)-1,3-oxazine 32 with S-(-)Andersen's reagent $18^{55}$ at $-78^{\circ} \mathrm{C}$ furnished compound 33 as a diastereomeric mixture to which the $R_{\mathrm{S}}$ configuration was assigned on the basis that such Anderson type reactions proceed with inversion at the sulfur atom. Reduction of oxazine 33 with $\mathrm{NaBH}_{4}$ at $-45^{\circ} \mathrm{C}$ gave oxazinane 34 . Acid catalyzed reactions of 34 with tryptamine $(\mathbf{5}, \mathbf{3 5 a})$ and tryptophan derivatives $(\mathbf{3 5 b}, \mathbf{3 5 c})$ afforded THBCs in chemical and optical yields comparable with previous syntheses.

By analogy with previous hypotheses, in the proposed reaction mechanism, combination of tryptamine with oxazinane 34 results in the formation of the hydrogen bonded iminium intermediate 36a and its spontaneous in situ conversion into a spiroindolenine, through acid induced intramolecular electrophilic attack of the iminium carbon at C-2 or at C-3 of the indole moiety and subsequent rearrangement-deprotonation yielding the expected THBC (38a and 37a) in $70: 30(1 R: 1 S)$ diastereomeric ratio, out of which $38 \mathbf{a}$ could be isolated in $40 \%$ yield. Interestingly, this methodology furnishes products with prevalent reverse stereochemistry than those obtained by the chiral acetylenic sulfoxide approach.

Another noteworthy fact is that when secondary amine (35a), prepared by reductive amination of tryptamine with $p$-methoxy benzaldehyde, was reacted with 34 in $\mathrm{MeCN}-\mathrm{AcOH}$ $80 \%$ of a mixture of $\mathbf{3 8 d}$ and $\mathbf{3 7 d}$ was isolated showing a 30:70 (1R:1S) diastereomeric ratio. The minor THBC 38d has been converted into the homochiral pentacyclic intermediate 39, which is a known precursor ${ }^{56}$ of pentacyclic yohimbine alkaloids such as yohimbinol and corynantheine.

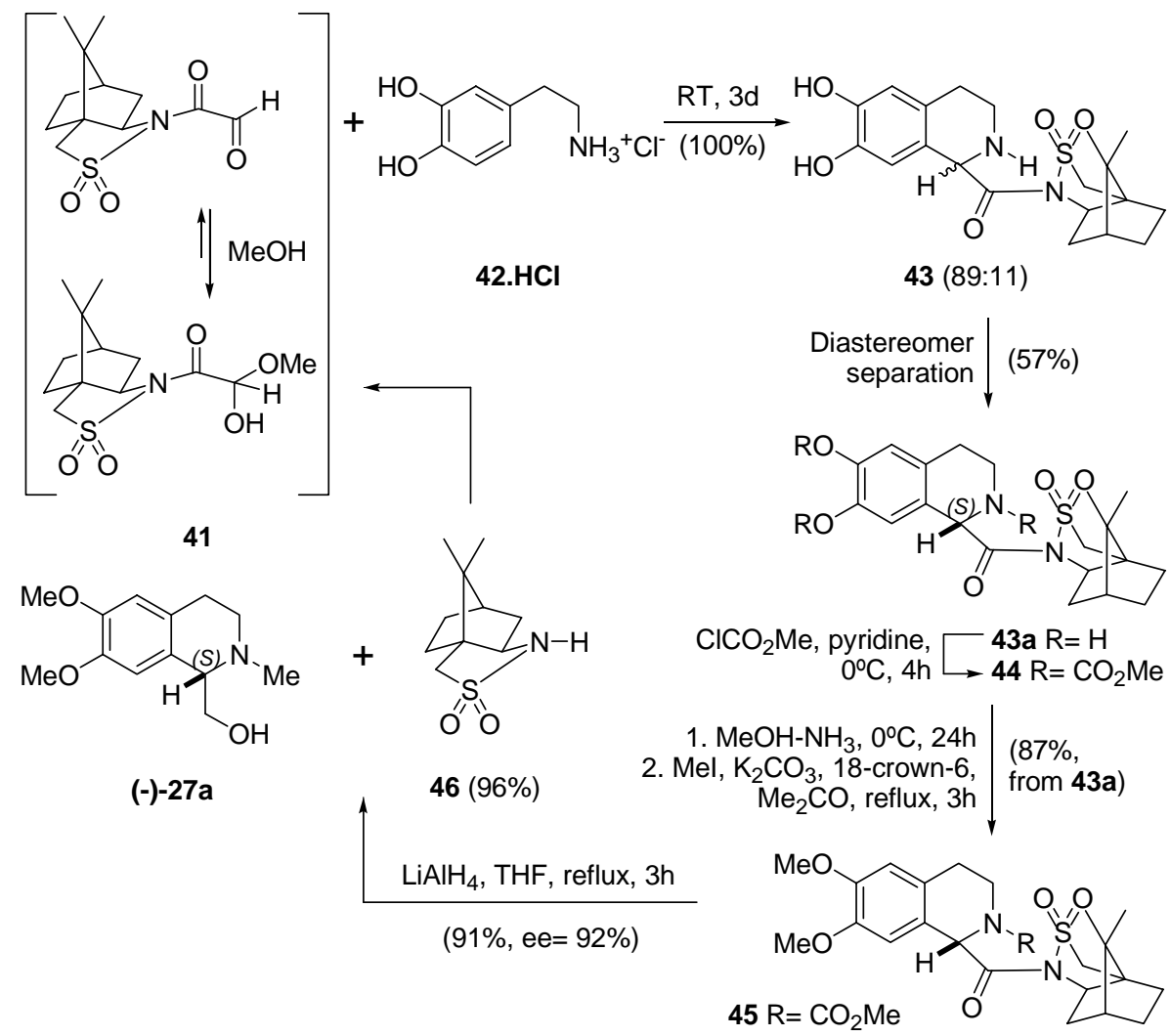

\section{Scheme 9}


However, reaction of $\mathbf{3 4}$ with $L$-tryptophan methyl (35b) and isopropyl esters (35c) gave $\mathbf{3 7 b}, \mathbf{c}$ and 38b,c in cis:trans ratios near $1: 2$ and isolated yields of $76 \%$ and $78 \%$, respectively. Raney nickel desulfurization of the THBCs (37b,c and 38b,c) furnished de corresponding 1methyl THBCs, such as 40a and $\mathbf{4 0 b}$. Eleagnine $40 \mathrm{c}^{57}$ can be obtained by Yamada's hydrolysis ${ }^{58}$ of $40 \mathrm{a}$ and $40 \mathrm{~b}$.

A synthesis of $N$-methyl-S-calycotomine (-)-27a (Scheme 9) was recently reported by the group of Czarnocki. ${ }^{59}$ This protocol employs (2R)- $N$-glyoxylbornane-10,2-sultam 41, a stable hemiacetal widely employed in Diels Alder chemistry, ${ }^{60}$ as a chiral aldehyde moiety. Condensation of $\mathbf{4 1}$ with dopamine $\mathbf{4 2}$ gave a separable 89:11 mixture of diastereomeric unstable tetrahydroisoquinoline derivatives 43 . Upon isolation of the major diastereomer 43 a in $57 \%$ yield, this was converted into the corresponding methyl carbamate 44 and submitted to mild ammonolysis and di-O-methylation, furnishing the amido-ester 45 in $87 \%$ yield. Final treatment of both reducible functional groups of 45 with lithium aluminum hydride gave $91 \%$ of $N$ methylcalycotomine (-)-27a, ${ }^{61}$ of known absolute configuration. Chiral ${ }^{1} \mathrm{H}$ NMR employing $\mathrm{Eu}(\mathrm{hfc})_{3}$ as chiral shift reagent revealed that the enantiomeric excess of the product was $92 \%$. Interestingly, the chiral auxiliary $\mathbf{4 6}$ was recovered in $96 \%$ yield, without loss of optical purity.

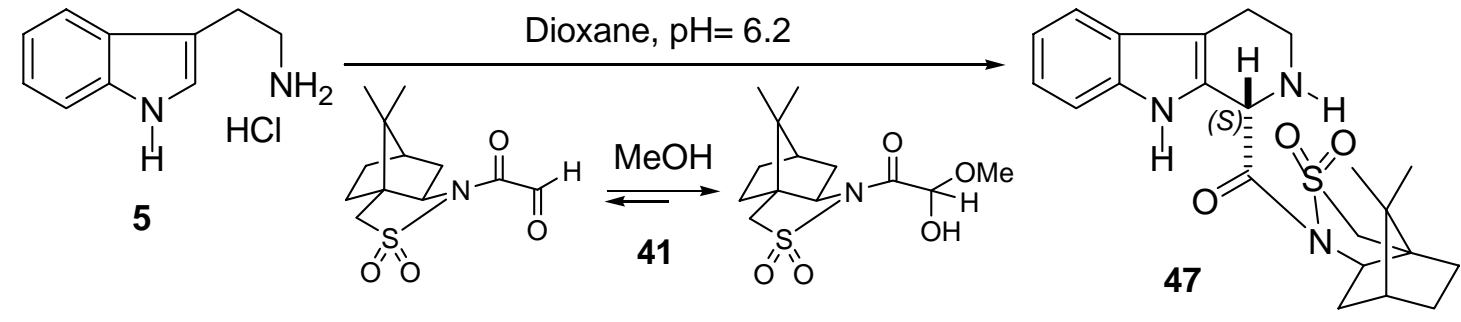

\section{Scheme 10}

The reaction of $\mathbf{4 1}$ with tryptamine hydrochloride $\mathbf{5}$ (Scheme 10) required special conditions and lead to the isolation of only one diastereomer in $59 \%$ yield to which structure 47 was attributed, when it was carried out employing a phosphate buffer of strictly controlled $\mathrm{pH}=6.2$.

Menthyl esters have been widely employed as source of chirality. A Korean team disclosed the synthesis of 1-substituted THIQ carboxylates by the activated Pictet-Spengler protocol. ${ }^{62}$ In their approach, methanesulfonyl derivatives of homoveratrylamine 48a-d were condensed with $L$-menthyl glyoxylate 49, furnishing 6,7-dimethoxy tetrahydroisoquinolines $\mathbf{5 0}$ and/or their 7,8dimethoxy-substituted congeners 51, as shown in Table 2. Diastereomeric excesses of the soproduced THIQ were not informed. An analogous approach was earlier reported by Silveira and Kaufman $^{63}$ during the course of their studies concerning the structure and synthetic applications of carbocations directly linked to an organoselenium group, ${ }^{64}$ which exploit the ability of the organoselenium group to stabilize a carbenium ion adjacent to an ester group. 
Table 2. Synthesis of 1-substituted 1,2,3,4-tetrahydroisoquinolines by the activated PictetSpengler approach with $L$-menthyl glyoxylate

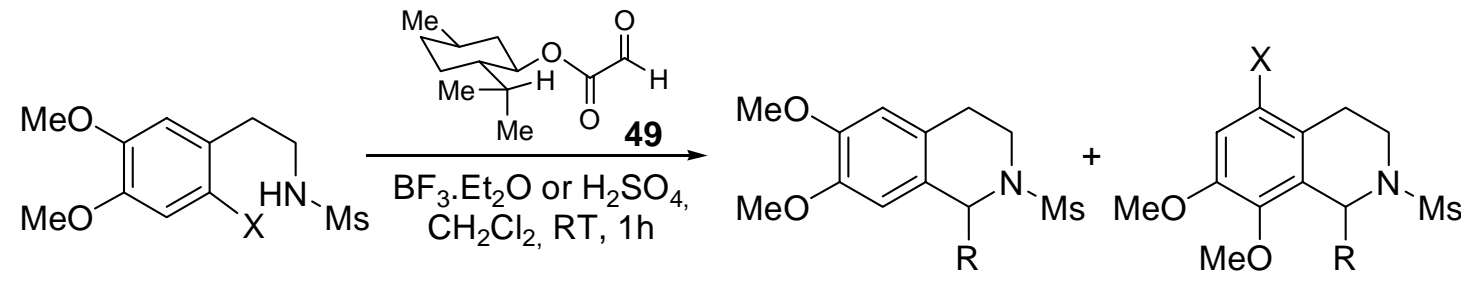

48
50

\begin{tabular}{cccccc}
\hline Entry $\mathrm{N}^{\mathbf{0}}$ & $\mathrm{X}$ & Compound $^{\mathrm{o}}$ & $\mathrm{R}$ & Yield (\%) & Ratio (50/51) \\
\hline 1 & $\mathrm{H}$ & $\mathbf{4 8 a}$ & $\mathrm{CO}_{2}-(L)$-Menthyl & 89 & $100 / 0$ \\
2 & $\mathrm{Cl}$ & $\mathbf{4 8 b}$ & $\mathrm{CO}_{2}-(L)$-Menthyl & 81 & $0 / 100$ \\
3 & $\mathrm{Br}$ & $\mathbf{4 8 c}$ & $\mathrm{CO}_{2}-(L)$-Menthyl & 76 & $12.8 / 87.2$ \\
4 & $\mathrm{I}$ & $\mathbf{4 8 d}$ & $\mathrm{CO}_{2}-(L)$-Menthyl & 83 & $61.4 / 38.6$ \\
\hline
\end{tabular}

These researchers employed chiral menthyl- $\alpha$-halo- $\alpha$-phenylseleno esters derived form natural $L$-menthol such as $\mathbf{5 4}$, as carbonyl equivalents, ${ }^{65}$ which were cyclocondensed with $N$ tosyl (52a) and $N$-camphorsulfonyl homoveratrylamine (52b), yielding THIQ derivatives 53a and $\mathbf{5 3 b}$, as shown in Table 3.

Table 3. Diastereoselective synthesis of 1,2,3,4-tetrahydroisoquinoline-1-carboxylate derivatives by Lewis acid promoted reaction of $N$-sulfonyl- $\beta$-phenethylamines $\mathbf{5 2 a}$ and $\mathbf{5 2 b}$ with chiral $\alpha$ halo- $\alpha$-phenylselenoester 54.

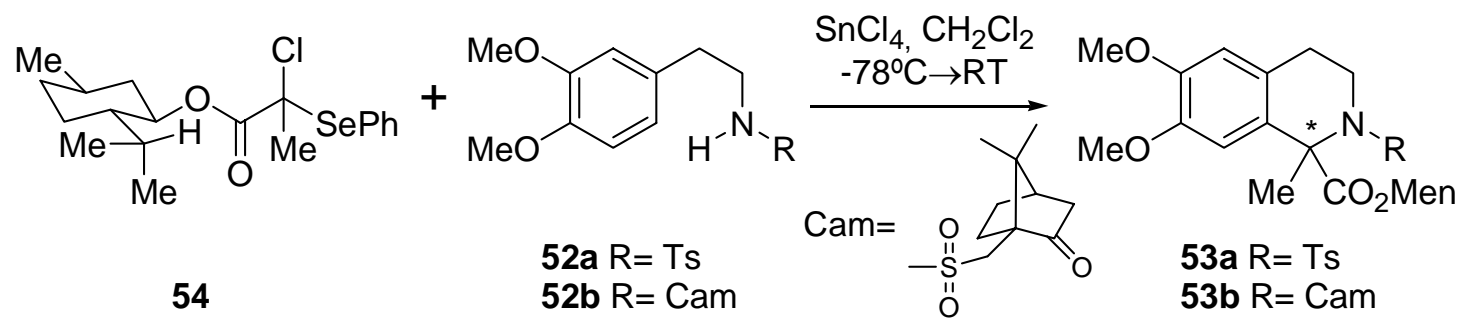

\begin{tabular}{ccccc}
\hline Entry N $^{\mathrm{o}}$ & $N$-Sulfonyl- $\beta$-phenethylamine & Product $^{\mathrm{o}}$ & Yield (\%) $^{\text {a }}$ & Diast. ratio \\
\hline 1 & $\mathbf{5 2 a}(\mathrm{R}=\mathrm{Ts})$ & $\mathbf{5 3 a}$ & $60(92)^{\mathrm{b}}$ & $4: 1(8.4: 1)^{\mathrm{c}}$ \\
2 & $\mathbf{5 2 b}(\mathrm{R}=\mathrm{Cam})$ & $\mathbf{5 3 b}$ & $62(72)^{\mathrm{b}}$ & $>25: 1$ \\
\hline
\end{tabular}

a. Men= $(1 R, 2 S, 5 R)$-menthyl; Cam= (1S)-10-camphorsulfonyl; b. Corrected yield for recovered starting material in parentheses; c. Diastereomeric ratio after crystallization in parentheses. The C-1 stereochemistry of the diastereomers was not reported.

These results, which made use of the reinforcing capabilities of two neighbor chiral groups, 
confirmed the poor asymmetry inducing ability of the camphorsulfonyl moiety in this reaction setup, probably due to its remoteness from the reaction site and the flexibility of the cyclizing intermediate. $^{66}$

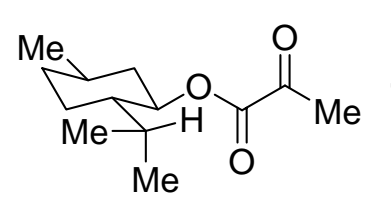

55

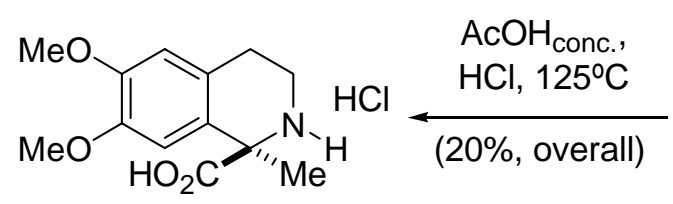

57
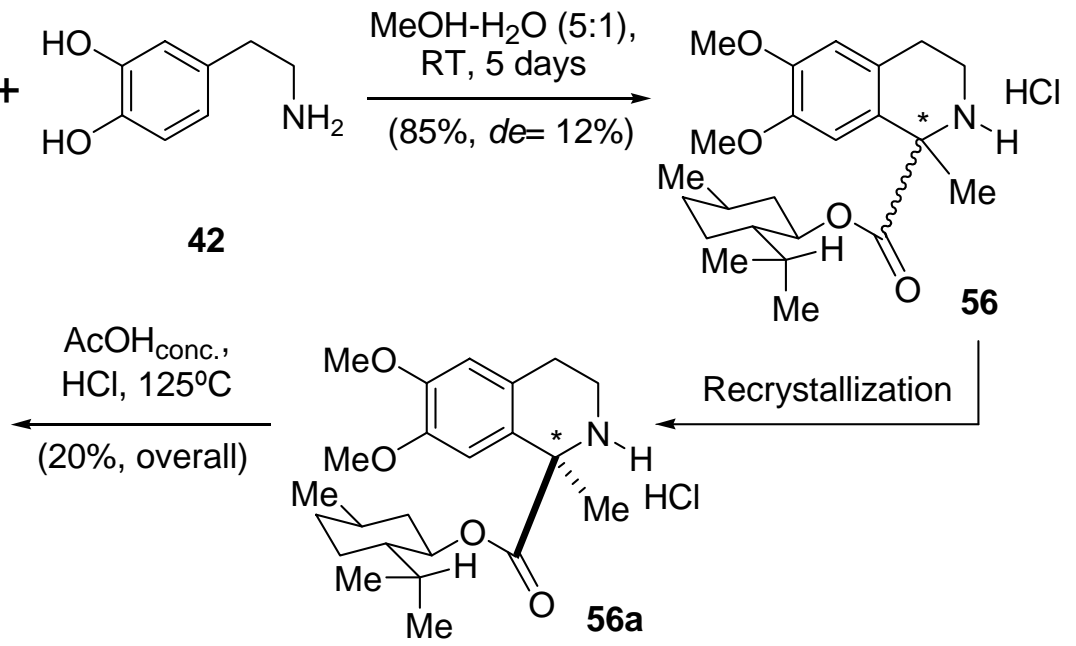

\section{Scheme 11}

Kawai and coworkers ${ }^{67}$ prepared chiral salsolinol carboxylates 56 employing the PictetSpengler condensation of dompamine (42) with (+)-menthyl pyruvate 55, prepared according to Harada, ${ }^{68}$ stirring the reactants in a $\mathrm{MeOH}$-water $(5: 1)$ system during 5 days at room temperature. The product, obtained in $85 \%$ yield as a $56: 44$ diastereomeric mixture $(d e=12 \%)$, afforded $R$-56 (56a) in approximately $20 \%$ yield after two or three recrystallizations and with ee $>99 \%$ when compared with synthetic resolved material. ${ }^{69}$ Interestingly, diastereomeric excess was dependent from the reaction temperature, and at $85^{\circ} \mathrm{C}$ it decreased to $4 \% . R-57$ can be enzymatically synthesized employing a newly discovered human brain enzyme. ${ }^{70}$

Compound 57 is the proposed intermediate in one of the biosynthetic pathways of the dopamine derived alkaloid $R$-salsolinol, which in turn is precursor of $N$-methyl- $R$-salsolinol, a neurotoxin specific for dopaminergic neurons and related to the cause of Parkinson's disease. ${ }^{71}$

Winterfeldt devised a general method for the synthesis of malonaldehyde monocycloacetals by transacetalization or selective hydrolysis of 1,1,3,3-tetramethoxypropane and its analogues and expanded the reaction to chiral amino-diol and 1,3-dioxacyclic diastereomers, thus accessing optically pure malonaldehyde monocycloacetals. ${ }^{72}$

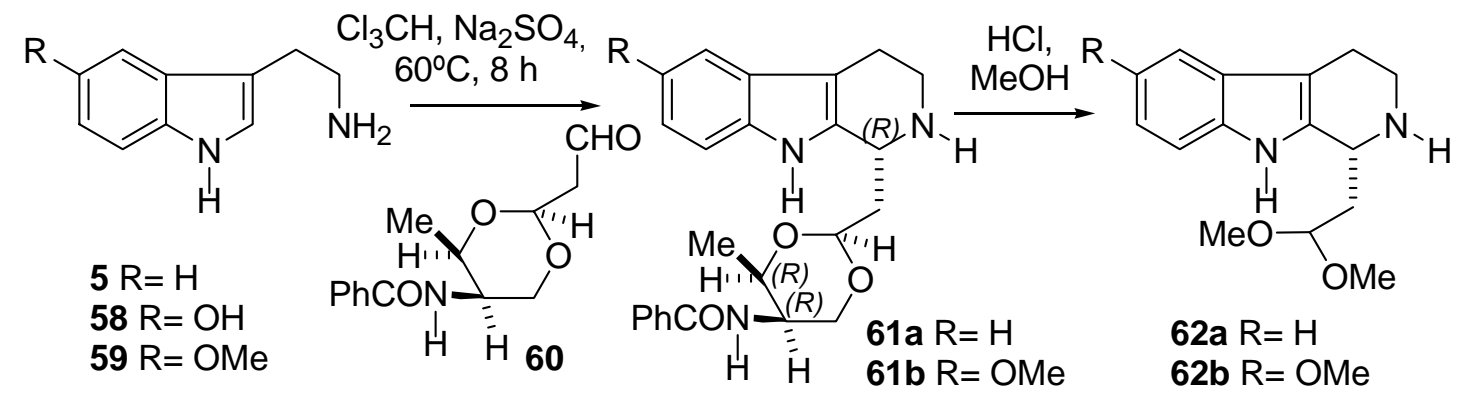

Scheme 12 
More recently, this group ${ }^{73}$ employed threonine derived malonaldehyde monocycloacetals such as 60 for the stereoselective synthesis of THBC $\mathbf{6 2 a}, \mathbf{b}$, as depicted in Scheme 12. For example, reaction of aldehyde $\mathbf{6 0}$ (obtained from the corresponding dimethyl acetal by oxalic acid hydrolysis) with 5 or 59, derived from 5-hydroxy tryptamine 58 gave 61 a and 61b, respectively in $85 \%$ yield; in turn, transacetalization of the latter with acidic methanol furnished acetals $62 \mathbf{a}$ and $\mathbf{6 2 b}$. Interestingly, when the transformation was carried out with tryptophan methyl ester (35b), a diastereomeric mixture of THBC was obtained in $80 \%$ combined yield, favoring (5:3) the $1 R$ diastereomer.

\section{Intermolecular condensation with optically active aldehydes}

\subsection{Carbohydrates and derivatives}

$L$-DOPA (63) is the mainstay for the pharmacological treatment of Parkinson's disease. The susceptibility of $L$-DOPA to condense with aldehydes is well documented on a chemical basis ${ }^{74}$ and is supported in vivo by the increased excretion of salsolinol and tetrahydropapaveroline in the urine of patients with Parkinson's disease receiving oral treatment with $L$-DOPA. ${ }^{75}$ These and other potentially neurotoxic species could exacerbate neuronal damage in the long term and have received some attention. ${ }^{76}$

Prota and coworkers have demonstrated ${ }^{77}$ that $L$-DOPA (63) and dopamine (42) react under physiologically relevant conditions with $D$-glyceraldehyde (64) as a model (Scheme 13), to give stereoisomeric THIQ 65 and 66. Structure 65 was assigned to the minor $1 R$ diastereomer on the basis of its ${ }^{13} \mathrm{C}$ NMR spectrum, which reflects the deshielding effects of a $\gamma$-gauche interaction, shifting upfield the $\mathrm{C}-1$ and $\mathrm{C}-3$ resonances. ${ }^{78}$<smiles>C[C@H](O)[C@]1([C@@H](C)O)NC(C(=O)O)Cc2cc(O)c(O)cc21</smiles>

65
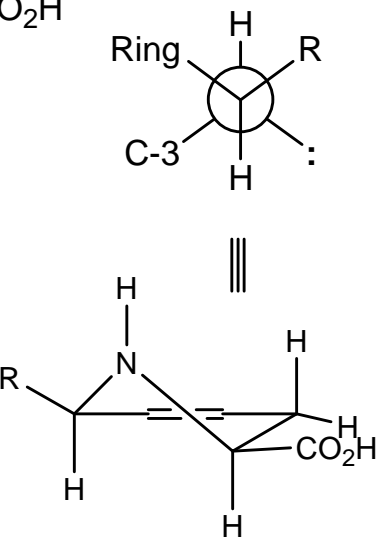
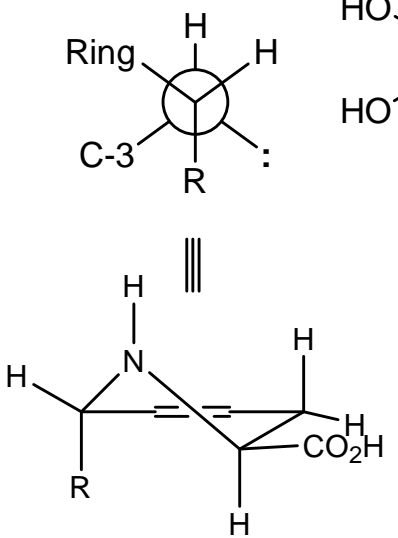<smiles>C[C@H](O)[C@H](NC(=O)O)c1cc(O)c(O)cc1C[C@@H](C)O</smiles>

66

\section{Scheme 13}

Transition metal cations were found to cause dichotomous effects on the reaction course with L-DOPA: whereas Fe(III) accelerated THIQ formation, $\mathrm{Cu}$ (II) caused a rate-decreasing effect. The results were in agreement with a mechanism including Schiff base formation followed by a 
ring-closure reaction in accordance with the Felkin-Anh model of asymmetric induction. ${ }^{79}$

Analogously, under physiologic conditions ( $0.1 \mathrm{M}$ phosphate buffer, $\mathrm{pH}=7.4$ and $\left.37^{\circ} \mathrm{C}\right), \mathrm{L}$ DOPA also reacts smoothly with $D$-glucose (69) to give three main products, two of which are the diastereomeric (1R,1'S,3S)- and (1S,1'S,3S)- 1-(D-gluco-pentitol-1'-yl)-3-carboxy-6,7dihydroxy-1,2,3,4- tetrahydroisoquinoline (67a) and (67b) in $25 \%$ and $15 \%$ yields, respectively, which were assigned by NMR. ${ }^{80}$ The preferential formation of the $1 R$ isomer (1,3-cis) is also predicted by the Felkin-Anh model of asymmetric induction and is consistent with previous observations in the case of the reaction of $L$-DOPA with $D$-glyceraldehyde. The third product detected is that resulting from a Maillard reaction, which yields decarboxylated condensation products. $^{81}$

Under comparable conditions (Scheme 14) dopamine (42) reacted at a similar rate yielding the diastereomeric tetrahydroisoquinolines $\mathbf{7 0 a}$ and $\mathbf{7 0 b}$ in an approximate $4: 1$ ratio. In these reactions, $\mathrm{Fe}(\mathrm{III})$ ions markedly accelerated the Pictet-Spengler condensation, while $\mathrm{Cu}$ (II) ions slowed the cyclization with $L$-DOPA but increased the reaction rate when the substrate was dopamine. Interestingly however, because of improper activation of its aromatic ring, no trace of Pictet-Spengler cyclization products could be detected in the reaction of $L$-tyrosine $(\mathbf{6 8})$ with $D$ glucose (69).

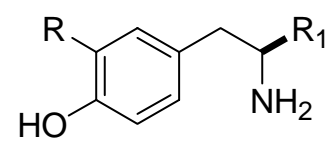

$42 \mathrm{R}=\mathrm{OH}, \mathrm{R}_{1}=\mathrm{H}$ $63 \mathrm{R}=\mathrm{OH}, \mathrm{R}_{1}=\mathrm{CO}_{2} \mathrm{H}$ $68 \mathrm{R}=\mathrm{H}, \mathrm{R}_{1}=\mathrm{CO}_{2} \mathrm{H}$

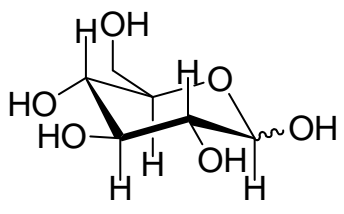

69

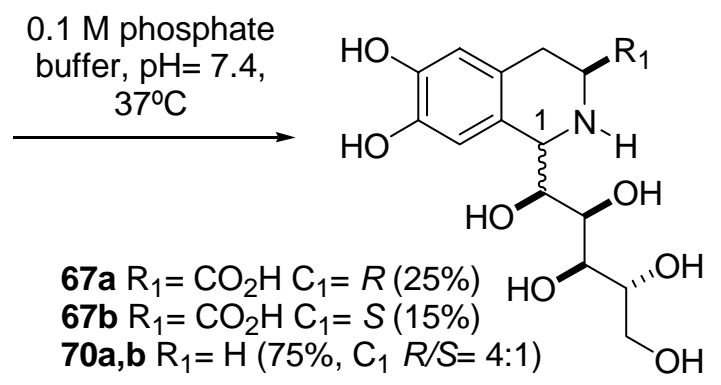

\section{Scheme 14}

A Polish-Canadian group studied in detail the use of sugars and their derivatives as the aldehyde components of the Pictet-Spengler condensation. The importance of this work stems from the facts that carbohydrates are readily available in enantiomerically pure form and that sugar chirality is transferred to the newly generated asymmetric center. The suitability of this observation for the elaboration of optically active natural products was successfully tested in several occasions. Along these lines, Czarnocki and coworkers disclosed a total synthesis of (-)carnegine (27) which employs $R-(+)$-glyceraldehyde (64) and dopamine (42) as starting materials. ${ }^{82}$

Their synthesis, depicted in Scheme 15, commenced with the Pictet-Spengler condensation of dopamine hydrochloride and (+)-glyceraldehyde to furnish a 9:1 mixture of cyclized diols $\mathbf{7 1}$ in $93 \%$ yield; the mixture was treated with ethyl chloroformate and the resulting tetracarbonates 72 were chromatographically separated, affording 59\% of the most abundant compound $\mathbf{7 2 b}$. Mild ammonolysis of $\mathbf{7 2 b}$ lead to catechol $\mathbf{7 3}$ in $98 \%$ yield, which was submitted to a 
conventional Williamson etherification to give $87 \%$ of $R, S$-diol $74 a$.

Next, periodic acid-mediated oxidative fission of the glycol moiety, followed by a reductive work-up provided $85 \%$ of carboxyethyl calycotomine (75). In turn, this product was reduced in $86 \%$ to $S$-carnegine [(-)-27] via the tosylate of the primary alcohol, employing lithium aluminum hydride in refluxing THF.

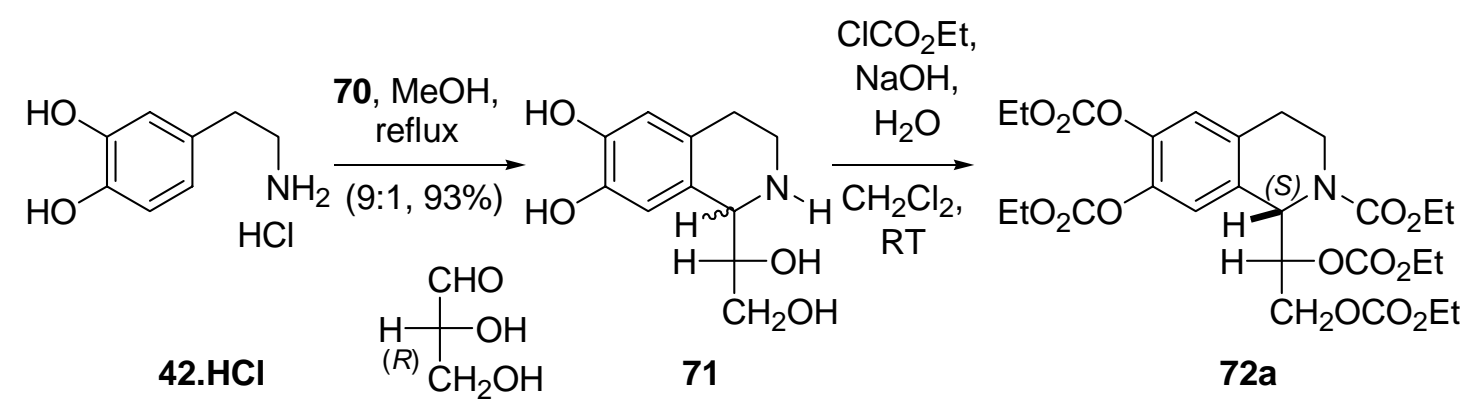

64

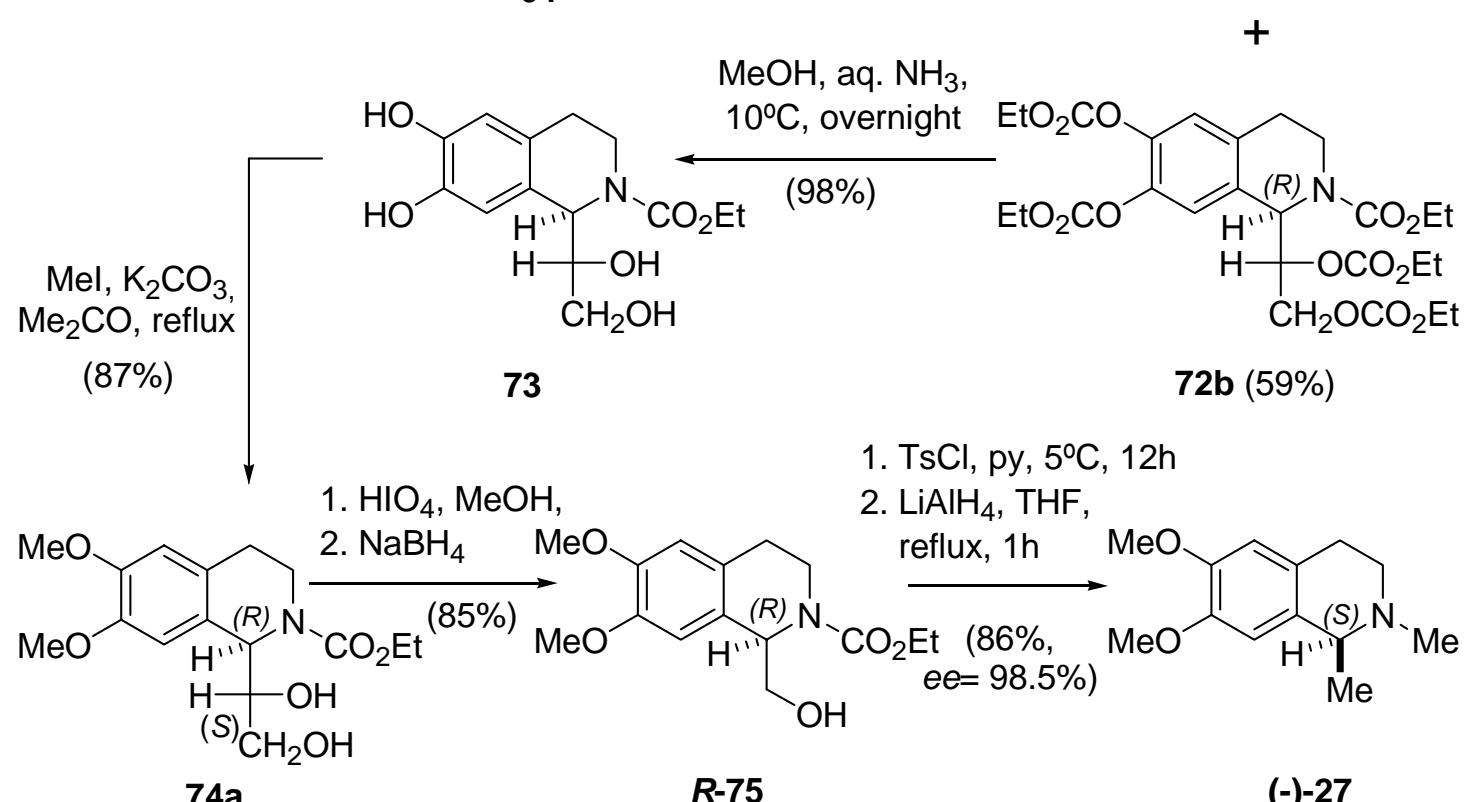

Scheme 15

\subsection{Use of aldehydes and derivatives prepared from aminoacids}

5.2.1 Alanine. A great effort has been focused on design and synthesis of constrained dipeptide motifs, especially in those that would nicely mimic the natural $\beta$-turn in a given target molecule, particularly if the target incorporates carboxyl and amino groups in geometrically suitable positions for peptide coupling. ${ }^{83}$

As shown in Scheme 16, Grieco and coworkers ${ }^{84}$ prepared compounds $77 \mathbf{a}, \mathbf{b}$ by the PictetSpengler condensation of $L$-DOPA (66) and aldehyde 76, prepared from Fmoc-alanine. ${ }^{85}$ After stirring in $\mathrm{MeOH}$ during 4 days at room temperature, the THIQ products were obtained as a 3:2 epimeric mixture, favoring the $\mathrm{C} 1-\mathrm{R}$ diastereomer $77 \mathbf{a}$. 
<smiles>NC(Cc1ccc(O)c(O)c1)C(=O)O</smiles>

66

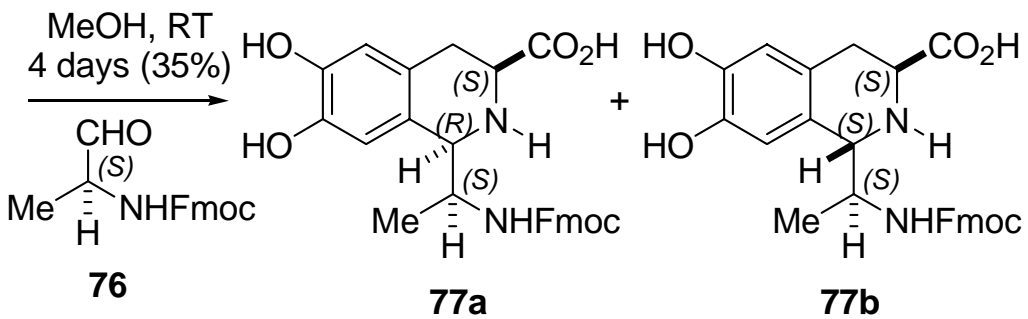

\section{Scheme 16}

5.2.2 Aspartic acid. The group of Muñiz ${ }^{86}$ prepared compounds 82 and $\mathbf{8 3}$ as key components towards the elaboration of $\beta$-turned dipeptoids with potent and selective agonist activity towards $\mathrm{CCK}_{1}$ receptors. The synthesis is shown in Scheme 17.<smiles>CC(=O)[C@H](Cc1cn([TlH])c2ccccc12)NCc1ccccc1</smiles>

1. TFA, $\mathrm{CH}_{2} \mathrm{Cl}_{2}, 0^{\circ} \mathrm{C}$

2. $\mathrm{ZCl}, \mathrm{CH}_{2} \mathrm{Cl}_{2}$, propylene oxide 3. $2 \mathrm{~N} \mathrm{NaOH}, \mathrm{MeOH}$<smiles>[Z]C[C@H]1C[C@@H]2c3[nH]c4ccccc4c3C[C@H](C(=O)O)N2C1=O</smiles>

82
TFA, PhMe,

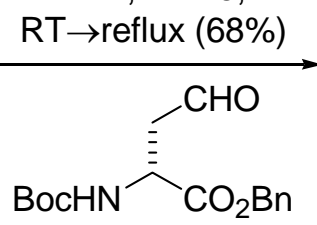

79<smiles></smiles>

81<smiles>COC(=O)N[C@@H](Cc1ccccc1)CC1c2[nH]c3ccccc3c2C[C@H]1C(=O)OC(C)(C)C</smiles>

80

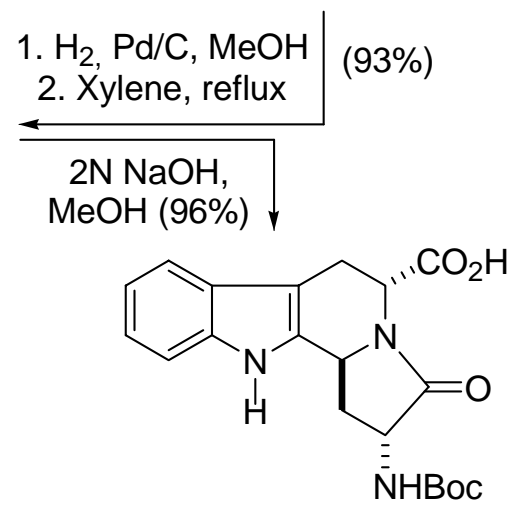

83

\section{Scheme 17}

The $D$-Aspartic acid derived aldehyde 79, prepared in $84 \%$ from the corresponding acid by way of reduction of its mixed anhydride formed with iso-butyl chloroformate, was condensed with $D$-tryptophan derivative $\mathbf{7 8}$ in the presence of TFA at room temperature, affording a 1.5:1 diastereomeric mixture of trans- and cis-tetrahydro- $\beta$-carbolines. This mixture was epimerized giving $68 \%$ of the desired trans derivative $\mathbf{8 0}$ by refluxing in toluene. ${ }^{87}$ Hydrogenolysis of the benzyl ester was followed by a reflux in xylene, furnishing $93 \%$ of lactam $\mathbf{8 1} .^{88}$

Removal of the Boc protecting group from $\mathbf{8 1}$ followed by treatment with benzyl chloroformate afforded the corresponding Z-protected derivative, while saponification of the 
methyl ester groups furnished the free carboxylic acid derivatives $\mathbf{8 2}$ and $\mathbf{8 3}$ in $52 \%$ (from $\mathbf{8 1}$ ) and $96 \%$ yield, respectively. An analogous approach was employed by Grimes and his group in their solid phase synthesis of this class of $\beta$-type peptido mimetics. ${ }^{89}$ The condensation of an analogous aldehyde with a solid phase bound tryptophan derivative gave diastereomeric mixtures of THBC.

5.2.3 Cysteine. The eudistomins are marine alkaloids with potent antiviral and antibacterial properties. ${ }^{90}$ The group of Nakagawa ${ }^{91}$ studied in detail the synthesis of these natural products employing as key transformation the Pictet- Spengler reaction of $N$-hydroxytryptamine $\mathbf{8 4}$ and $D$-cysteinal derivatives. They found that at room temperature tetracyclic products such as $\mathbf{8 7}$ were obtained while THBC like $\mathbf{8 9}$ with the correct stereochemistry for eudistomins resulted as major products at low temperature together with their diastereomers. Interestingly, compounds 87 could be readily converted into the useful $\beta$-carbolines by acid treatment and a mechanism for such conversion was proposed. ${ }^{92}$ Employing these observations, they were able to develop a total synthesis of (-)-eudistomin L (91), depicted in Scheme 18.

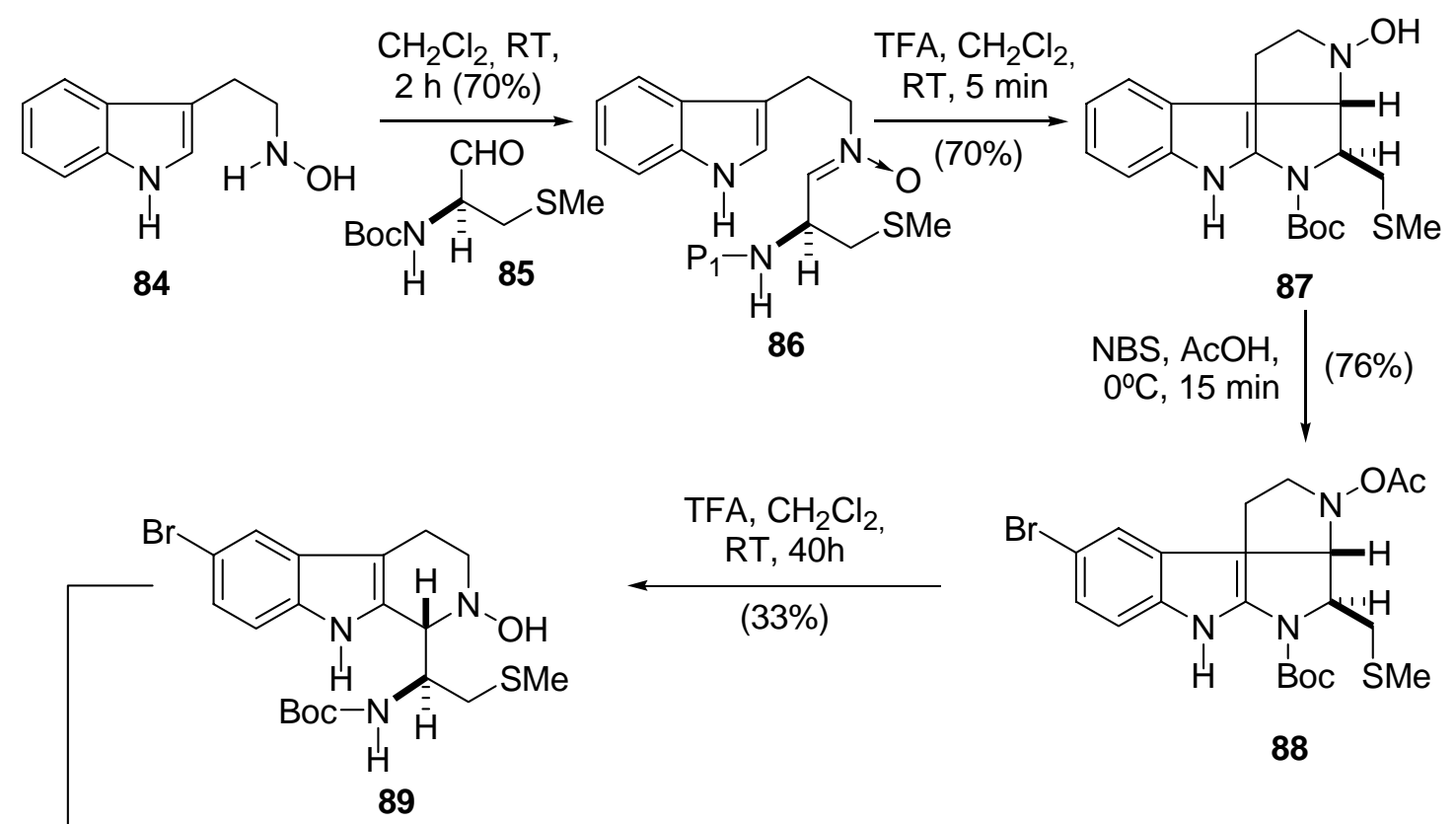

$\mathrm{NCS}, \mathrm{CCl}_{4}$ $8-12^{\circ} \mathrm{C}, 1.5 \mathrm{~h}$

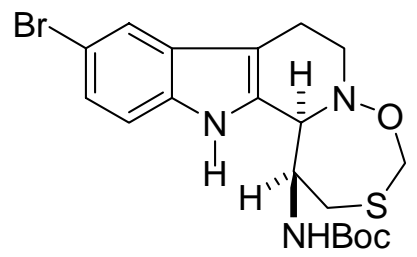

90<smiles>N[C@H]1CSCON2CCc3c([nH]c4ccc(Br)cc34)[C@H]12</smiles>

91

\section{Scheme 18}


To that end, $N$-hydroxytryptamine $\mathbf{8 4}$ was condensed with cysteinal derivative $\mathbf{8 5}$ and the resulting nitrone 86 was cyclized in $70 \%$ to $\mathbf{8 7}$ with TFA at room temperature. Nuclear bromination of $\mathbf{8 7}$ to $\mathbf{8 8}$ with NBS in acetic acid coursed in $76 \%$ yield with concomitant acetylation; this was followed by TFA-mediated rearrangement, which furnished $33 \%$ of 89; in turn, this was transformed into tetracyclic derivative 90 in $13 \%$ yield by a modified Pummerer reaction, ${ }^{93}$ which yielded (-)-eudistomin L (91) upon removal of the Boc protecting group. ${ }^{94}$ Other eudistomins (K, C, E and F), that differ on the substitution of the benzene ring, were prepared employing the same general strategy. ${ }^{95}$

These Japanese authors also employed thiazolidinyl derivatives of cysteine (Table 4, series c), as well as oxazolidinyl derivatives of serine (Table 4, series a and b) to synthesize nitrones 92 as intermediates towards THBCs 93 and $\mathbf{9 4}$, en route to eudistomins $95 .{ }^{96}$ Kruse also prepared analogs of eudistomins employing different cysteine derivatives $;{ }^{97}$ when these were assayed as antivirals, the observed results underscored the importance of the seven-membered ring for the biological activity.

Table 4. Pictet-Spengler condensation for the synthesis of eudistomin derivatives 95

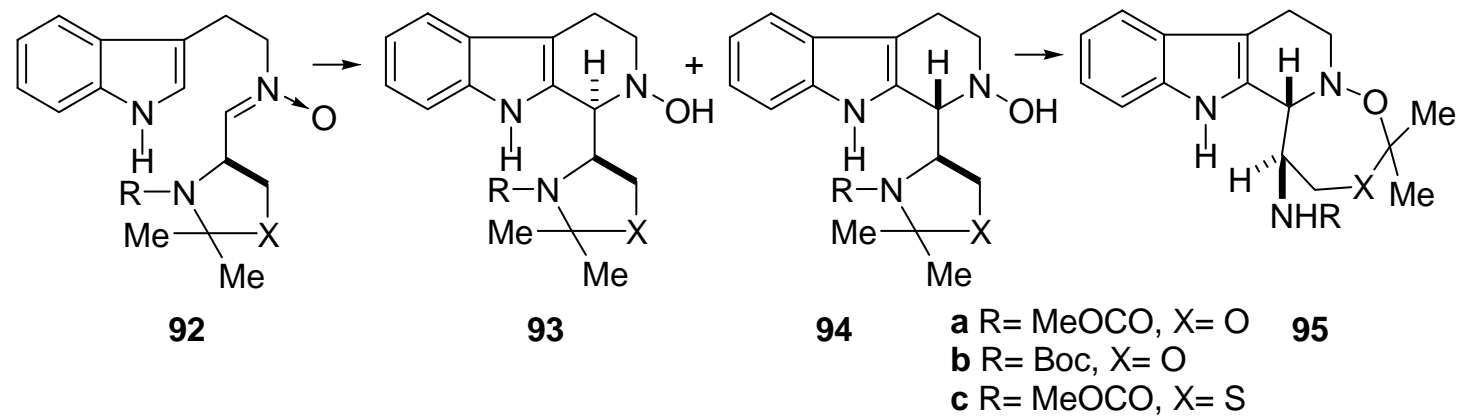

\begin{tabular}{cccc}
\hline Entry $\mathrm{N}^{\mathbf{0}}$ & Substrates & Conditions & Yield (95, \%) \\
\hline 1 & $\mathbf{9 4 a}$ & TsOH, DMP, PhH, RT, 1h & 95a, 44 \\
2 & $\mathbf{9 4 a}$ & TFA, PhH, reflux, 3h & 95a, 15 \\
3 & 93a & TFA, PhH, reflux, 3h & - \\
4 & 93b, 94b & TFA, $\mathrm{CH}_{2} \mathrm{Cl}_{2}$, reflux, $5 \mathrm{~h}$ & 95b, 24 \\
5 & $\mathbf{9 4 c}$ & TsOH, $\mathrm{PhMe}$, reflux, $1.5 \mathrm{~h}$ & 95c, 11 \\
\hline
\end{tabular}

5.2.4 Glutamic acid. Thal ${ }^{98}$ prepared differently substituted aldehydes from protected glutamic acid (96) and glutamic anhydride (104). Scheme 19 displays an example of the synthetic sequence employed from Cbz-glutamic acid (96). Treatment of 96 with excess of formalin under tosic acid catalysis furnished $94 \%$ of oxazolidinone 97 , which was transformed into the corresponding ester 98 by way of a mixed anhydride in $80 \%$ yield; next, hydrolysis of the oxazolidinone moiety afforded $68 \%$ of the free acid 99 , which was transformed into differently protected Weinreb amides 102 by intermediacy of 100 and 101. Final reduction of 102 gave aldehydes $\mathbf{1 0 3}$ in good to excellent yields. 
In the sequence starting with protected glutamic anhydride 104, highlighted in Scheme 20, this was selectively opened with diethylamine, providing $64 \%$ of $N, N$-diethylamide 105; formation of the mixed anhydride with iso-butyl chloroformate, followed by sodium borohydride reduction gave alcohol 106, which was oxidized with PCC to aldehyde 107 in $60 \%$ overall yield.
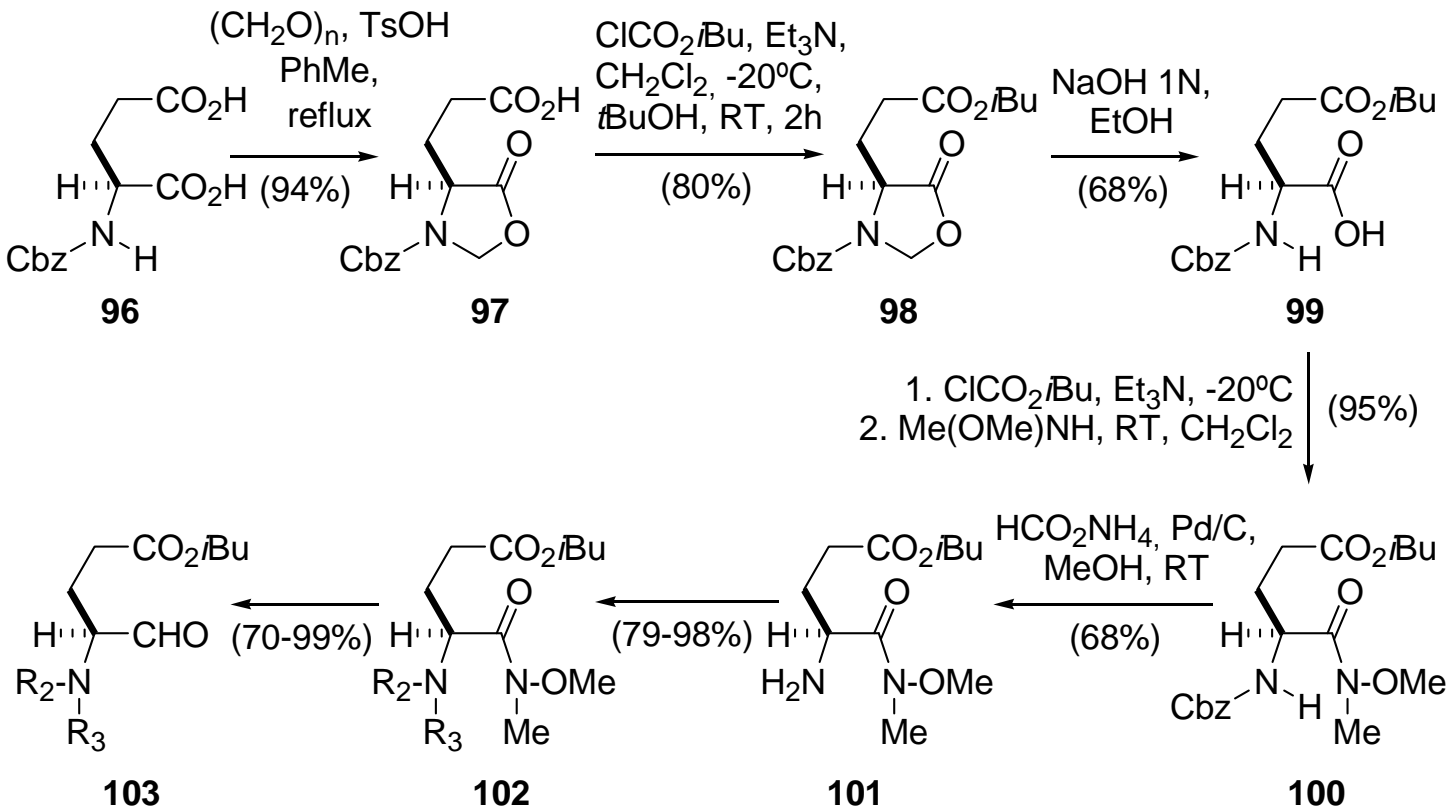

\section{Scheme 19}

The aldehydes 103/107 were then condensed with tryptamine (5) under a variety of conditions in an attempt to form selectively cis and trans $\beta$-carbolines $\mathbf{1 0 8}$, as summarized in Table 5. In the carbamate series (entries 1-5), the cis $\beta$-carboline was always the major diastereomer formed, and the size of the carbamate group had little influence on the diastereoselectivity of the reaction.

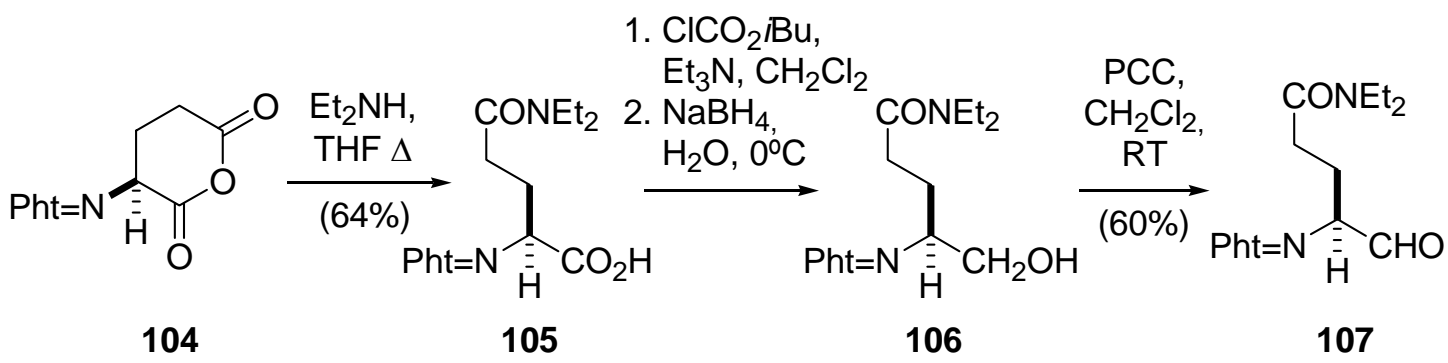

\section{Scheme 20}

The best diastereoselectivity was observed with the benzyl carbamate, where the $R_{1}$ ester group proved to have no influence. Conversely, either with pyrrole or phthalimide groups, it was 
detected that the diastereoselectivity was reversed (entries 6 and 7). Interestingly, however, in the $\mathrm{N}$-Cbz series, low temperatures (below $-20^{\circ} \mathrm{C}$, entries $1,2,8$, and 9) led exclusively to the cis THBC.

A temperature increase produced the diastereomeric trans-product and tetracyclic compound 109 (entries 10-13). Formation of the latter was favored by a short reaction time at $40^{\circ} \mathrm{C}$ (entry 12), whereas a higher temperature (entry 13) led to decomposition of the starting materials. Acidity had no effect on the diastereoselectivity of the reaction (entries 11, 14 and 15).

Table 5. Pictet-Spengler condensation of tryptamine (5) with aldehydes 103/107

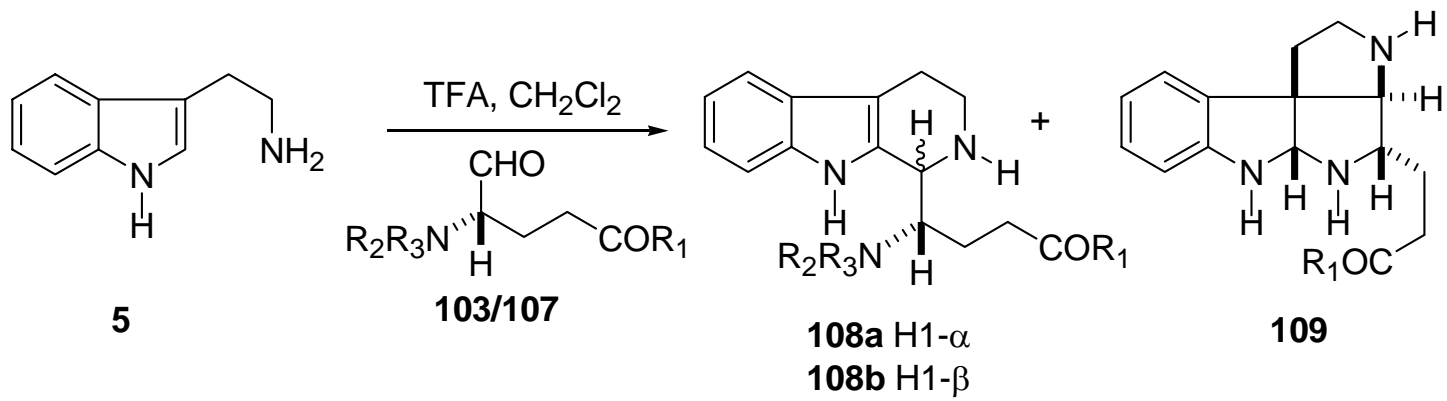

\begin{tabular}{ccccccccccccc}
\hline $\begin{array}{c}\text { Entry } \\
\mathrm{N}^{\mathbf{1 0 3}}\end{array}$ & $\mathbf{1 0 7}$ & $\mathrm{R}_{2}$ & $\mathrm{R}_{3}$ & $\mathrm{R}_{1}$ & Solvent & $\begin{array}{c}\mathrm{T} \\
\left({ }^{\circ} \mathrm{C}\right)\end{array}$ & $\begin{array}{c}\text { Time } \\
(\mathrm{h})\end{array}$ & $\begin{array}{c}\mathrm{TFA} \\
(\mathrm{eq} .)\end{array}$ & $\begin{array}{c}\mathbf{1 0 8} \\
(\%)\end{array}$ & $\begin{array}{c}\mathbf{1 0 8 a} \\
(\%)\end{array}$ & $\begin{array}{c}\mathbf{1 0 8 b} \\
(\%)\end{array}$ & $\begin{array}{c}\mathbf{1 0 9} \\
(\%)\end{array}$ \\
\hline 1 & $\mathbf{1 0 3 a}$ & $\mathrm{Cbz}$ & $\mathrm{H}$ & $\mathrm{Ot}-\mathrm{Bu}$ & $\mathrm{CH}_{2} \mathrm{Cl}_{2}$ & -40 & 2 & 2 & 81 & 0 & 100 & 0 \\
2 & $\mathbf{1 0 3 b}$ & $\mathrm{Cbz}$ & $\mathrm{H}$ & $\mathrm{O}-\mathrm{Bu}$ & $\mathrm{CH}_{2} \mathrm{Cl}_{2}$ & -40 & 2 & 2 & 77 & 0 & 100 & 0 \\
3 & $\mathbf{1 0 3 c}$ & $\mathrm{Boc}$ & $\mathrm{H}$ & $\mathrm{Ot}-\mathrm{Bu}$ & $\mathrm{CH}_{2} \mathrm{Cl}_{2}$ & -40 & 2 & 2 & 71 & 10 & 90 & 0 \\
4 & $\mathbf{1 0 3 d}$ & $\mathrm{CO}_{2} \mathrm{Me}$ & $\mathrm{H}$ & $\mathrm{Ot}-\mathrm{Bu}$ & $\mathrm{CH}_{2} \mathrm{Cl}_{2}$ & -40 & 2 & 2 & 73 & 9 & 91 & 0 \\
5 & $\mathbf{1 0 3 e}$ & Troc & $\mathrm{H}$ & $\mathrm{Oi}-\mathrm{Bu}$ & $\mathrm{CH}_{2} \mathrm{Cl}_{2}$ & -40 & 2 & 2 & 74 & 14 & 86 & 0 \\
6 & $\mathbf{1 0 3 f}$ & pyrrole & $\mathrm{Ot}-\mathrm{Bu}$ & $\mathrm{CH}_{2} \mathrm{Cl}_{2}$ & -50 & 2 & 2 & 62 & 100 & 0 & 0 \\
7 & $\mathbf{1 0 7}$ & phth & & $\mathrm{NEt} 2$ & $\mathrm{CH}_{2} \mathrm{Cl}_{2}$ & $\mathrm{RT}$ & 2 & 2 & 68 & 93 & 7 & 0 \\
8 & $\mathbf{1 0 3 a}$ & $\mathrm{Cbz}$ & $\mathrm{H}$ & $\mathrm{Ot}-\mathrm{Bu}$ & $\mathrm{CH}_{2} \mathrm{Cl}_{2}$ & -65 & 24 & 2 & 68 & 0 & 100 & 0 \\
9 & $\mathbf{1 0 3 a}$ & $\mathrm{Cbz}$ & $\mathrm{H}$ & $\mathrm{Ot}-\mathrm{Bu}$ & $\mathrm{CH}_{2} \mathrm{Cl}_{2}$ & -20 & 2 & 2 & 69 & 0 & 100 & 0 \\
10 & $\mathbf{1 0 3 a}$ & $\mathrm{Cbz}$ & $\mathrm{H}$ & $\mathrm{Ot}-\mathrm{Bu}$ & $\mathrm{CH}_{2} \mathrm{Cl}_{2}$ & 0 & 1 & 2 & 66 & 10 & 90 & 5 \\
11 & $\mathbf{1 0 3 a}$ & $\mathrm{Cbz}$ & $\mathrm{H}$ & $\mathrm{Ot}-\mathrm{Bu}$ & $\mathrm{CH}_{2} \mathrm{Cl}_{2}$ & $\mathrm{RT}$ & 0.5 & 2 & 61 & 25 & 75 & 9 \\
12 & $\mathbf{1 0 3 a}$ & $\mathrm{Cbz}$ & $\mathrm{H}$ & $\mathrm{Ot}-\mathrm{Bu}$ & $\mathrm{CH}_{2} \mathrm{Cl}_{2}$ & 40 & 0.25 & 2 & 54 & 28 & 72 & 30 \\
13 & $\mathbf{1 0 3 a}$ & $\mathrm{Cbz}$ & $\mathrm{H}$ & $\mathrm{Ot}-\mathrm{Bu}$ & $\mathrm{CH}_{2} \mathrm{Cl}_{2}$ & 60 & 0.12 & 2 & 51 & 23 & 77 & 5 \\
14 & $\mathbf{1 0 3 a}$ & $\mathrm{Cbz}$ & $\mathrm{H}$ & $\mathrm{Ot}-\mathrm{Bu}$ & $\mathrm{CH}_{2} \mathrm{Cl}_{2}$ & $\mathrm{RT}$ & 1 & 5 & 61 & 25 & 75 & 8 \\
15 & $\mathbf{1 0 3 a}$ & $\mathrm{Cbz}$ & $\mathrm{H}$ & $\mathrm{Ot}-\mathrm{Bu}$ & $\mathrm{CH}_{2} \mathrm{Cl}_{2}$ & $\mathrm{RT}$ & 1 & 15 & 51 & 25 & 75 & $<5$ \\
\hline
\end{tabular}

5.2.5 Phenylalanine. Reaction of tryptamine 5 with the Boc-protected $L$-phenylalaninal derivative 110 and TFA in dichloromethane furnished the Pictet-Spengler adduct 111 with high diastereoselectivity, as displayed in Scheme 21. 


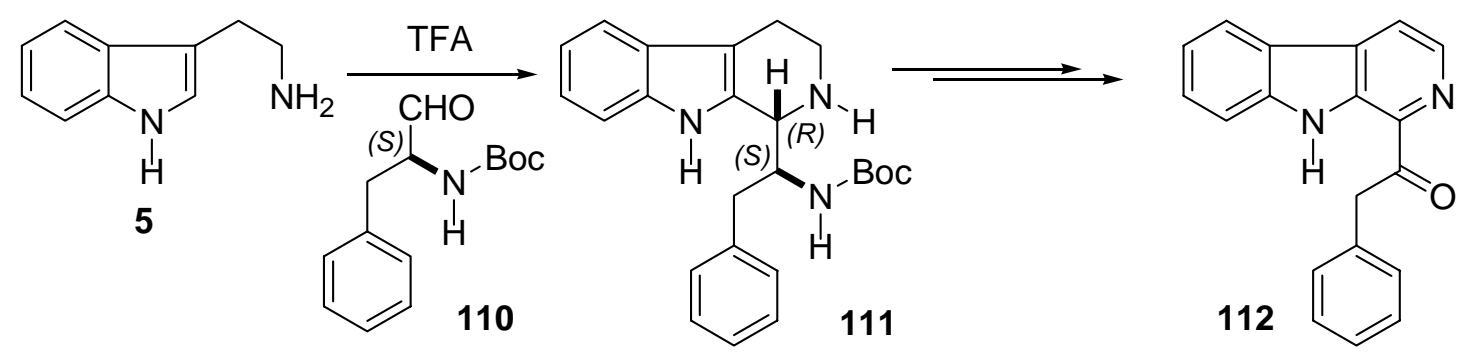

\section{Scheme 21}

The C-1 $\alpha$ diastereomer, a valuable precursor of eudistomin B, was not detectable by 400 $\mathrm{MHz}$ NMR analysis. Dehydrogenation with $\mathrm{Pd} / \mathrm{C}$ or elemental sulfur, followed by removal of the Boc-protecting group and subsequent exposure to sodium hypochlorite under basic conditions completed the synthesis of eudistomin T 112.

During their studies on the use of $\alpha$-aminonitriles as aldehyde protecting groups, Myers and coworkers $^{99}$ disclosed the reaction of aminonitrile 113 with protected phenylalaninal 114 under acidic conditions to afford imine $\mathbf{1 1 5}$ in 90\% yield. They also reported the cyclization of the latter under mild conditions, completing the Pictet-Spengler sequence leading to 116 in $82 \%$ yield; 116 is a structure related to the saframycins (Scheme 22). The cyclization gave a 2:1 mixture of diastereomers on C-1 and the stereochemistry of the products was not disclosed.

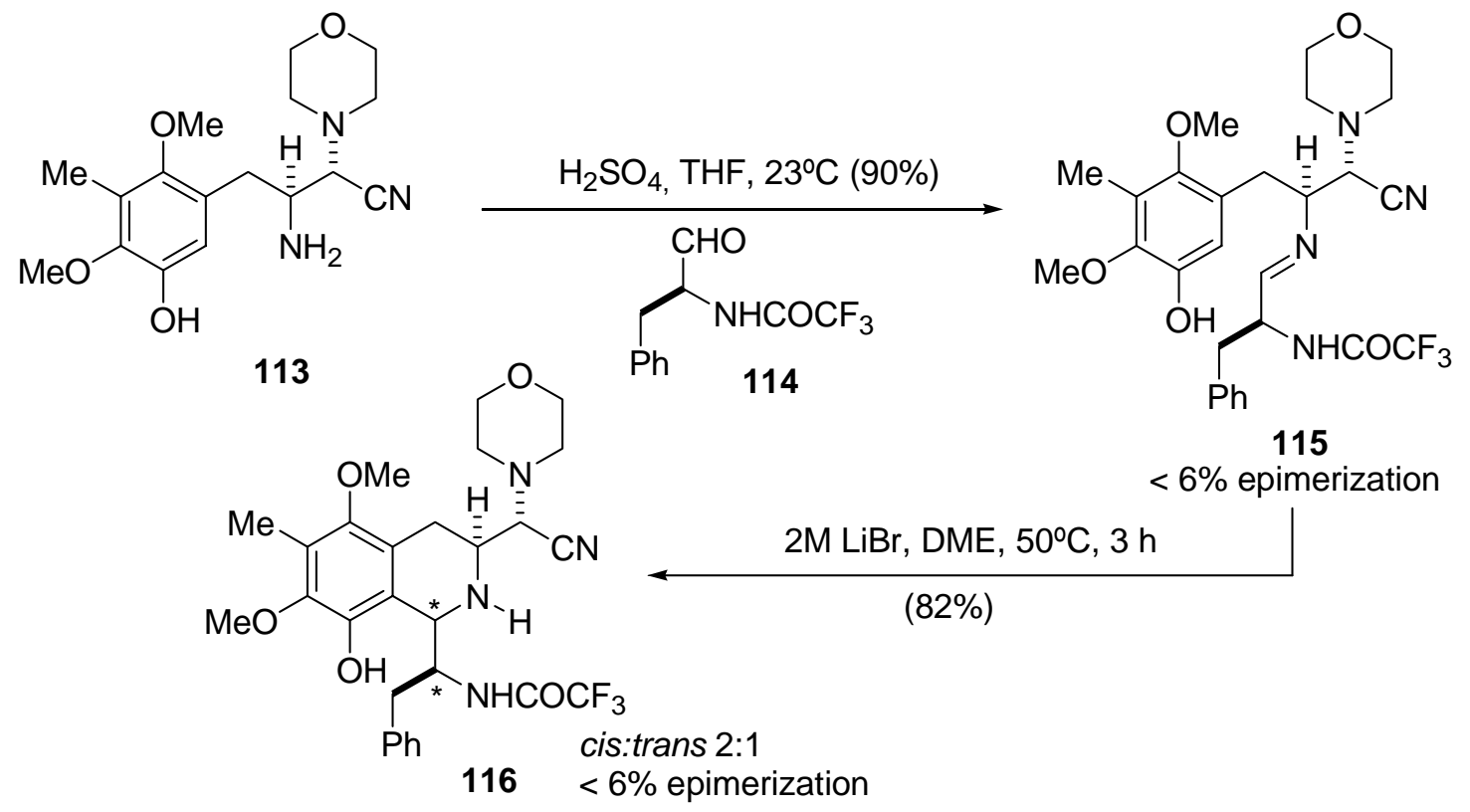

\section{Scheme 22}

5.2.6 Proline. Reaction of tryptamine 5 with Boc-protected $L$-prolinal 118, [which was prepared by diisobutylaluminum hydride (DIBAL-H) reduction of Boc-proline], ${ }^{100}$ in dichloromethane containing TFA diastereoselectively gave the THBC 119a and 120a in the ratio of 85:15 
(Scheme 23). ${ }^{101}$ The observed diastereoselectivity is similar to that reported in the cysteinal series, being explained by a modified Cram-type transition state. ${ }^{102}$

Conversion of 120a to 121a, followed by reduction with lithium aluminum hydride gave (-)debromowoodinine 122a (and its $\mathrm{C}-1$ epimer from 119a). Initial attempts to complete the synthesis of woodinine involving direct ring A bromination at C-6 (122a $\rightarrow \mathbf{1 2 2} \mathbf{b})$ proved largely inefficient, because reaction of $\mathbf{1 2 2} \mathbf{a}$ with bromine in acetic acid gave woodinine $\mathbf{1 2 2 b}(10 \%)$ requiring extensive purification. However, repetition of the sequence described above with 5bromotryptamine 117 gave (-)- woodinine 122b in good overall yield.

During their synthesis of an eudistomin analog (125), Mahboobi and coworkers ${ }^{103}$ resorted to the use of a Pictet-Spengler condensation of tryptamine derivative $\mathbf{1 2 3}$ with Boc-prolinal 118, giving $63 \%$ yield of a mixture of diastereomeric THBC 124, the proportion of which was not informed (Scheme 24).<smiles>[R]c1ccc2[nH]cc(CCN)c2c1</smiles>

$5 \mathrm{R}=\mathrm{H}$ $117 \mathrm{R}=\mathrm{Br}$

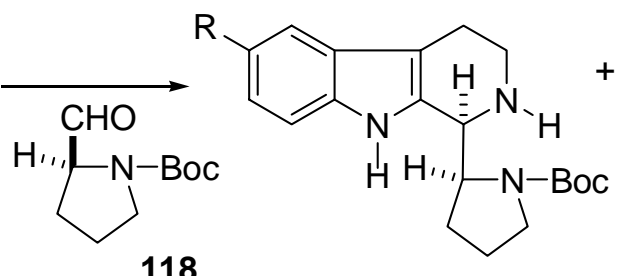

118
$119 a \mathrm{R}=\mathrm{H}$ 119b $\mathrm{R}=\mathrm{Br}$<smiles></smiles>
$120 a \mathrm{R}=\mathrm{H}$ 120b $\mathrm{R}=\mathrm{Br}$

$\mathrm{R}$<smiles>[R]c1ccc2[nH]c3c(c2c1)[C@@H](C)N1CCC[C@@H]31</smiles>
122a $\mathrm{R}=\mathrm{H}$ 122b $\mathrm{R}=\mathrm{Br}$

121a $\mathrm{R}=\mathrm{H}$ 121b $\mathrm{R}=\mathrm{Br}$

\section{Scheme 23}

$\mathrm{Pd} / \mathrm{C}$-mediated dehydrogenation to the $\beta$-carboline followed by reduction of the Boc protecting groups furnished the final product. 


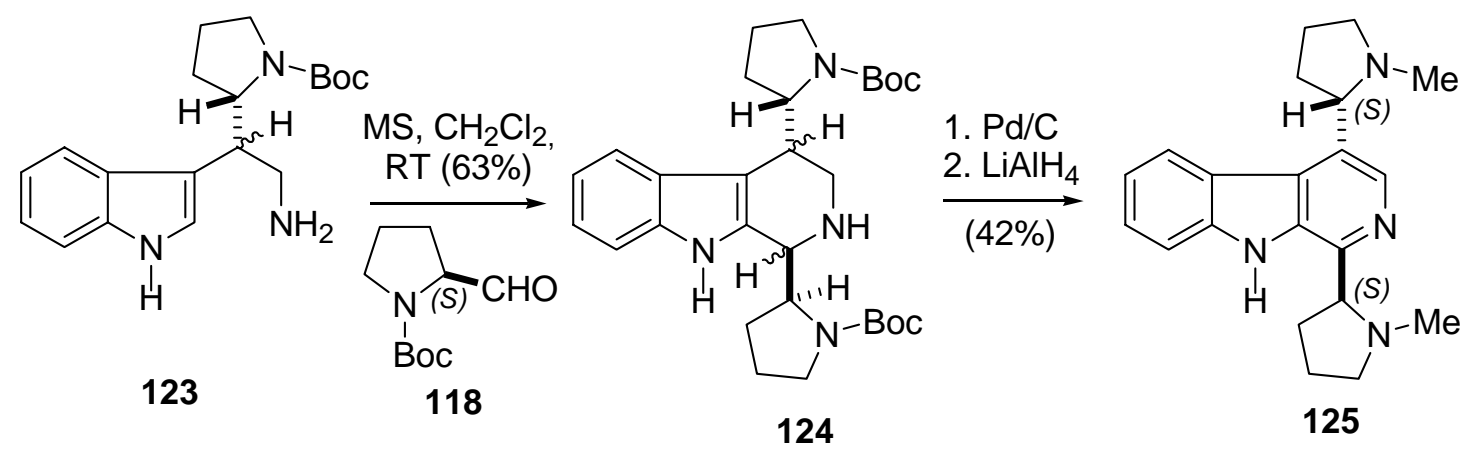

\section{Scheme 24}

5.2.7 Threonine. Lemonomycin (134), is a member of the tetrahydroisoquinoline family of antitumor antibiotics that includes the saframycins, ecteinascidins, and quinocarcins. This natural product was isolated from a fermentation broth of Streptomyces candidus and has potent antibiotic activity against Staphylococcus aureus and Bacillus subtilis. Its structure was recently elucidated, ${ }^{104}$ demonstrating the unique presence of a glycoside unit based on a rare sugar.

During their 15-step synthesis of (-)-lemonomycin, the group of Stoltz employed the $D$ threonine derived aldehyde $\mathbf{1 3 1}^{105}$ to perform a Pictet-Spengler condensation with $\beta$ phenethylamine 132. ${ }^{106}$ The synthesis of $\mathbf{1 3 4}$ is shown in Scheme 25. Two carbon homologation of starting ketone 126 with the anion of EtOAc to 127 in $96 \%$ yield under Felkin-Ahn control ${ }^{107}$ was followed by acid hydrolysis of the isopropylidene protecting group, while reprotection of the vicinal sulfonamido alcohol with formaldehyde under acidic conditions furnished a six-member lactone, which was partially reduced with DIBAL-H to the corresponding lactol, which in turn was trapped with allyl alcohol affording amino glycoside 128 in 50\% overall yield. REDALmediated opening of the oxazolidine ring to $\mathbf{1 2 9}$ and its $N$-methylation to $\mathbf{1 3 0}$ in $81 \%$ overall yield was followed by oxidative cleavage of the terminal olefin moiety in $85 \%$ yield, giving access to the expected aldehyde $\mathbf{1 3 1 .}$ 


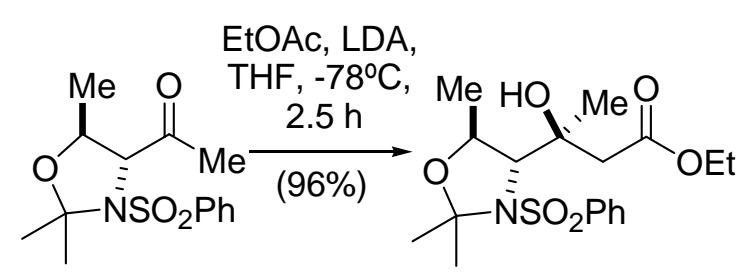

126

127
1. $\mathrm{HCl}, \mathrm{H}_{2} \mathrm{O}, \mathrm{THF}, 13 \mathrm{~h}(86 \%)$
2. $\mathrm{H}_{2} \mathrm{C}(\mathrm{OMe})_{2}, \mathrm{TMSOTf}(77 \%)$
3. DIBAL-H, THF, $-78^{\circ} \mathrm{C}(96 \%)$
4. $\mathrm{MeOH}, \mathrm{H}_{2} \mathrm{C}=\mathrm{CHCH}_{2} \mathrm{OH}$,
$\mathrm{CH}_{2} \mathrm{Cl}_{2}, 13 \mathrm{~h}(79 \%)$

128

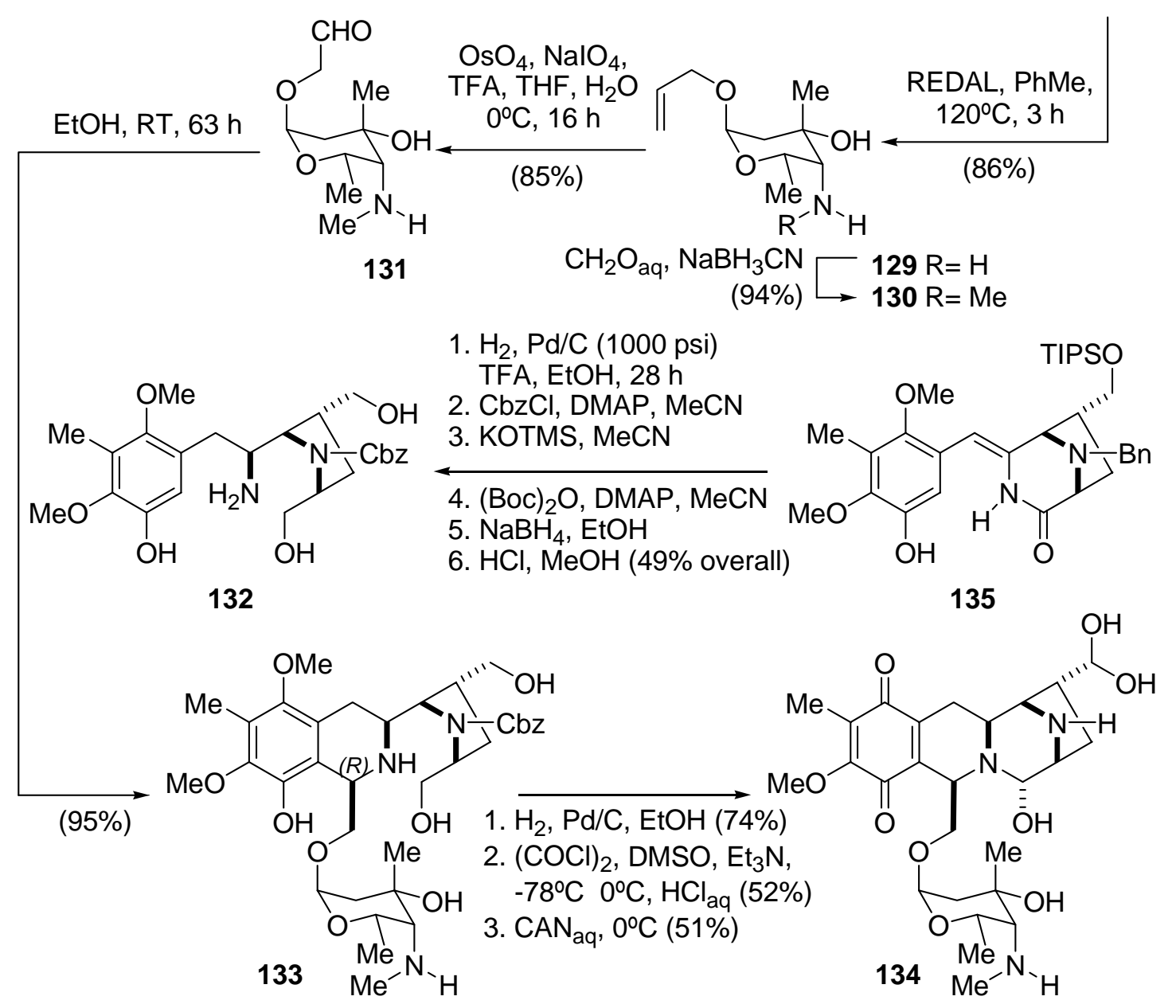

\section{Scheme 25}

On the other hand, a series of chemical transformations yielded $\beta$-phenethylamine derivative 132 in 49\% yield from benzylidene ketopiperidine 135 and the former was subjected to PictetSpengler condensation with aldehyde $\mathbf{1 3 1}$ in ethanol at room temperature, affording $95 \%$ of the desired polysubstituted THIQ 133 in diastereomerically pure form after reacting more than 2.5 days at room temperature. Hydrogenolysis of the $\mathrm{Cbz}$ protecting group, followed by Swern oxidation of both primary alcohols with concomitant cyclization and final CAN oxidation to the quinone afforded the natural product 134. 
5.2.8 Tyrosine. The saframycins are structurally complex alkaloids that constitute a series of natural antiproliferative agents containing a cyanopiperazine core, or its functional equivalent, within a complex polycyclic framework. ${ }^{108}$ These alkaloids are derived from tyrosine and members of this series have shown promising clinical efficacy in the treatment of solid tumors and have proven amenable to structural modification in the search for analogues with improved pharmacological properties. ${ }^{109}$

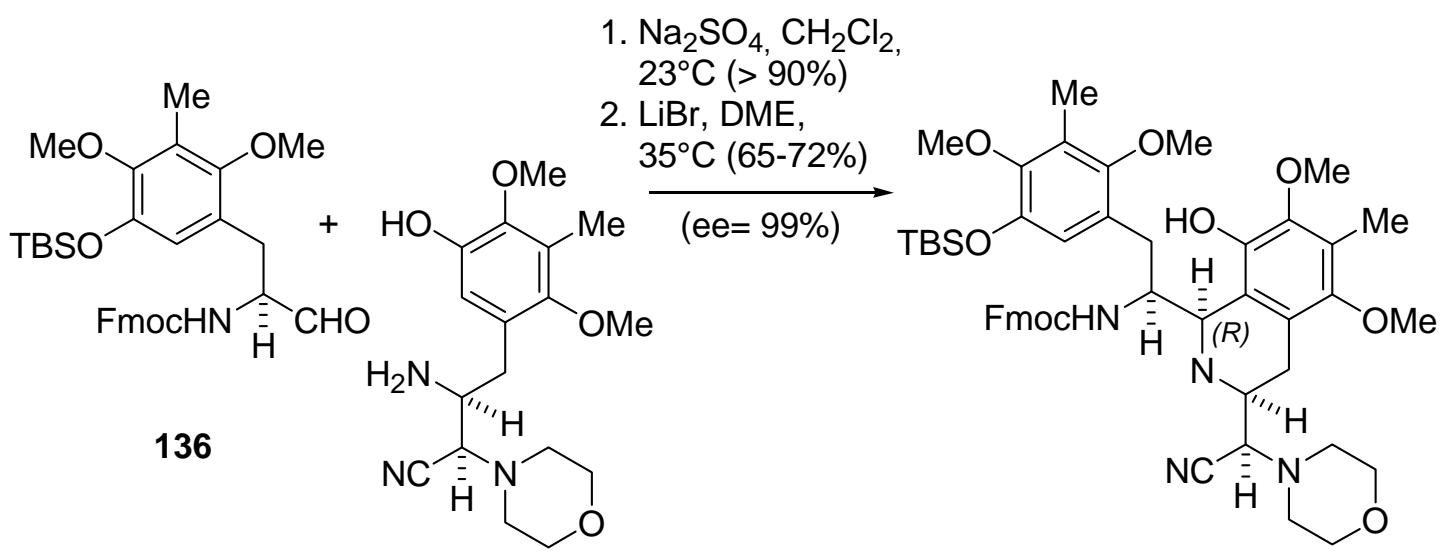

137

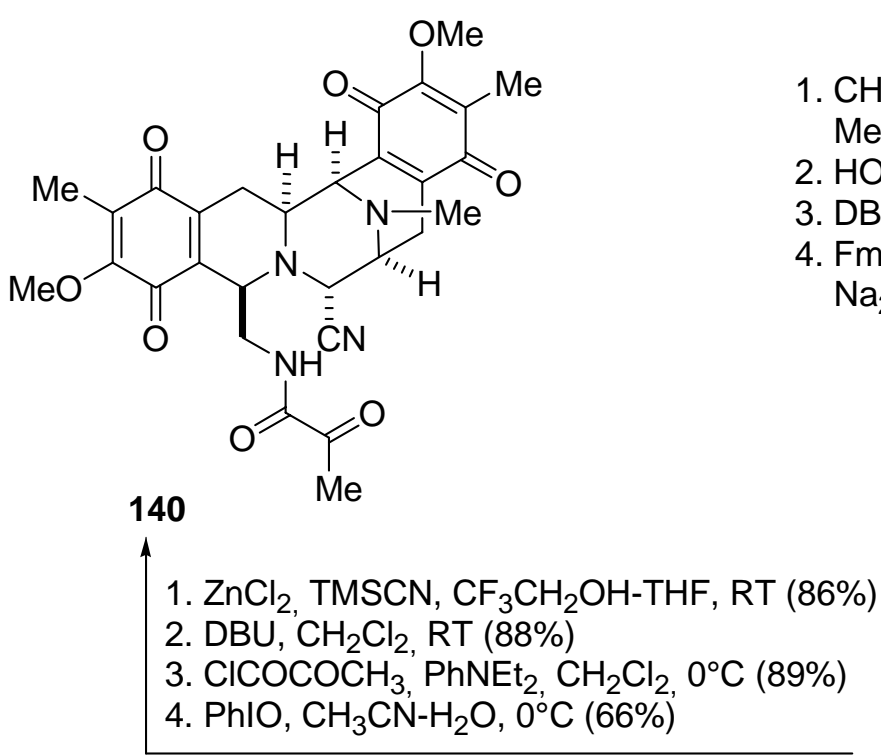

1. $\mathrm{CH}_{2} \mathrm{O}-\mathrm{H}_{2} \mathrm{O}, \mathrm{NaBH}(\mathrm{OAc})_{3}$, $\mathrm{MeCN}, \mathrm{RT}$ (94\%)

2. HOAC, TBAF, THF, RT

3. $\mathrm{DBU}, \mathrm{CH}_{2} \mathrm{Cl}_{2}$, RT (92\%)

4. $\mathrm{FmOCHNCH} \mathrm{CHO}_{2}$ $\mathrm{Na}_{2} \mathrm{SO}_{4}, \mathrm{CH}_{2} \mathrm{Cl}_{2}$, RT (66\%)

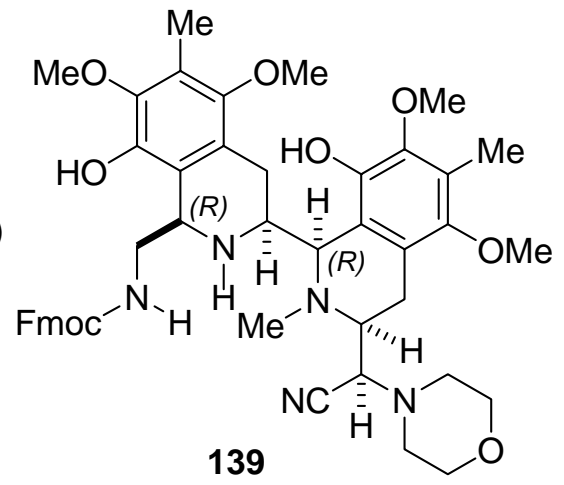

\section{Scheme 26}

During their synthesis of saframycin A (140), the group of Myers ${ }^{110}$ employed aldehyde 136, which can be considered as a polysubstituted tyrosine derivative (Scheme 26). Pictet-Spengler condensation of $\mathbf{1 3 6}$ with $\alpha$-aminonitrile 137, prepared from the same aldehyde furnished THIQ 138 in greater than $60 \%$ yield and with $e e=99 \%$. The key aldehyde was prepared by the 
diastereoselective alkylation of pseudoephedrine glycinamide hydrate, followed by amide reduction with lithium aminoborohydride, $N$-protection, and oxidation. ${ }^{111}$

Next, $N$-methylation of $\mathbf{1 3 8}$ followed by functional group deprotection set the stage for a second highly stereospecific Pictet Spengler reaction with Fmoc-glycinal, furnishing 139 in 57\% overall yield. In turn, this was converted into saframycin A (140) by reductive removal of the Fmoc group, cyclization to form the piperazine ring, followed by installation of the glyoxamide side chain and final oxidation to the diquinone state in $45 \%$ overall yield. A solid supported synthesis of this natural product has also been disclosed by this group, employing the same strategy. $^{112}$

\subsection{Asymmetric cyclopropanation of enol ethers}

The group of Andersson ${ }^{113}$ reported the five step synthesis of the aspidosperma-type alkaloid (+)-quebrachamine (148). ${ }^{114}$

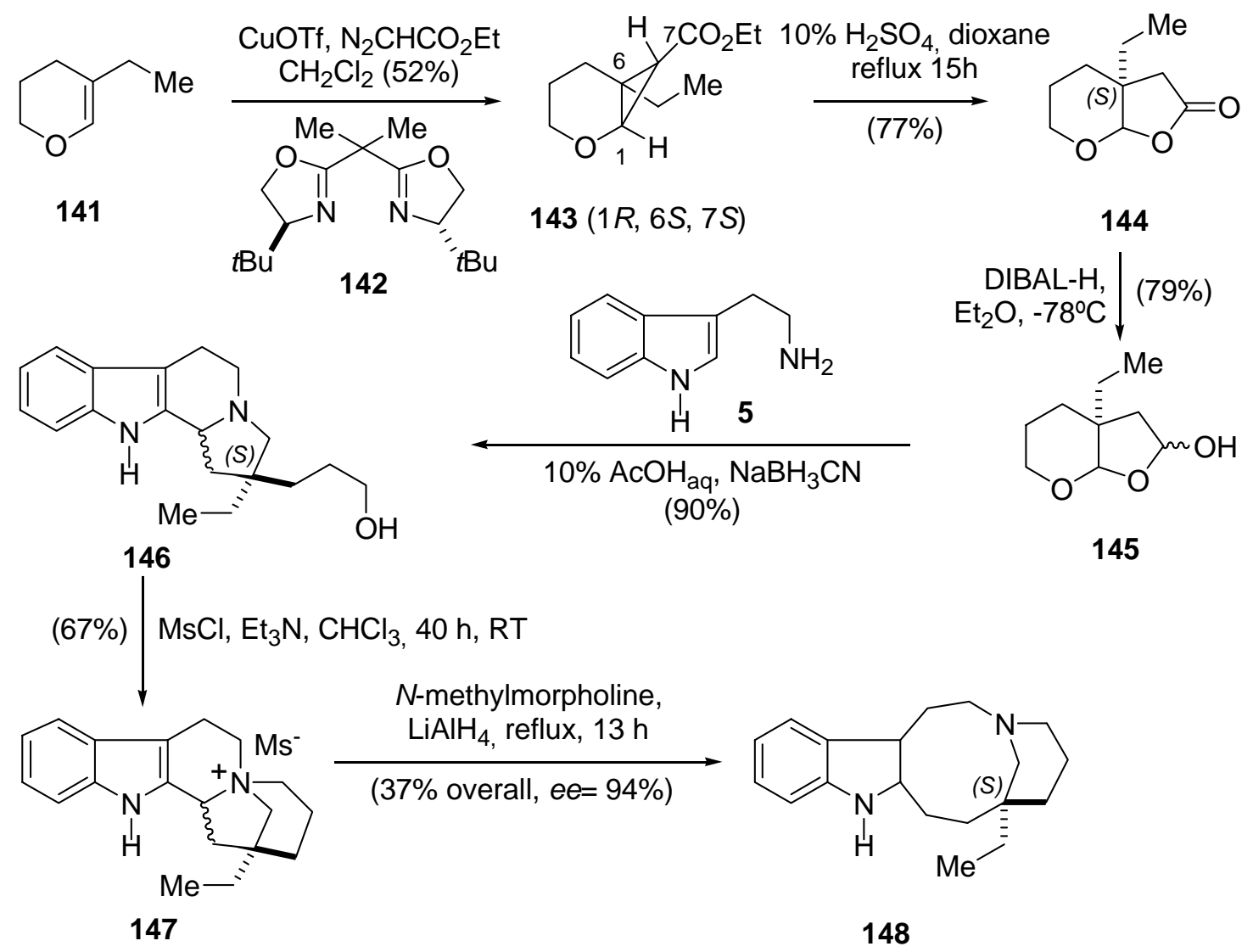

\section{Scheme 27}


This natural product carries a quaternary chiral center with known configuration. Therefore, the synthesis was carried out by means of a Pictet Spengler condensation ${ }^{115}$ of lactol-acetal 145 with tryptamine $\mathbf{5}$, in order to determine the absolute configuration of lactone-acetal $\mathbf{1 4 4}$. This complemented previous routes in which chiral templates derived from $L$-glutamic acid were employed. $^{116}$

The preparation of the required lactol-acetal was highly stereoselectively carried out (exo:endo up to 95:5, ee= 95\%) in 52\% yield by the CuOTf-promoted asymmetric cyclopropanation of dihydropyran $\mathbf{1 4 1}^{117}$ with ethyl diazoacetate ${ }^{118}$ and Evans' bisoxazoline 142 as catalyst, as depicted in Scheme $27 .{ }^{119}$

The acid-induced ring cleavage of cyclopropane 143 gave lactone 144 in $77 \%$ yield. Reduction of lactone 144 with DIBAL-H in $79 \%$ was followed by acid-catalyzed condensation with tryptamine (5) and subsequent reduction with sodium cyanoborohydride, which led to the diastereomeric mixture of alcohols 146 in 90\% yield. Next, an improved version of Kutney's protocol was employed, via the quaternary ammonium salt 147 formed spontaneously in $67 \%$ yield when the alcohols were treated with methanesulfonyl chloride and triethylamine. Reductive cleavage of the $\mathrm{C}_{\text {benzylic }}-\mathrm{N}$ bond with concomitant ring expansion, employing $\mathrm{LiAlH}_{4}$ in refluxing $\mathrm{N}$-methylmorpholine completed the sequence.

\subsection{Use of structurally complex non-carbohydrate naturally occurring aldehydes}

5.4.1 Ircinal A and the synthesis of the manzamines. Manzamine A (152) is a cytotoxic alkaloid isolated in 1986 from a sponge harvested near the coast of Okinawa. ${ }^{120}$ Its unique structure consists of a $\beta$-carboline heterocycle attached to a pentacyclic diamine core containing both eight- and thirteen-member rings on a pyrrolo[2,3-i]isoquinoline framework. Recently, Winkler and Axten $^{121}$ reported a complex intramolecular vinylogous amide photoadditionfragmentation-Mannich closure sequence approach towards Manzamine A (Scheme 28). ${ }^{122}$

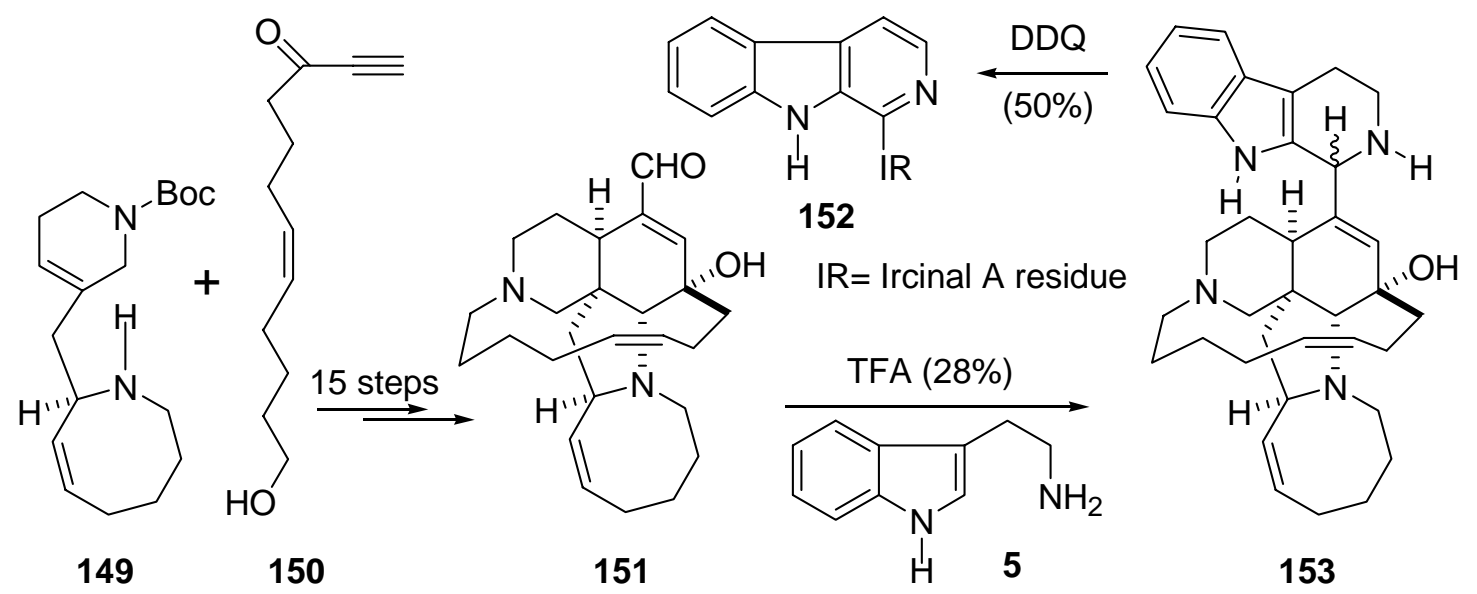

Scheme 28 
Starting with diamine 149 and acetylenic ketone 150, the polycyclic aldehyde ircinal A $(\mathbf{1 5 1})^{123}$ was assembled in approximately 15 steps; this was Pictet-Spengler condensed with tryptamine (5) yielding 58\% of manzamine D (153), as a diastereomeric mixture of THBC, the proportion of which was not informed. Final oxidation of 153 with DDQ provided $50 \%$ of manzamine A (152).

Analogously, Kobayashi submitted tryptamine to a Pictet-Spengler condensation with ircinal $\mathrm{B}$, which differs from ircinal $\mathrm{A}$ in that the bond between the allylic position and the tertiary nitrogen of the eight-member ring is missing. This gave manzamine $\mathrm{H}$, which upon treatment with DDQ furnished manzamine J. These manzamines and the starting ircinals are cytotoxic to L1210 murine leukemia and KB human epidermoid carcinoma cells.

5.4.2 Condensation of secologanin with naturally occurring amines and derivatives. The pioneering work of the group of Battersby demonstrated that secologanin (154) reacts with tryptamine (5) and dopamine (42), giving strictosidine (155) and vincoside (161a), which are parent compounds of the large class of terpenoid indole and ipecac alkaloids. ${ }^{124}$ Recently, the regio- and stereoselectivity of these reactions was investigated in detail. ${ }^{125}$

The well-known monoterpene indole alkaloid glycoside strictosidine (155a) ${ }^{127}$ was first isolated from Rhazya stricta ${ }^{126}$ and is the precursor of more than 2200 monoterpene indole and related alkaloids. In vivo, it results from the Pictet-Spengler condensation of secologanin (154) and tryptamine (5) by plant species, in the presence of the enzyme strictosidine synthase, ${ }^{128}$ or under biomimetic conditions in aqueous solution at $\mathrm{pH}=4.5$ (Scheme 29). ${ }^{129}$ In the presence of the enzyme, the new chiral center is formed with complete stereoselectivity, while a 1:1 diastereomeric ratio is obtained in the absence of the enzyme.

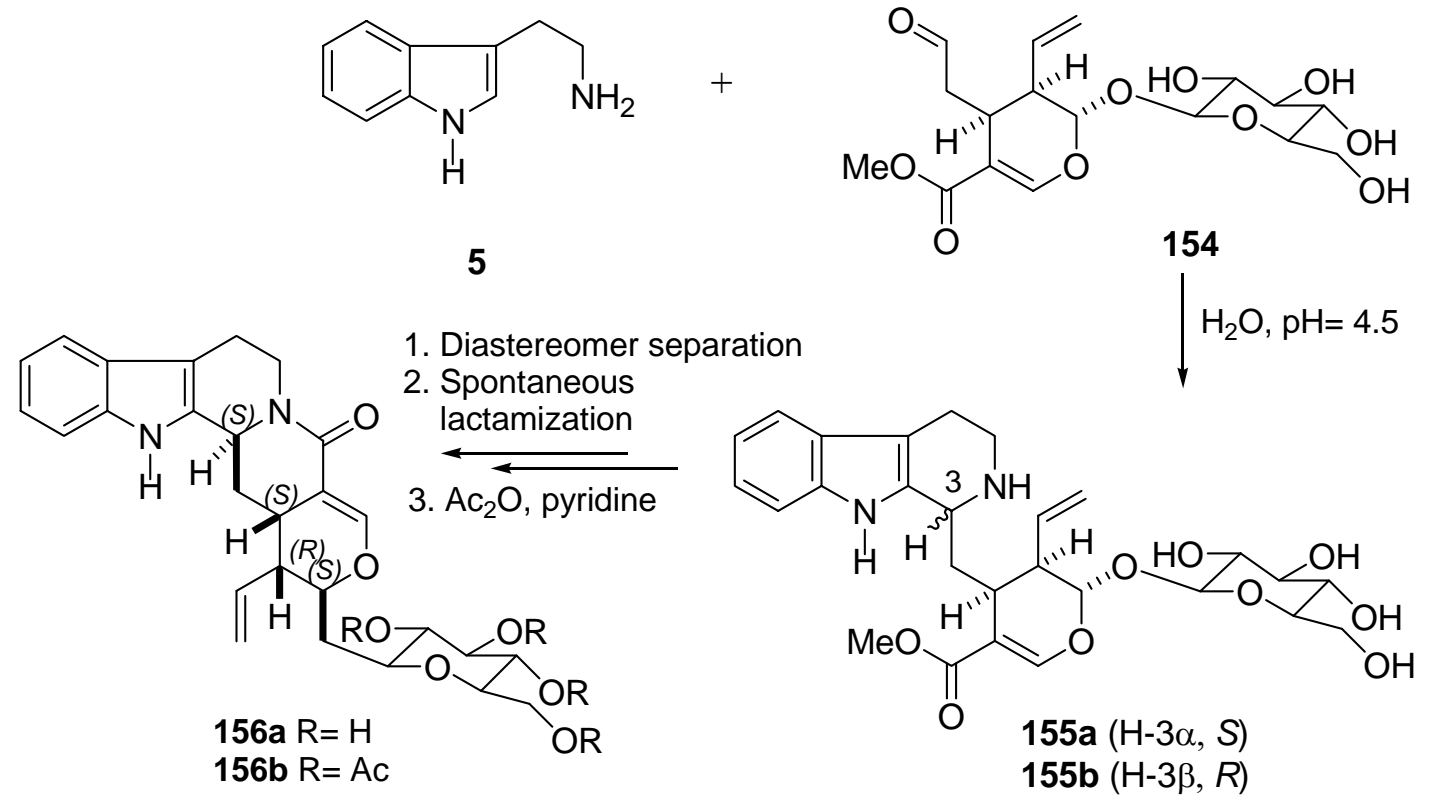

Scheme 29 
For many years, there was much controversy about the configuration of the new center of chirality at C-3, as well as about the question of which stereoisomer is the precursor of the alkaloids mentioned above. ${ }^{130}$ Recent chemical and optical correlations carried out in the strictosidine-vincoside series suggested that the configuration of C-3 in strictosidine is $S .{ }^{131}$ This was also confirmed by the 2D-NMR analysis of the natural product, prepared in epimer-free form using the easy lactamization of of the H-3 $\beta$ derivative vincoside (155b). ${ }^{132}$

There is also a special group of more than 120 terpenoid indole alkaloids, formally derived from secologanin (154) and oxotryptamine (157a). ${ }^{133}$ The biogenesis of this class of alkaloids has not been fully investigated and oxotryptamine was not isolated from any plant species to date. Brown reported ${ }^{134}$ about the coupling reaction of oxotryptamine and the secologanin aglycon and indicated that the formation of this type of compounds under abiotic conditions is possible. Recently Szabó and coworkers investigated the direct coupling of secologanin (154) and oxotryptamine finding that the reaction gives pentacyclic lactams 160, as shown in Scheme 30.
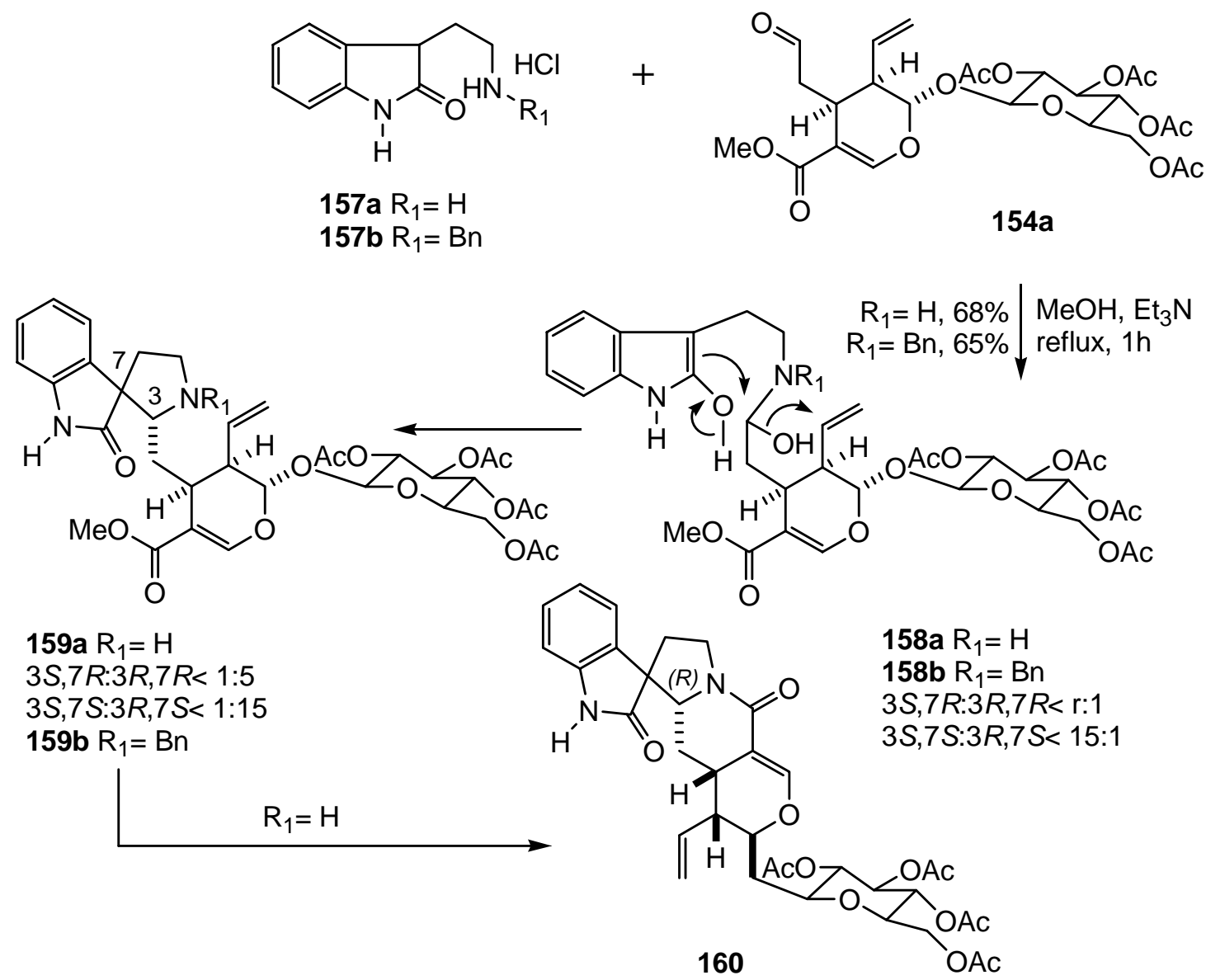

\section{Scheme 30}


With the benzylated amine $\mathbf{1 5 7 b}$, the reaction was stopped at the tetracyclic ester level

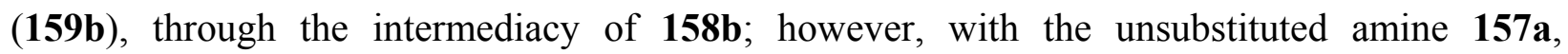
generation of 159a by way of $\mathbf{1 5 8 a}$ was followed by spontaneous lactamization to 160 . In both cases, the products were formed with high stereoselectivity at $\mathrm{C}-3$, but as an epimeric pair of $7 R$ and $7 S$ in a ratio of 1:3. The bulky $N$-benzyl substituent directed the stereoselectivity at C-3 in favor of the $S$ configuration. In the non-benzylated compounds, the reversible coupling reaction is probably non-stereoselective, but during the lactamization the $3 R$ epimer is sterically favored and gives the final lactam in this configuration.

It has been proposed that the formation of the $\beta$-carboline system takes place through a spiroindolenine intermediate such as $\mathbf{8}$ (see Scheme 2), ${ }^{135}$ which might be considered a sterically close analogue of the spirooxindole structure 159.

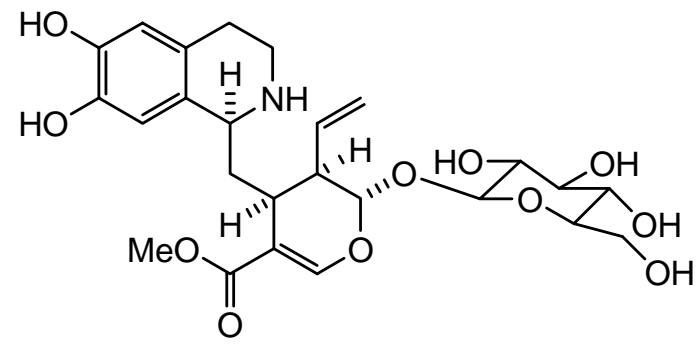

$161 a$

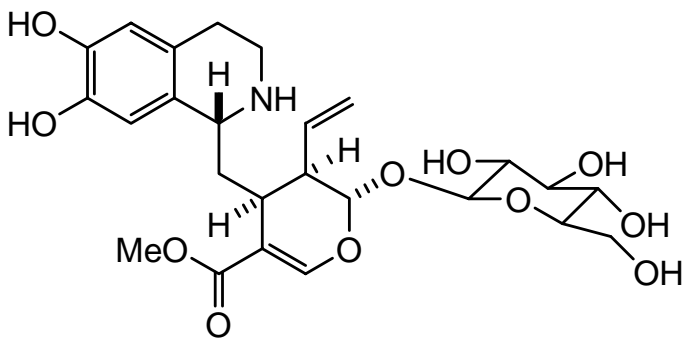

161b

\section{Figure 1}

In this case, these results may explain the preferential formation of $3 S$ strictosidine and related alkaloids. 

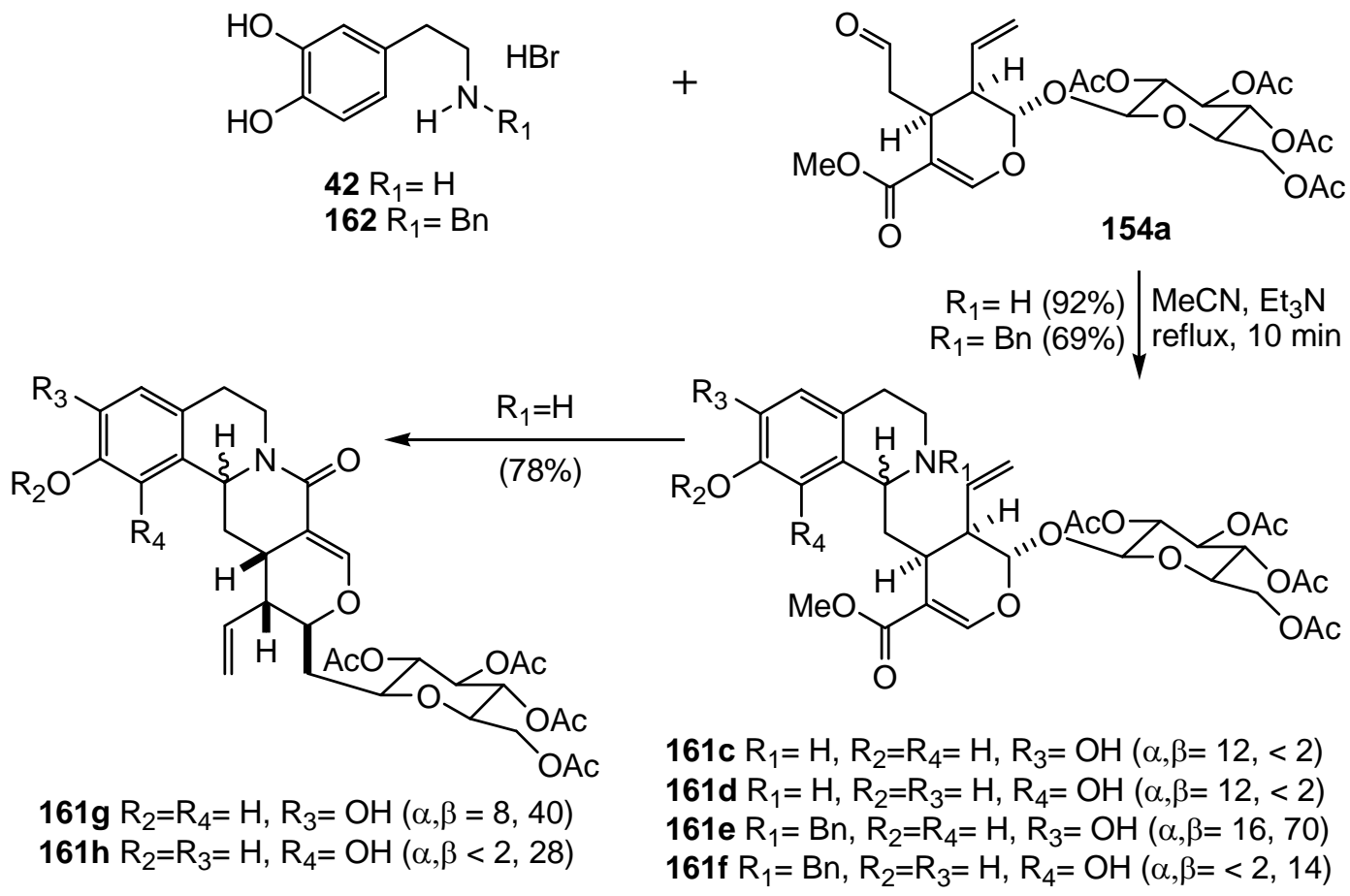

\section{Scheme 31}

The enzyme might work like the benzyl group, except that its attachment to N-4 would be temporary rather than constant. In the subsequent, stereoconservative 1,2-rearrangement into the $\beta$-carboline system, the enzyme could leave the N-4 atom, the product retaining the $S$ configuration at C-3.

A special class of isoquinoline alkaloids, which includes the widely known emetine from Cephaelis ipecacuanha can be formed by Pictet-Spengler coupling secologanin (154) with dopamine (42) and related compounds. ${ }^{136}$ It has been reported that secologanin 154 reacts with dopamine 42 at $\mathrm{pH}=5$ to give 2-deacetylisoipecoside (161a) and 2-deacetylipecoside (161b) in approximately a 1:4 ratio and an X-ray diffraction analysis of an ipecoside derivative proved unequivocally the $R$ configuration at $\mathrm{C}-1 .^{137}$

Since in dopamine the C-2 and C-6 are chemically nonequivalent, it was expected that the coupling reaction might give normal (cyclization at C-6) and "neo" (cyclization at C-2) regioisomers. Neo derivatives were isolated from Cephaelis ipecacuanha and Alangium lamarckii Thw. (Alangiaceae), ${ }^{138}$ and De-Eknamkul described the enzymatic condensation of secologanin and dopamine under cell-free conditions yielding both series $R$ and $S$ of condensation products. 


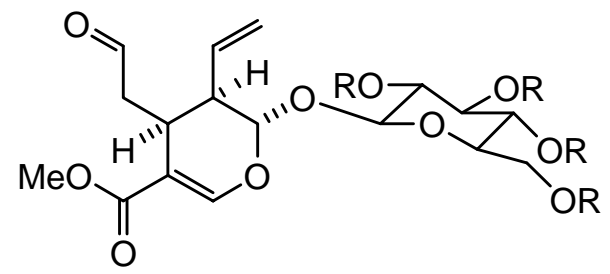

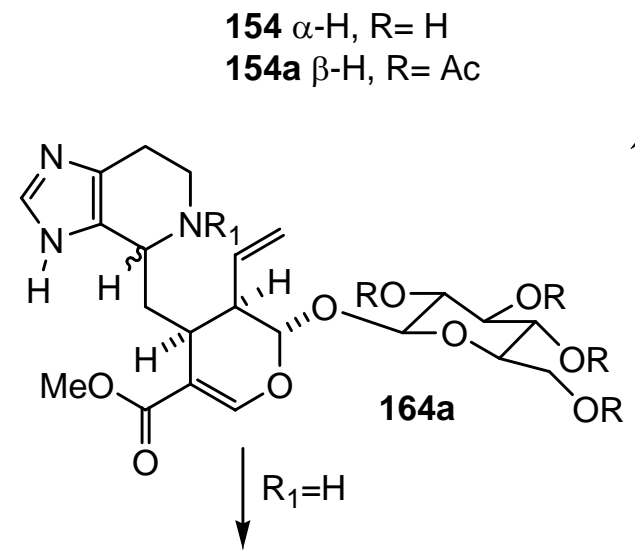

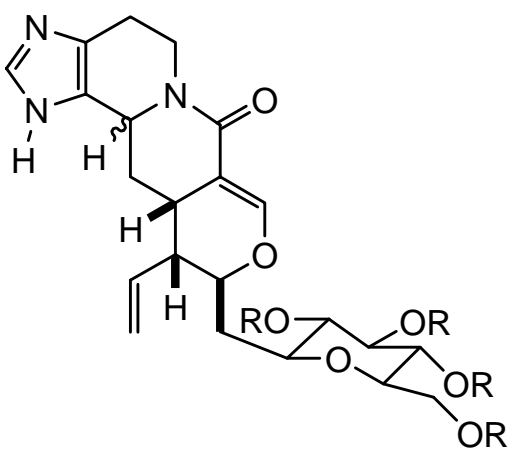

$165 a$

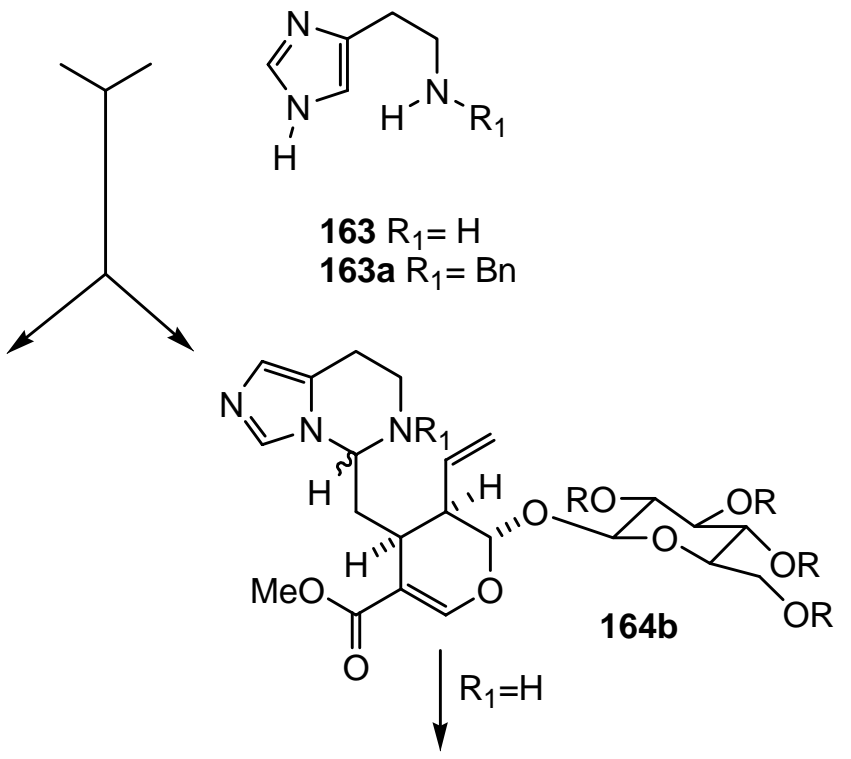

\section{Scheme 32}

However, purification of the crude preparation, gave an enzyme catalyzing the formation of the compounds of the $R$ series. ${ }^{139}$ Szabó and coworkers ${ }^{140}$ studied the reaction of dopamine (42) and $N$-benzyldopamine (162) with tetraacetyl loganin (154a) and found that reaction with the natural product gave preferably the $\mathrm{H}-1 \alpha$ isoquinolines $161 \mathrm{c}, \mathbf{d}$, while the $N$-benzyl derivative 162 provided preferentially the $H-1 \beta$ heterocycles 161 ,f.

In both cases, the 7,8-disubstituted THIQ ("neo", 161d and 161f) were formed. The dopamine-derived heterocycles 161c,d were lactamized to a mixture of tetracyclic compounds 161g,h bearing different substitution on the aromatic ring and as well as $\alpha$ and $\beta$ configurations on the new chiral center.

Analogously, Szabó and coworkers also studied the reactions of tetraacetyl secologanin 154a and histamine (163) as well as with $N$-benzyl histamine (163a). ${ }^{141}$ They found (Scheme 32) that with the benzylated amine 163a, the main product was the normal, tetraacetylated benzyl derivative of histeloside (164a), having the $R$ configuration at the new center of chirality $\mathrm{C}-1$, 
with a small amount of an unidentified minor component which could probably be the $1 S$ epimer.

However, in a slightly acidic medium, the reaction with histamine (163) gave two products in an approximately 6:4 ratio. The main compound proved to be the expected, tetraacetylated derivative of the lactam histelosamide with the $R$ configuration at $\mathrm{C}-1$ (165a), and the minor product was the uncyclized 164a bearing the $S$ configuration at the same $\mathrm{C}-1$ center. When the transformation was carried out under acid-free conditions, in addition to the epimeric pair of the normal tetraacetylated lactam (165a) and the tetraacetylisohisteloside with $1 S$ configuration (164a), tetraacetylneohistelosamide (165b) was also isolated, in which the cyclization took place at one of the cyclic nitrogens of the imidazole ring, through the intermediacy of $\mathbf{1 6 4 b}$. Probably, 165b is also an intermediate in the formation of the normal isomers, because under slightly acidic conditions it is rapidly isomerized into the normal alkaloid 165a. The tendencies observed in the histamine series were that at $\mathrm{C}-1$, the $R$ configuration is favored over the $S$ one, and lactamization is faster in the former than in the latter case.

\subsection{Use of structurally complex synthetic carbonyls}

Strychnofoline (177b), shown in Scheme 34, belongs to a class of natural products isolated from the leaves of Strychnos usambarensis, which displays high antimitotic activity against cultures of mouse melanoma and Ehrlich tumor cells. ${ }^{142}$

A prominent structural feature of these alkaloids is the presence of a spiro[pyrrolidin-3,3'oxindole] nucleus. The diastereoselective total synthesis of $( \pm)$-strichnofoline recently disclosed by Carreira ${ }^{143}$ resorts to the preparation of terminal olefin 172 as a precursor of polysubstituted aldehyde 175 and its Pictet-Spengler condensation with $N$-methyl tryptamine (176). Key for the synthesis of aldehyde 175 was the stereoselective preparation of imine 170, which was carried out from 166, ${ }^{144}$ as shown in Scheme 33. Exposure of the enolate of $\mathbf{1 6 6}$ to $\mathrm{PhSeCl}$, followed by $\mathrm{H}_{2} \mathrm{O}_{2}$ oxidation of the resulting selenide afforded the unsaturated lactam 167 in $80 \%$ yield. Next, conjugate addition of an allyl moiety through organocuprate chemistry gave $75 \%$ of $\mathbf{1 6 8}$ as an inseparable 5:1 mixture of diastereomers. ${ }^{145}$ Reduction of $\mathbf{1 6 8}$ followed by facile conversion of the corresponding lactamol to enamine $169^{146}$ in $75 \%$ yield and mild cleavage of the Boc-group gave access to unstable imine 170. The imine was heated with 171 furnishing tetracyclic intermediate $\mathbf{1 7 2}$ in $55 \%$ yield as a single isomer. The stereochemical outcome of this ring expansion is in agreement with previous observations. ${ }^{147}$

Osmilation of the side chain of $\mathbf{1 7 2}$ was followed by oxidative cleavage of the intermediate diol and acetalization of the resulting aldehyde, furnishing $\mathbf{1 7 3}$ in $80 \%$ yield. Deprotection of the silyl ether and oxidation of the so uncovered primary alcohol gave an aldehyde which was methylenated under classical Wittig conditions, affording acetal 174 in $66 \%$ overall yield, the deprotection of which provided aldehyde 175, ready for condensation with $N$-methyl tryptamine 176. 

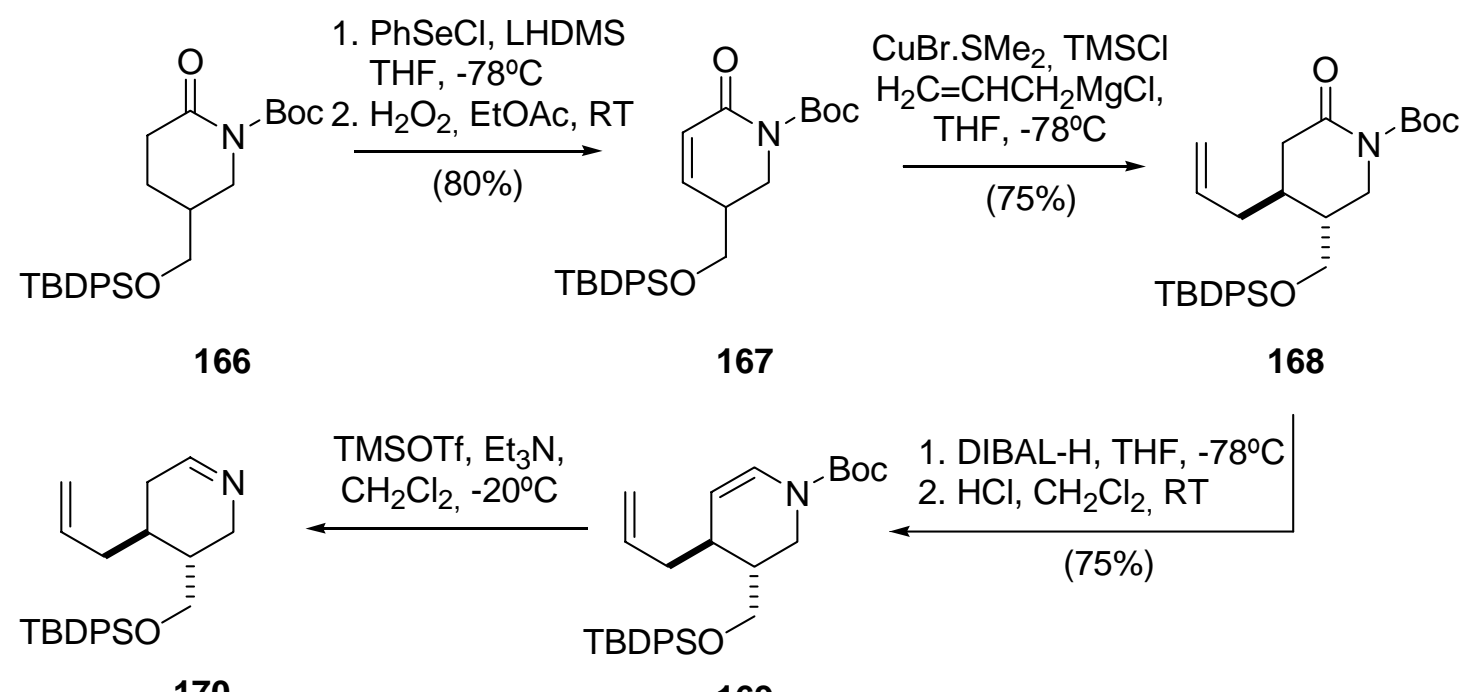

170

169
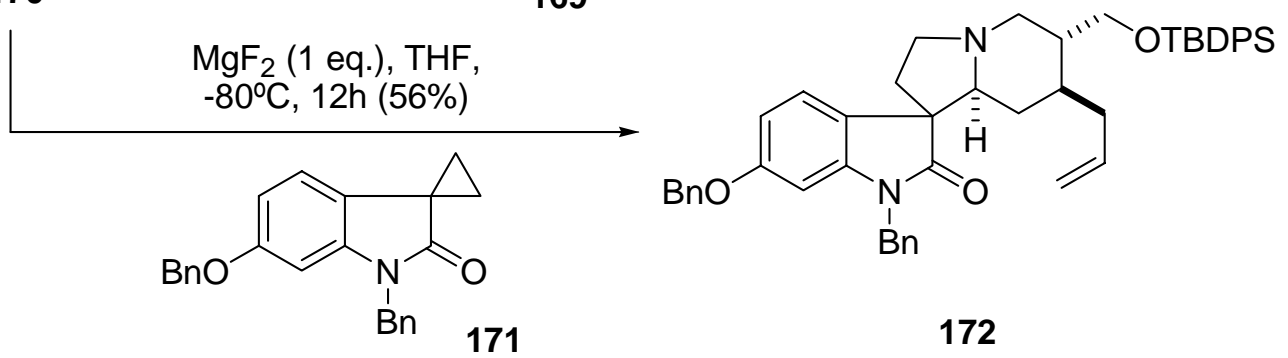

172

\section{Scheme 33}

This Pictet-Spengler reaction ${ }^{148}$ gave a mixture of $\alpha$ and $\beta$ diastereomers in a 1.5:1 proportion and $64 \%$ yield. Debenzylation of the less abundant $\beta$-diastereomer of $177 \mathbf{a}$ with sodium in liquid ammonia gave the final product $\mathbf{1 7 7 b}$ in $82 \%$ yield, as shown in Scheme 34.

Ecteinascidin 743 (ET-743, 181) is an extremely potent antitumor agent isolated from the marine tunicate Ecteinascidia turbinata, which is currently undergoing phase II clinical trials and is also attracting considerable attention owing to its unique mechanism of action. ${ }^{149}$ The novelty of its structure, its remarkable biological activities and natural scarcity have attracted the attention of Chemists during the last decade. Rinehart and coworkers proposed that biosynthesis of some of the ecteinascidins could take place by Pictet-Spengler condensation of an $\alpha$-keto macrolactone with properly substituted $\beta$-phenethylamine (ET-743, ET-729, ET-745, ET-770 and congeners) or tryptamine (ET-736 and ET-722, ET-752, ET-808 and similar compounds) moieties. $^{150}$

The group of Fukuyama ${ }^{151}$ recently reported a total synthesis ET-743. To this end, the advanced intermediate $\mathbf{1 7 8}$ was submitted to a reaction with zinc in acetic acid in order to cleave the Troc group; this was followed by reductive alkylation affording an $N$-methyl amine, whose Alloc group and allyl ether were simultaneously cleaved with a palladium catalyst to give an intermediate aminophenol.

Next, according to Corey's protocol, ${ }^{152}$ a biomimetic transamination reaction ${ }^{153}$ afforded the related known $R$-ketolactone, ${ }^{154}$ similar to $\mathbf{1 8 3}$, and subsequent Pictet-Spengler reaction with 
amine 179 furnished ET-770 (180).

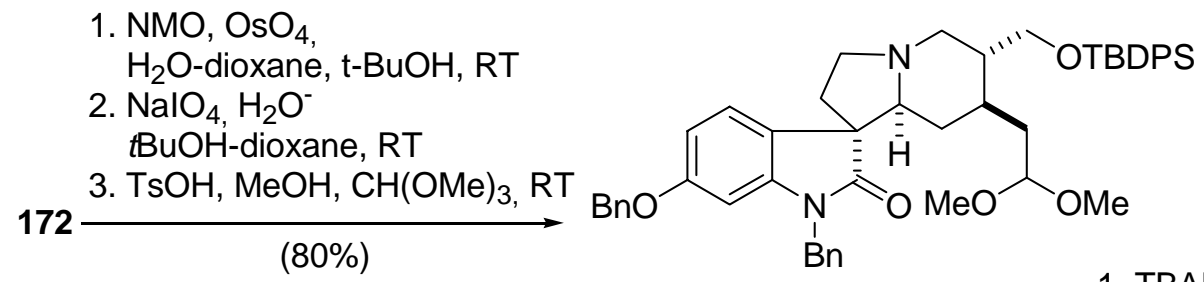

$\mathrm{NMO}, \mathrm{OsO}_{4}$

$\mathrm{H}_{2} \mathrm{O}$-dioxane, t-BuOH, RT

. $\mathrm{NaIO}_{4}, \mathrm{H}_{2} \mathrm{O}$

tBuOH-dioxane, RT

$(80 \%)$

1. TBAF, THF, RT

173

2. IBX, DMSO, RT

3. $t \mathrm{BuOK}, \mathrm{Ph}_{3} \mathrm{PMeBr}$,

THF, RT (66\%)<smiles>C=C[C@H]1CN2CC[C@@]3(C(=O)Nc4cc(OCc5ccccc5)ccc43)[C@@H]2CC1CCO</smiles>

175

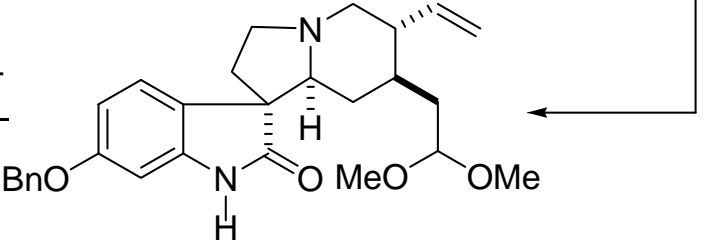

174

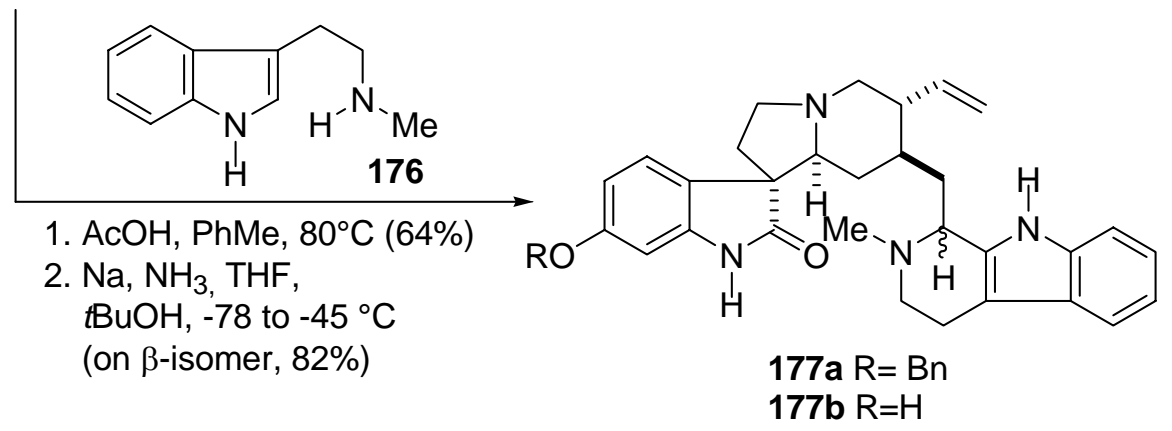

\section{Scheme 34}

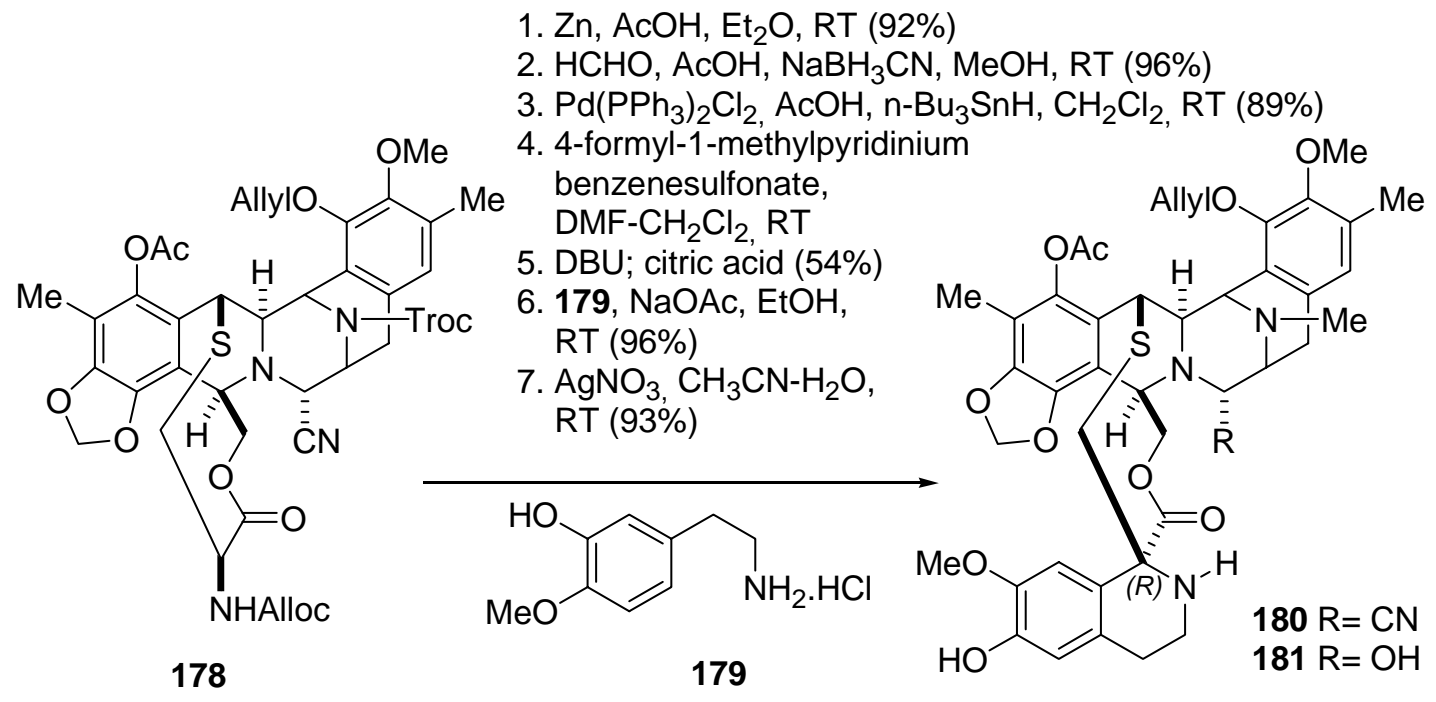

Scheme 35 
Finally, treatment with $\mathrm{AgNO}_{3}$ in $\mathrm{CH}_{3} \mathrm{CN}-\mathrm{H}_{2} \mathrm{O}$ generated the labile hemiaminal to give ecteinascidin 743 (181).

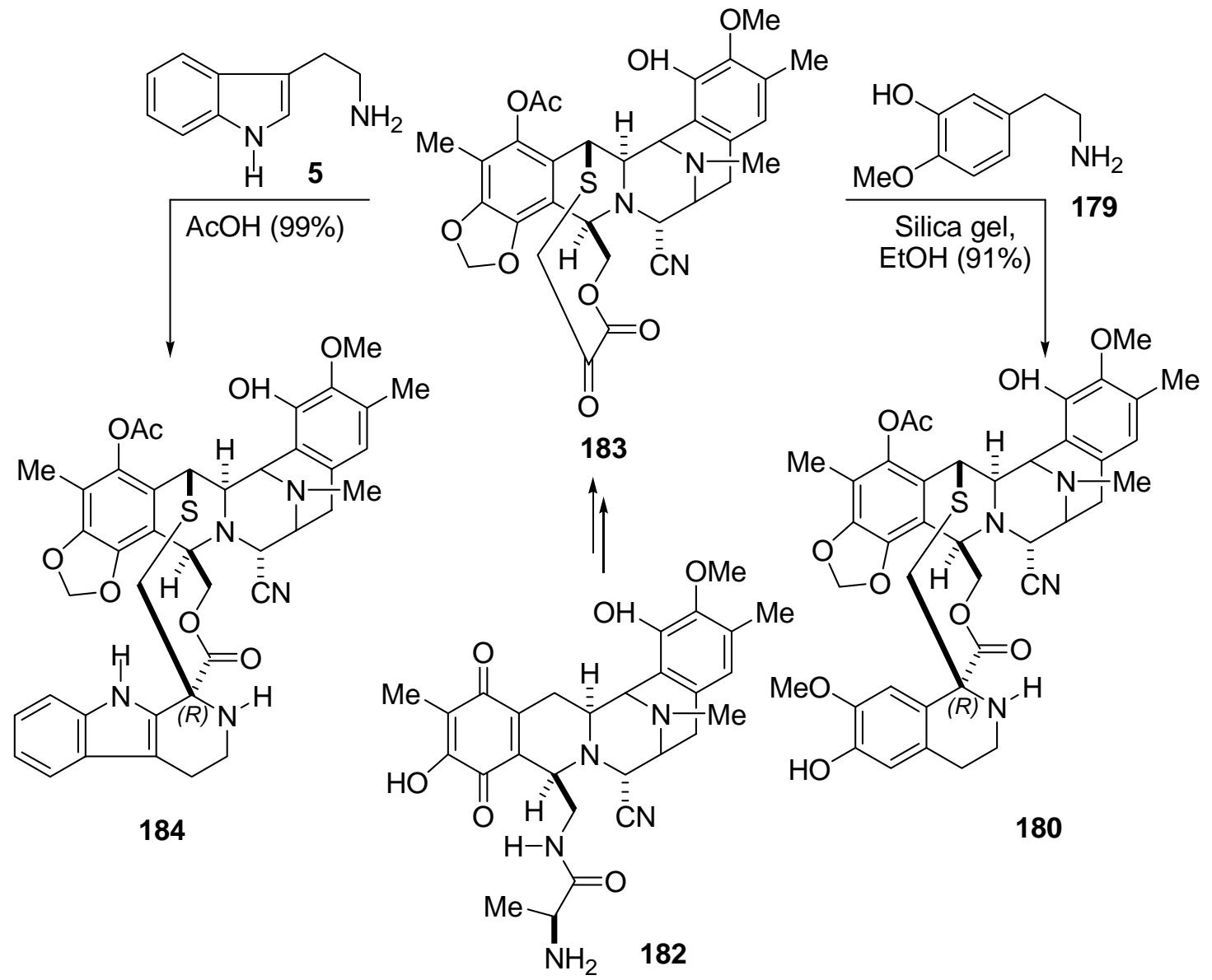

\section{Scheme 36}

Cuevas and coworkers ${ }^{155}$ disclosed the syntheses of several ecteinascidins from cyanosafracin B (182), employing 183 as their common key intermediate. Again, the PictetSpengler reactions with 179 to give $\mathbf{1 8 0}$ and with tryptamine (5) to afford 184, were highly stereoselective.

An analogous strategy was employed by Danishefsky as the end part of his synthesis of analogs of ET-743, the Pictet-Spengler reaction furnishing the desired product as a single diastereomer, with the configuration required by ET-743. ${ }^{156}$

\subsection{Quinic acid as a source of chirality}

Recently, the group of Hanessian reported a new synthesis of reserpine (197) by the chiron approach, ${ }^{157}$ employing the readily available quinic acid (185) as starting material and source of chirality for the elaboration of ring $E$ of the natural product. 


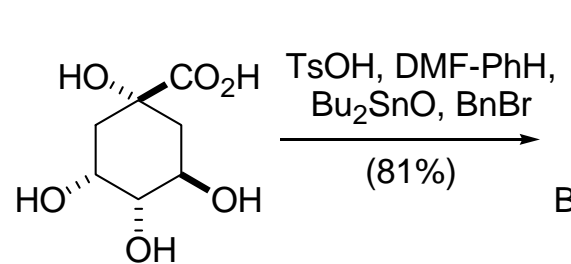

185<smiles>O=C1OC2C[C@]1(O)C[C@@H](OBr)[C@@H]2O</smiles>

186a $\mathrm{R}=\mathrm{H}$ 186b $\mathrm{R}=\mathrm{Bn}$

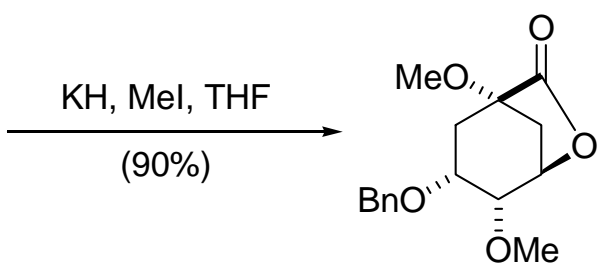

187

$$
\begin{array}{r}
\mathrm{Pd}(\mathrm{OH})_{2} / \mathrm{C}, \mathrm{H}_{2}, \mathrm{MeOH}(98 \%) \\
\mathrm{NalO}_{4}, \mathrm{RuO}_{x} \cdot \mathrm{XH}_{2} \mathrm{O}, \\
\text { EtOAc- }-\mathrm{Me}_{2} \mathrm{CO}-\mathrm{H}_{2} \mathrm{O}(90 \%)
\end{array}
$$<smiles>C=C[C@]1(O)C=C(C(C)=O)CC(O[BH2-]C(C)(C)C)[C@H]1OC</smiles>

190

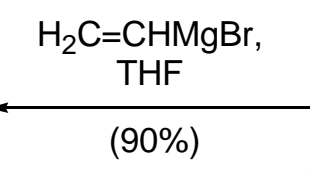

$(90 \%)$

TBDMSOTf, 2,6-lutidine (90\%)<smiles>[R]C1CC(C(=O)OC)=CC(=O)C1OC</smiles>

189a $\mathrm{R}=\mathrm{H}$ $\rightarrow$ 189b $R=$ TBDMS

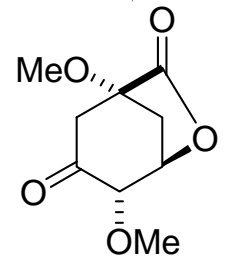

188

1. DCC, $\mathrm{ClCH}_{2} \mathrm{CO}_{2} \mathrm{H}$, DMAP, $\mathrm{CH}_{2} \mathrm{Cl}_{2}$

2. Nal, MeCN ( $80 \%$ overall)

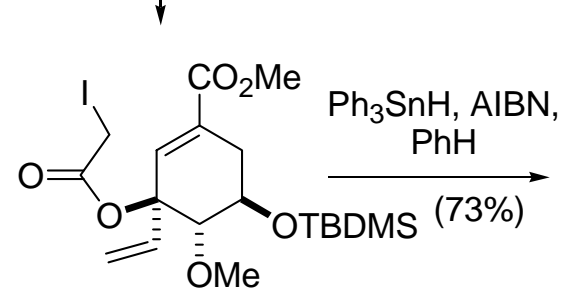

191

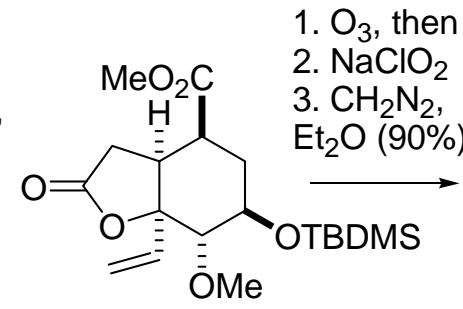

192<smiles>CO[C@H]1CC(C(C)=O)[C@H]2CC(=O)O[C@]2(C)[C@@H]1OC</smiles>

193

\section{Scheme 37}

Thus, treatment of quinic acid with $\mathrm{TsOH}$ in benzene-DMF gave bicyclic lactone 186a, which was selectively benzylated on the equatorial hydroxyl group through the intermediacy of a stannylene acetal to provide $\mathbf{1 8 6 b}$ (Scheme 37). ${ }^{158}$ Methylation of $\mathbf{1 8 6 b}$ with methyl iodide gave the dimethoxy derivative $\mathbf{1 8 7}$, which once subjected to catalytic hydrogenolytic debenzylation with Pearlman's catalyst furnished the corresponding free alcohol.

Next, oxidation of the latter with the ruthenium dioxide-sodium periodate reagent produced the ketone 188 which was treated with methanol and $\mathrm{KHCO}_{3}$, resulting in mild methanolysis of the lactone. This was followed by spontaneous $\beta$-elimination to give the alcoholic $\alpha, \beta$ unsaturated ester 189a converted in turn to its protected derivative 189b in excellent yield. The regio- and stereocontrolled introduction of functional groups which would led to ring D was next accomplished by introduction of a vinyl group by means of a vinyl Grignard-mediated 1,2addition to the carbonyl to 190, followed by DCC-mediated esterification of the resulting alcohol with chloroacetic acid. The vinyl Grignard attacked the ketone from the same side of the 
methoxy group indicating the operation of a chelation controlled addition mode, which resulted crucial for ensuring the cis orientation of the $\mathrm{D} / \mathrm{E}$ ring junction.

Transformation of the chloroacetate into the related iodoacetate 191 was readily carried out by halogen exchange and this set the stage for an intramolecular free radical-mediated conjugate addition across the $\alpha, \beta$ - unsaturated ester, which was effected with triphenyltin hydride and AIBN, furnishing lactone 192 and its epimer on the $\alpha-\mathrm{CO}_{2} \mathrm{Me}$ carbon atom, which was recycled by equilibration with DBU.

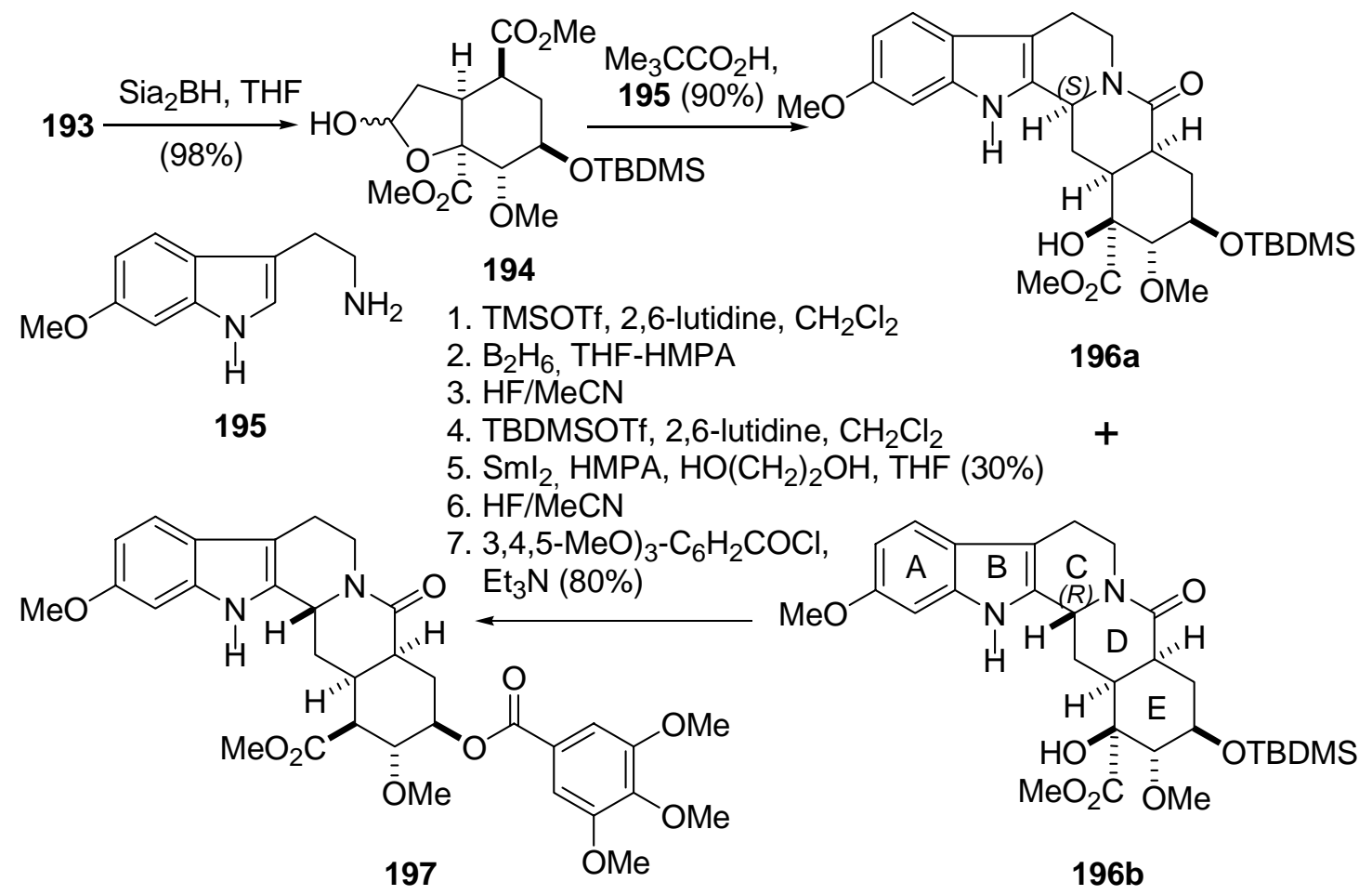

\section{Scheme 38}

Once the lactone 192 was conveniently accessed, the vinyl moiety was oxidatively cleaved with ozone, and the intermediate aldehyde resulting from reductive work-up was oxidized to the corresponding acid with sodium chlorite. Diazomethane esterification completed the sequence and gave 193 ready for coupling with 6-methoxytryptamine (195). The complete sequence involved 10 steps and furnished lactone 193 in $24 \%$ overall yield.

Mild and selective reduction of $\mathbf{1 9 3}$ with disiamyl borane afforded diastereomeric lactols 194, which after treatment with 6-methoxytryptamine (195) in refluxing toluene containing pivalic acid resulted in a 1.4:1 mixture of 196a and 196b, favoring the C-3 $\beta$ epimer 196b. Interestingly, trials with other acids furnished only 1:1 mixtures of the epimers (Scheme 38).

Removal of the lactam carbonyl with borane proved tricky, and unsuccessful unless previous protection of the tertiary carbinol as the related TMS ether. However, once the reduction was accomplished, the TMS ether required removal previous to the required $\mathrm{SmI}_{2}$ mediated 
deoxygenation of the tertiary alcohol. Although this last reaction was not very clean, it furnished an advanced intermediate, the desilylation of which followed by esterification with 3,4,5trimethoxy benzoyl chloride furnished the final product 197.

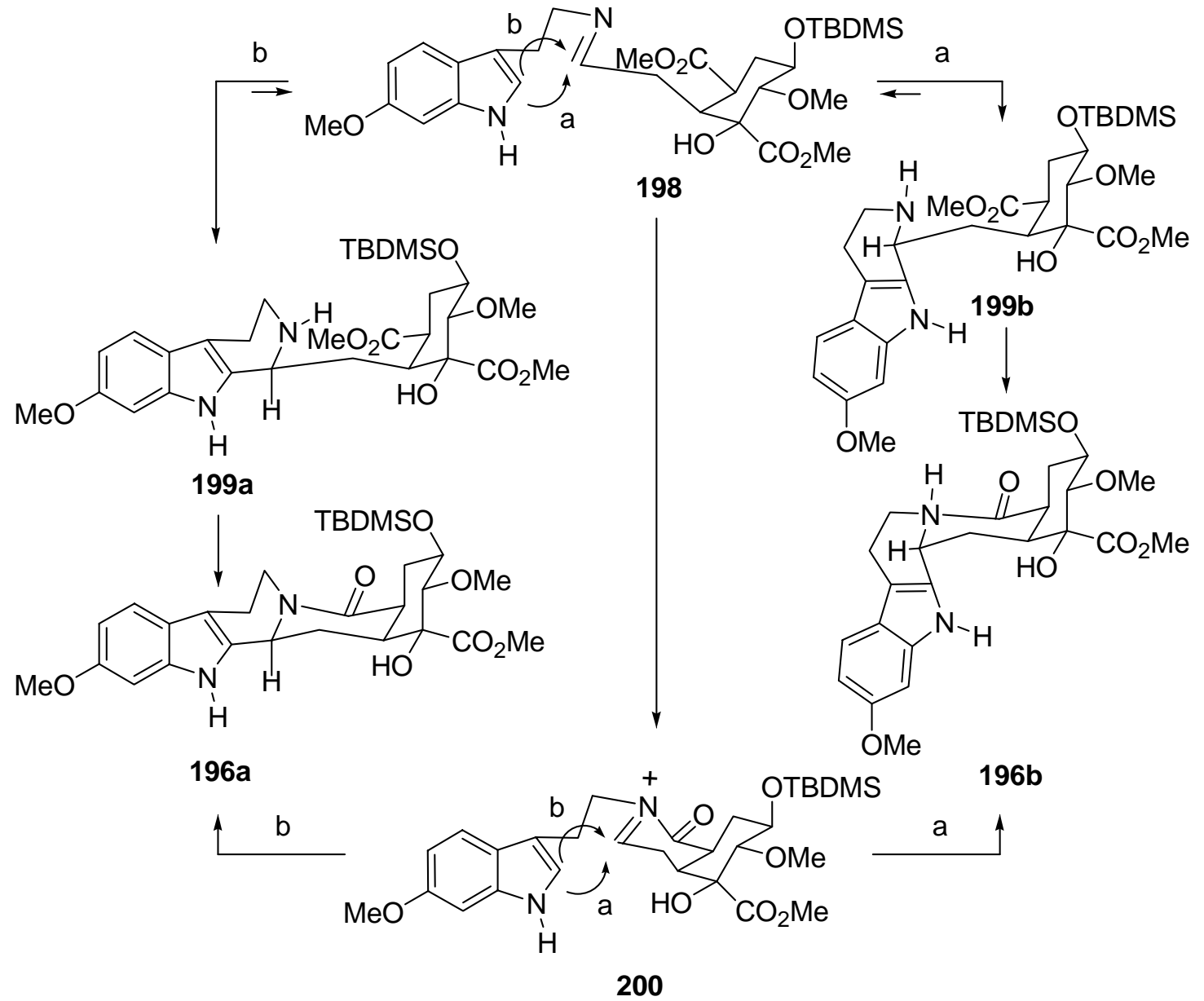

\section{Scheme 39}

A plausible mechanism for the cyclizations leading to $196 \mathbf{a}$ and $196 \mathrm{~b}$ was proposed. This involves attack of the indole moiety of 198 on a half-chairlike imine or immonium ion intermediate via pseudoaxial (path a) or pseudoequatorial (path b) approaches to transient intermediates 199a and 199b, respectively, followed by spontaneous elimination of methanol and lactam formation (Scheme 39).

An alternative mechanistic rationale for the preference of the desired isomer 196b over 196a may depend on the intermediacy of a putative immonium ion lactam structure 200. Thus, the initially formed imine may lactamize and then furnish intermediate 200. The resulting extended conjugated immonium lactam system could benefit from a pseudoaxial attack en route to the desired 196a. 


\section{Concluding remarks}

During the last 15 years, organic chemists have made remarkable progress in their quest for optically active THIQ and THBC derivatives, employing the intermolecular asymmetric PictetSpengler with chiral aldehydes or aldehydes tethered to chiral auxiliaries. This has been mainly a consequence of the general advances in synthetic organic chemistry, which resulted in a greater variety and availability of reagents and synthetic transformations, as well as by the increasing need of optically pure materials for activity testing and the challenges posed by attractive complex natural products which unique structures have been elucidated during this period.

In this context, the preparation of optically active THIQ and THBC and other heterocycles with the aid of optically active aldehydes by the intermolecular Pictet-Spengler condensation strategy not only expanded the synthetic possibilities of this almost centennial reaction, through the synthesis of increasingly daring targets, but also allowed chemists a relatively easy access to valuable compounds otherwise difficult to obtain.

The current perspectives are that increase of the demand for chiral compounds will continue at its steady pace; this will keep driving organic chemists in their indefatigable search for more imaginative ways to synthesize new chiral carbonyl moieties, to design improved auxiliaries, as well as novel strategies to introduce and remove chiral auxiliaries and to find reaction conditions were the potential of the asymmetric moieties could be fully exploited, favoring high chemical and optical yields of the Pictet-Spengler condensation products.

In conclusion, during the past 15 years of febrile and productive activity we have witnessed just the first but important steps towards renewed and more exciting applications of the PictetSpengler cyclization, this old but extremely useful reaction.

\section{Acknowledgements}

The authors gratefully acknowledge CONICET, Fundación Antorchas, SECyT-UNR and ANPCyT (Grant $\mathrm{N}^{\circ}$ 06-12532) for continuous financial support. ABJB and ELL thank CONICET for their fellowships; MA acknowledges the receipt of a fellowship from ANPCyT.

\section{References and Notes}

1. Mundy, B. P.; Ellerd, M. G. Name Reactions and Reagents in Organic Synthesis, Wiley: New York, USA, 1988; p 164.

2. (a) Pictet, A.; Spengler, T. Ber. 1911, 44, 2030. (b) Whaley, W. M.; Govindachari, T. R. The Pictet-Spengler Synthesis of Tetrahydro-isoquinolines and related compounds in Organic Reactions; Adams, R. Ed.; Wiley : New York, USA, 1951, Vol. 6, p 151. (c) Kametani, T. In The Total Synthesis of Natural Products; ApSimon, J.; Wiley: New York, , 1977, Vol. 3, 
pp 1-272. (d) Kutney, J. P. In The Total Synthesis of Natural Products; ApSimon, J.; Wiley: New York, , 1977, Vol. 3, pp 273-288. (e) Jones, G. In Comprehensive Heterocyclic Chemistry; Katritzky, A. R.; Rees, C. W. Eds., Pergamon: Oxford, 1984, Vol. 2, pp 438-440. (f) Shamma, M. and Moniot, J.L. In Isoquinoline Alkaloids Research. 1972-1977. Plenum Press: New York, 1978. Chapter 1. (g) For a recent review, see Cox, E. D.; Cook, J. M. Chem. Rev. 1995, 95, 1797.

3. (a) Konda, M.; Shioiri, T.; Yamada, S. Chem. Pharm. Bull. 1975, 23, 1063. (b) Konda, M.; Shioiri, T.; Yamada, S. Chem. Pharm. Bull. 1977, 25, 69.

4. Tatsui, G. J. Pharm. Soc. Jpn. 1928, 48, 92.

5. Bailey, P. D. J. Chem. Res. 1987, 202.

6. Kowalski, P.; Bojarski, A. J.; Mokrosz, J. L. Tetrahedron 1995, 51, 2737.

7. (a) Jackes, B.; Deeks, R. H. L. Shah, P. K. J. J. Chem. Soc. (D) 1969, 1283. (b) Martínez, E. J.; Corey. E. J. Org. Lett. 2000, 2, 993. (c) Ezquerra, J.; Pedregal, C.; Lamas, C.; Pastor, A.; Alvarez, P.; Vaquero, J. J.; Prowse, W. G. Tetrahedron Lett. 1996, 37, 5813. (d) Bringmann, G.; Ewers, C. L. J.; Walter, R. Use of Carbonyl Derivatives for Heterocyclic Synthesis, In Comprehensive Organic Synthesis, Vol. 6; Winterfeldt, E., Ed.; Pergamon Press: Oxford, UK, 1991; pp 736-740. (e) Leonard, M. S.; Hauze, D. B.; Carroll, P. J. Joullie, M. M. Tetrahedron 2003, 59, 6933. (f) González, J. F.; de la Cuesta, E.; Avendaño, C. Tetrahedron Lett. 2003, 44, 4395. (g) Kang, I.-J.; Wang, H.-M.; Su, C.-H.; Chen, L. C. Heterocycles 2002, 57, 1. (h) Kohno, H.; Yamada, K. Heterocycles 1999, 51, 103. (i) Lee, S. S.; Kim, S. H.; Yoon, H. S.; Lee, C.-H. Bull. Korean Chem. Soc. 2003, 24, 1041. (j) Kubo, A.; Saito, N.; Kawakami, N.; Matsuyama, Y.; Miwa, T. Synthesis 1987, 824. (k) Cheung, G. K.; Earle, M. J.; Fairhurst, R. A.; Heaney, H.; Shihaibar, K. F.; Eyley, S. C.; Ince, F. Synlett 1991, 721. (1) Padwa, A.; Brodney, M. A.; Marino, Jr., J. P.; Osterhout, M. H.; Price, A. T. J. Org. Chem. 1997, 62, 67. (m) Enders, D.; Shilvock, J. P. Chem. Soc. Rev. 2000, 29, 359. (n) Myers, A. G.; Kung, D. W. Org. Lett. 2000, 2, 3019. (o) Cho, S.-D.; Park, Y.-D.; Kim, J.-J.; Joo, W.H.; Shiro, M.; Esser, L.; Falck, J. R.; Ahn, C.; Shinb, D.-S.; Yoon,Y.-J. Tetrahedron 2004, 60, 3763.

8. (a) Pancrazi, A.; Kervagoret, J.; Khuong-Huu, Q. Synlett 1991, 589. (b) Wee, A. G. H; Yu, Q. J. Org. Chem. 2001, 66, 8935. (c) Ducrot, P.; Thai, C. Tetrahedron Lett. 1999, 40, 9037. (d) van Maarseveen, J. H.; Scheeren, H. W.; De Clercq, E.; Balzarini, J.; Kruse, C. G. Bioorg. Med. Chem. Lett. 1997, 5, 955.

9. (a) For a review, see: Sammelson, R. E.; Kurth, M. J. Chem. Rev. 2001, 101, 137. (b) Nielsen, T. E.; Meldal, M. J. Org. Chem. 2004, 69, 3765. (c) Sauerbrei, B.; Jungmann, V.; Waldmann, H. Angew. Chem. Int., Ed. 1998, 37, 1143. (d) Cheng, C. C.; Chu, Y.-H. J. Comb. Chem. 1999, 1, 461. (e) Yang, L.; Guo, L. Tetrahedron Lett. 1996, 37, 5041. (f) van Loevezijn, A.; van Maarseveen, J. H.; Stegman, K.; Visser, G. M.; Koomen, G.-J. Tetrahedron Lett. 1998, 39, 4737. (g) Mohan, R.; Chou, Y.-L.; Morrissey, M. M. Tetrahedron Lett. 1996, 37, 3963. (h) Chou, Y.-L.; Morrissey, M. M.; Mohan, R. Tetrahedron Lett. 1998, 39, 757. (i) Wang, H.; Ganesan, A. Org. Lett. 1999, 1, 1647. (j) 
Kaljuste, K.; Undén, A. Tetrahedron Lett. 1995, 36, 9211. (k) Fantauzzi, P. P.; Yager, K. M. Tetrahedron Lett. 1998, 39, 1291. (1) Bonnet, D.; Ganesan, A. J. Comb. Chem. 2002, 4, 546. (m) Mayer, J. P.; Bankaitis-Davis, D.; Zhang, J.; Beaton, G.; Bjergarde, K.; Andersen, C. M.; Goodman, B. A.; Herrera, C. J. Tetrahedron Lett. 1996, 37, 5633.

10. (a) Rousseau, J.-F.; Dodd, R. H. J. Org. Chem. 1998, 63, 2731. (b) Klutchko, S.; Hodges, J. C.; Blankley, C. J.; Colbry, N. L. J. Heterocycl. Chem. 1991, 28, 97 and references therein.(c) Sanchez-Sanchez, M. M.; Tel-Alberdi, L. M.; Rioseras, M. J.; Rico-Ferreira, M. R.; Bermejo-Gonzalez, F. Bull. Chem. Soc. Jpn. 1993, 66, 191. (d) Kim, S.; Lee, J.; Lee, T.; Park, H.-G.; Kim, D. Org. Lett. 2003, 5, 2703. (e) Xu, G.; Sayre, L. M. Chem. Res. Toxicol. 1999, 12, 862. (f) Albaneze-Walker, J.; Rossen, K.; Reamer, R. A.; Volante, R. P.; Reider, P. J. Tetrahedron Lett. 1999, 40, 4917. (g) Krause, M.; Rouleau, A.; Stark, H.; Luger, P.; Lipp, R.; Garbarg, M.; Schwartz, J. C.; Schunack, W. J. Med. Chem. 1995, 38, 4070.

11. (a) Bianchi, D. A.; Rúa, F.; Kaufman, T. S. Tetrahedron Lett. 2004, 45, 411. (b) Bianchi, D. A.; Cipulli, M. A.; Kaufman, T. S. Eur. J. Org. Chem. 2003, 4731. (c) Guiso, M.; Marra, C.; Cavarischia, C. Tetrahedron Lett. 2001, 42, 6531.

12. (a) Cordell, G. A. Introduction to Alkaloids: A Biogenetic Approach; Wiley and Sons: New York, USA, 1981. (b) Rahman, A. U.; Basha, A. Biosynthesis of Indole Alkaloids; Clarendon Press: Oxford, UK, 1983. (c) Kutney, J. P. Nat. Prod. Rep. 1990, 85. (d) Battersby, A. R. In Specialist Periodical Reports. The Alkaloids; The Royal Society of Chemistry: London, UK., 1971; Vol. 1, p 31. (e) Stockigt, J.; Zenk, M. H. J. Chem. Soc. Chem. Commun. 1977, 646. (f) Scholz, U.; Winterfeldt, E. Nat. Prod. Rep. 2000, 17, 349.

13. Naoi, M.; Maruyama, W.; Nagy, G. M. Neurotoxicology 2004, 25, 193.

14. (a) Brown, R. T.; Row, L. R. J. Chem. Soc. Chem. Commun. 1967, 453. (b) Yu, S.; Berner, O. M. Cook, J. M. J. Am. Chem. Soc. 2000, 122, 7827. (c) Edmondson, S.; Danishefsky, S. J.; Sepp-Lorenzino, L.; Rosen, N. J. Am. Chem. Soc. 1999, 121, 2147. (d) Daugan, A.; Grondin, P.; Ruault, C.; Le Monnier de Gouville, A. C.; Coste, H.; Kirilovsky, J.; Hyafil, F.; Labaudinie, R. J. Med. Chem. 2003, 46, 4525.

15. (a) Herraiz, T.; Galisteo, J. J. Agric. Food Chem. 2003, 51, 7156. (b) Papavergou E.; Herraiz T. Food Res. Int. 2003, 36, 843. (c) Herraiz, T. J. Agric. Food Chem. 1998, 46, 3484. (d) Herraiz, T.; Galisteo, J. J. Agric. Food Chem. 2002, 50, 4690. (e) Herraiz, T.; Galisteo, J.; Chamorro, C. J. Agric. Food Chem. 2003, 51, 2168. (f) Herraiz, T.; Papavergou, E. J. Agric. Food Chem. 2004, 52, 2652. (g) Herraiz, T. J. Agric. Food Chem. 1999, 47, 4883.

16. (a) Bringmann, G.; Brückner, R.; Mössner, R.; Feineis, D.; Heils, A.; Lesch, K.-P. Neurochem. Res. 2000, 25, 837. (b) Kim, H.-J.; Soh, Y.; Jang, J.-H.; Lee, J.-S.; Oh, Y.-J.; Surh, Y.-J. Molec. Pharm. 2001, 60, 440. (c) Pari, K.; Sundari, C. S.; Chandani, S.; Balasubramanian, D. J. Biol. Chem. 2000, 275, 2455. (d) Brossi, A.; Focella, A.; Teitel, S. J. Med. Chem. 1973, 16, 418. (e) Tsuchiya, H.; Shimizu, H.; Munekazu, I. Chem. Pharm. Bull. 1999, 47, 440. (f) Davis, V. E.; Waleh, M. J. Science 1970, 167, 1005. (g) Cohen, G.; Collins. M. Science 1970. 167, 1749. (h) Robbins, J. H. Clin. Res. 1968, 16, 554. (i) Lasala, J. M.; Coscia, C. J. Science 1979, 203, 283. (j) Coscia, C. J.; Burke, W.; Jamroz, G.; Lasala, 
J. M.; McFarlane, J.; Mitchell, J.; O'Toole, M. M.; Wilson, M. L. Nature 1977, 269, 617. (k) Rommelapacher, H. Naunyn-Schmiedebergs Arch. Pharmacol. 1978, 305, 135. (1) Braestmp, C.; Nielsen, M.; Olsen, C. E. Proc. Natl. Acad. Sci. U.S.A. 1980, 77, 2288. (m) Barker, S. A.; Harrison, R. E.; Brown, G. B.; Christian, S. T. Biochem. Biophys. Res. Commun. 1979, 87, 146. (n) Dietrich, R.; Erwin, V. Ann. Rev. Pharmacol. Toxicol. 1980, 20, 55. (o) Yamanaka, Y.; Walsh, M. J.; Davis, V. E. Nature 1970, 227, 1143.

17. (a) Noble, R. L.; Beer, C. T.; Cutts, J. H. Ann. New York Acad. Sci. 1958, 76, 882. (b) Farnsworth, N. R. Lloydia 1961, 24, 105. (c) Johnson, I. S.; Armstrong, J. G.; Gorman, M.; Burnett, J. P. Cancer Res. 1963, 23, 1390.

18. (a) Bein, H. J. Experientia 1953, 9, 107. (b) Chopra, R. N.; Gupta, J. C.; Mukherjee, B. Ind. J. Med. Res. 1933, 21, 261. (c) Manske, R. H. F.; Ed., The Alkaloids, Chemistry and Physiology; Academis Press: New York, 1981; Vol. 20.

19. Wright, C. W.; Allen, D.; Cai, Y.; Phillipson, J. D.; Said, I. M.; Kirby, G. C.; Warhurst, D. C. Phytother. Res. 1992, 6, 121.

20. (a) Ho, B. T. J. Pharm. Sci. 1972, 61, 821. (b) Glennon, R. A. Life Sci. 1981, 29, 861. (c) Callaway, J. C.; Gynther, J.; Poso, A.; Vepsäläinen, J.; Airaksinen, M. M. J. Heterocyclic Chem. 1994, 31, 431.

21. (a) Ninan, P. T.; Insel, T. M.; Cohen, R. M.; Cook, J. M.; Skolnick, P.; Paul, S. M. Science 1982, 218, 1332. (b) Mendelson, W. B.; Cain, M.; Cook, J. M.; Paul, S. M.; Skolnick, P. Science 1983, 219, 414.

22. (a) Sakai, R.; Rinehart, K. L.; Guan, Y.; Wang, A. H.-J. Proc. Natl. Acad. Sci. U.S.A. 1992, 89, 11456. (b) Rinehart, K. L.; Shield, L. S. In Topics in Pharmaceutical Sciences; Breimer, D. D.; Crommelin, D. J. A.; Midha, K. K.; Ed.; Amsterdam Medical Press: Noordwijk, The Netherlands, 1989, p 613.

23. Fukuyama, T.; Yang, L.; Ajeck, K. L.; Sachleben, R. A. J. Am. Chem. Soc. 1990, 112, 3712.

24. Hotha, S.; Yarrow, J. C.; Yang, J. G.; Garrett, S.; Renduchintala, K. V.; Mayer, T. U.; Kapoor, T. M. Angew. Chem., Int. Ed. 2003, 42, 2379.

25. For some reviews, see: (a) Rozwadowska, M. D. Heterocycles 1994, 39, 903. (b) Scott, J. D.; Williams, R. M. Chem. Rev. 2002, 102, 1669. (c) Chrzanowska, M.; Rozwadowska, M. D. Chem. Rev. 2004, 104, 3341.

26. Dyke, S. F.; Kinsman, R. G. Kametami, T. G.; Fukumoto, K.; McDonald, E. Isoquinolines, In The Chemistry of Heterocyclic Compounds; Grethe, G., Ed.; Wiley: New York, 1981, 38, 1 .

27. (a) Burm, B. E. A.; Gremmen, C.; Wanner, M. J.; Koomen, G.-J. Tetrahedron 2001, 57, 2039. (b) Jin, W.; Metobo, S.; Williams, R. M. Org. Lett. 2003, 5, 2095.

28. (a) Cox, E. D.; Hamaker, L. K.; Li, J.; Yu, P.; Czerwinski, K. M.; Deng, L.; Bennett, D. W.; Cook, J. M.; Watson, W. H.; Krawiec, M. J. Org. Chem. 1997, 62, 44. (b) Madrigal, A.; Grande, M.; Avendaño, C. J. Org. Chem. 1998, 63, 2724. (c) Bailey, P. D.; Moore, M. H.; Morgan, K. M.; Smith, D. I.; Vernon, J. M. Tetrahedron Lett. 1994, 35, 3587. (d) Albrech, L.; Bailey, P. D.; Clingan, P. D.; Mills, T. J.; Price, R. A.; Pritchard, R. G. Eur. J. Org. 
Chem. 2004, 1887. (e) Bailey, P. D.; McLay, N. R. J. Chem. Soc., Perkin Trans. 1 1993, 441. (f) Bringmann, G.; Gunter, C.; Peters, E.; Peters, K. Tetrahedron 2001, 57, 1253. (g) Zhang, L.-H.; Bi, Y.; Yu, F.; Menzia, G.; Cook, J. M. Heterocycles 1992, 34, 517. (h) Peng, S.; Winterfeldt, E. Liebigs Ann. Chem. 1990, 313. (i) Cox, E. D.; Li, J.; Hamaker, L. K.; Yu, P.; Cook, J. M. J. Chem. Soc. Chem. Commun. 1996, 2477. (j) McDonald, I. M.; Dunstone, D. J.; Barret Kalindjian, S.; Linney, I. D.; Low, C. M. R.; Pether, M. J.; Steel, K. I. M.; Tozer, M. J.; Vinter, J. G. J. Med. Chem. 2000, 43, 3518.

29. Kaufman, T. S. "Synthesis of Optically-Active Isoquinoline and Indole Alkaloids Employing the Pictet-Spengler Condensation with Removable Chiral Auxiliaries Bound to Nitrogen". In New Methods for the Asymmetric Synthesis of Nitrogen Heterocycles; Vicario, J. L.; Carrillo, L.; Badía, D. Eds.; Research Signpost: India, 2005, Chapter 4.

30. (a) Kawate, T.; Yamada, H.; Soe, T.; Nakagawa, M. Tetrahedron: Asymmetry 1996, 7, 1249.

(b) Yamada, H.; Kawate, T.; Matsumizu, M.; Nishida, A.; Yamaguchi, K.; Nakagawa, M. J. Org. Chem. 1998, 63, 6348. (c) Kawate, T.; Yamada, H.; Matsumizu, M.; Nishida, A.; Nakagawa, M. Synlett 1997, 761. (d) Taylor, M. S.; Jacobsen, E. N. J. Am. Chem. Soc. 2004, 126,. 10558. (e) Hino, T.; Nakagawa, M.; Heterocycles 1998, 49, 499.

31. (a) Lee, Y. S.; Cho, D. J.; Kim, S. N.; Choi, J. H.; Park, H. J. Org. Chem. 1999, 64, 9727. (b) Manna, R. K.; Jaisankar, P.; Giri, V. S. Synth. Comm. 1995, 25, 3027.

32. (a) MacLean, D. B.; Szarek, W. A.; Kvarnström, I. J. Chem. Soc., Chem. Commun. 1983, 601. (b) Cho, S. D.; Song, S.-Y.; Hur, E.-J.; Chen, M.; Joo, W.-H.; Falck, J. R.; Yoon, Y.-J.; Shin, D.-S. Tetrahedron Lett. 2001, 42, 6251.

33. (a) Jaisankar, P.; Pal, B.; Manna, R. K.; Pradhan, P. K.; Medda, S.; Basu, M. K.; Giri, V. S. Arkivoc 2003, ix, 150. (b) Wang, H.; Usui, T.; Osada, H.; Ganesan, A. J. Med. Chem. 2000, 43, 1577. (c) Melnyk, P.; Ducrot, P.; Thal, C. Tetrahedron 1993, 49, 8589. (d) Wang, H.; Ganesan, A. Tetrahedron Lett. 1997, 38, 4327. (e) Ezquerra, J.; Pedregal, C.; Lamas, C.; Pastor, A.; Alvarez, P.; Vaquero, J. J. Tetrahedron 1997, 53, 8231.

34. (a) Allin, S. M.; James, S. L.; Martin, W. P.; Smith, T. A. D.; Elsegood, M. R. J. J. Chem. Soc., Perkin Trans. 1 2001, 3029. (b) Allin, S. M.; James, S. L.; Elsegood, M. R. J.; Martin, W. P. J. Org. Chem. 2002, 67, 9464. (c) Allin, S. M.; Northfield, C. J.; Page, M. I.; Slawin, A. M. Z. Tetrahedron Lett. 1998, 39, 4905. (d) Allin, S. M.; James, S. L.; Martin, W. P.; Smith, T. A. D. Tetrahedron Lett. 2001, 42, 3943.

35. Padwa, A.; Danca, D. Org. Lett. 2002, 4, 715.

36. (a) Siwicka, A.; Wojtasiewicz, K.; Leniewski, A.; Maurinb, J. K.; Czarnocki, Z. Tetrahedron:Asymmetry 2002, 13, 2295. (b) Grigg, R.; Thornton-Pett, M.; Yoganathan, G. Tetrahedron 1999, 55, 8129. (c) Mangeney, P.; Gosmini, R.; Raussou, S.; Commerc,on, M.; Alexakis, A. J. Org. Chem. 1994, 59, 1877. (d) Lee, J. Y.; Lee, Y. S.; Chung, B. Y.; Park, H. Tetrahedron 1997, 53, 2449. (e) Oppolzer, W.; Bienaymé, H.; Genevois-Borella A. J Am. Chem. Soc. 1991, 113, 9660.

37. (a) van Maarseveen, J. H.; Scheeren, H. W. Tetrahedron 1993, 49, 2325. (b) van Maameveen, J. H.; Hermkens, P. H. H.; De Clercq, E.; Balzarini, J.; Scheeren, H. W.; 
Kruse, C. G. J. Med. Chem. 1992, 35, 3223. (c) Hermkens, P. H. H.; van Maarseveen, J. H.; Ottenheijm, H. C. J.; Kruse, C. J.; Scheeren, H. W. J. Org. Chem. 1990, 55, 3998. (d) Knapp, S.; Hale, J. J. J. Org. Chem. 1993, 58, 2650. (e) Zawadzka, A.; Leniewski, A.; Maurin, J. K.; Wojtasiewicz, K.; Czarnocki, Z. Org. Lett. 2001, 3, 997. (f) Miyazawa, N.; Ogasawara, K. Tetrahedron Lett. 2002, 43, 4773. (g) Szabó, L.; Szentirmay, E.; Baitz-Gacs, E.; Kalaus, G.; Szantay, C. Tetrahedron Lett. 1997, 38, 115.

38. (a) Gutsche, B.; Grun, C.; Scheutzow, D.; Herderich, M. Biochem. J. 1999, 343, 11. (b) Diem, S.; Albert, J.; Herderich, M. Eur. Food Res. Technol. 2001, 213, 439.

39. Rönner, B.; Lerche, H.; Bergmüller, W.; Freilinger, C.; Severin, T.; Pischetsrieder, M. J. Agric. Food Chem. 2000, 48, 2111.

40. Wang, M.; Jin, Y.; Li, J.; Ho, C.-T. J. Agric. Food Chem. 1999, 47, 48.

41. Diem, S.; Herderich, M. J. Agric. Food Chem. 2001, 49, 2486.

42. Diem, S.; Herderich, M. J. Agric. Food. Chem. 2001, 49, 5473.

43. For reviews, see: (a) Mikolajczk, M.; Drabowicz, J.; Kielbasinski, P. In Chiral Sulfur Reagents, CRC Press: Boca Raton, 1997. (b) Posner, G. H. In The Chemistry of Sulfones and Sulfoxides; Patai, S.; Rappoport, Z.; Stirling, C. J. M., Eds.; Wiley: New York, 1988; pp 828-850. (c) Posner, G. H. In Asymmetric Synthesis; Morrison, J. D., Ed.; Academic Press: New York, 1983; pp 225-242.

44. For a review, see: Carreño, M. C. Chem. Rev. 1995, 95, 1717.

45. Lee, A. W. M.; Chan, W. H. In Topics in Current Chemistry, Springer-Verlag, 1997; Vol. 190, pp 103-129, and references cited therein.

46. Pyne, S. G.; Dikic, B. J. Org. Chem. 1990, 55, 1932 and references cited therein.

47. (a) Pyne, S. G.; Bloem, P.; Chapman, S. L.; Dixon, C. E.; Griffith, R. J. Org. Chem. 1990, 55, 1086. (b) Pyne, S. G. Tetrahedron Lett. 1987, 28, 4737.

48. (a) Chan, W. H.; Lee, A. W. M.; Tao, Y. Youji Huaxue 1993, 13, 178; Chem. Abstr. 1993, 119:95895. (b) Lee, A. W. M.; Chan, W. H.; Lee, Y. K. Tetrahedron Lett. 1991, 32, 6861.

49. (a) Anderson, K. K. Tetrahedron Lett. 1962, 93. (b) Anderson, K. K. J. Org. Chem. 1964, 29, 1953. (c) Klunder, J. M.; Sharpless, K. B. J. Org. Chem. 1987, 52, 2598.

50. (a) Pyne, S. G.; Chapman, S. L. J. Chem. Soc., Chem. Commun. 1986, 1686. (b) Pyne, S. G.; Chapman, S. L. J. Chem. Soc., Chem. Commun. 1986, 1688.

51. Chan, W. H.; Lee, A. W. M.; Jiang, L. Tetrahedron Lett. 1995, 36, 715.

52. Bravo, P.; Crucianelli, M.; Farina, A.; Valdo Meille, S.; Volonterio, A.; Zanda, M. Eur. J. Org. Chem. 1998, 435.

53. (a) Singh, K.; Deb, P. K. Tetrahedron Lett. 2000, 41, 4977. (b) Singh, K.; Deb, P. K. Heterocycles 1999, 51, 1509. (c) Singh, K.; Deb, P. K.; Venugopalan, P. Tetrahedron 2001, 57, 7939.

54. Meyers, A. I.; Nabeya, A.; Adickes, H. W.; Politzer, I. R.; Malone, G. R.; Kovelesky, A. C.; Nolen, R. L.; Portnoy, R. C. J. Org. Chem. 1973, 38, 36.

55. Soladie, G. Synthesis 1981, 185 and references cited therein.

56. Okamura, K.; Yamada, S. Chem. Pharm. Bull. 1978, 26, 2305. 
57. Lee, A. W. M.; Chan, W. H.; Tao, Y.; Lee, Y. K. J. Chem. Soc., Perkin Trans. I 1994, 477.

58. Yamada, S. Y.; Tomioka, K.; Koga, K. Tetrahedron Lett. 1976, 61.

59. (a) Czarnocki, Z.; Mieczowski, J. B.; Kiegiel, J.; Arazni, Z. Tetrahedron: Asymmetry 1995, 6, 2899. (b) Czarnocki, Z.; Arazni, Z. Heterocycles 1999, 51, 2871.

60. (a) Bauer, T.; Chapuis, C.; Kozak, J. and Jurczak, J. Helv. Chim. Acta 1989, 72, 482. (b) Oppolzer, W. Pure Appl. Chem. 1990, 43, 1969, and references cited therein.

61. Kerekes, P.; Sharma, P. N.; Brossi, A.; McLaughlin, J. L. J. Nat. Prod. 1985, 48, 152.

62. Cho, S. D.; Song, S.Y.; Hur, E. J.; Chen, M.; Joo, W. H.; Falck, J. R.; Yoon, Y. J.; Shin, D. S. Tetrahedron Lett. 2001, 42, 6251.

63. Silveira, C. C.; Bernardi, C. R.; Braga, A. L.; Kaufman, T. S. Tetrahedron Lett. 1999, 40, 4969.

64. Silveira, C. C.; Larghi, E. L. J. Braz. Chem. Soc. 1998, 9, 327.

65. Ganem, B.; Ikota, N. J. Org. Chem. 1978, 43, 1607.

66. Nagarajan, K.; Chandmsekharan, J.; Rodrigues, P. J. J. Ind. Inst. Sci. 1994, 74, 247.

67. Kawai, M.; Deng, Y.; Kimura, I.; Yamamura, H.; Araki, S.; Naoi, M. Tetrahedron: Asymmetry 1997, 8, 1487.

68. Matsumoto, K.; Harada, K. J. Org. Chem. 1966, 31, 1956.

69. Dostert, P.; Varasi, M.; Della Torre, A.; Monti, C.; Rizzo, V. Eur. J. Med. Chem. 1992, 27, 57.

70. Naoi, M.; Maruyama, W.; Dostert, P.; Kohda, K.; Kaiya, T. Neurosci. Lett. 1996, 212, 1.

71. (a) Maruyama, W.; Nakahara, D.; Ota, M.; Takahashi, T.; Takahashi, A.; Nagatsu, T.; Naoi, M. J. Neurochem. 1992, 59, 395. (b) Naoi, M.; Maruyama, W.; Dostert, P.; Hashizume, Y.; Nakahara, D.; Takahashi, T.; Ota, M. Brain Res. 1996, 709, 285. (c) Deng, Y.; Maruyama, W.; Dostert, P.; Takahashi, T.; Kawai, M.; Naoi, M. J. Chromatogr. B 1995, 670, 47.

72. (a) Botteghi, C.; Soccolini, F. Synthesis 1985, 592. Tietze, L. F.; Glusenkamp, K. H. W. Angew. Chem. 1982, 94, 793. (b) Peng, S.; Winterfeldt, E. Liebigs Ann. Chem. 1989, 1045. (c) Bi, L.; Zhao, M.; Wang, C.; Peng, S. Eur. J. Org. Chem. 2000, 2669.

73. Bi, L.; Zhao, M.; Wang, C.; Peng, S.; Winterfeldt, E. J. Org. Chem. 2002, 67, 22.

74. (a) Brossi, A.; Folcella, A.; Teitel, S. Helv. Chim. Acta 1972, 55, 15. (b) Daxenbichler, M. E.; Kleiman, R.; Weisleder, D.; VanEtten, C. H.; Carlson, K. D. Tetrahedron Lett. 1972, 18, 1801.

75. Sandler, M.; Bonham Carter, S.; Hunter, K. R.; Stern, G. M. Nature 1973, 439.

76. Piper, I. M.; MacLean, D. B.; Kvarnström, I.; Szarek, W. A. Can. J. Chem. 1983, 61, 2721.

77. (a) Manini, P.; d'Ischia, M.; Prota, G. Bioorg. Med. Chem. 2001, 9, 923. (b) Manini, P.; d'Ischia, M.; Lanzetta, R.; Parrilli, M.; Prota, G. Bioorg. Med. Chem. 1999, 7, 2525.

78. Whitesell, J. K.; Minton, M. A. In Stereochemical Analysis of Alyciclic Compounds by 13C NMR spectroscopy; Chapman and Hall: London, 1987.

79. Eliel, E. L.; Wilen, S. H.; Mander, L. N. Stereochemistry of Organic Compounds; Wiley: New York, 1995; p 115. 
80. Ibañez, A. F.; Yaculiano, G. B.; Moltrasio-Iglesias, G. Y. J. Heterocyclic Chem. 1989, 26, 907.

81. Manini, P.; d'Ischia, M.; Prota, G. J. Org. Chem. 2001, 66, 5048.

82. (a) Czarnocki, Z.; MacLean, D. B.; Szarek, W. A. J. Chem. Soc., Chem. Commun. 1985, 1318. (b) Czarnocki, Z.; MacLean, D. B.; Szarek, W. A. Can. J. Chem. 1986, 64, 2205. (c) Czarnocki, Z.; MacLean, D. B.; Szarek, W. A. Bull. Soc. Chim. Belg. 1986, 95, 749. (d) Royer, J.; Bonin, M.; Micouin, L. Chem. Rev. 2004, 104, 2311.

83. Hanessian, S.; McNaughton-Smith, G.; Lombard, H.-G.; Lubell, W. D. Tetrahedron 1997, $38,12789$.

84. Grieco, P.; Campiglia, P.; Gomez-Monterrey, I.; Novellino, E. Tetrahedron Lett. 2002, 43, 6297.

85. (a) Fehrentz, J.-A.; Castro, B. Synthesis 1983, 676. (b) Meyer, J.-P.; Davis, P.; Lee, K. B.; Porreca, F.; Yamamura, H.; Hruby, V. J. J. Med. Chem. 1995, 38, 3462.

86. Martín-Martínez, M.; De la Figuera, N.; Latorre, M.; Herranz, R.; García-López, M. R.; Cenarruzabeitia, E.; del Río, J.; González-Muñiz, R. J. Med. Chem. 2000, 43, 3770.

87. Bailey, P. D.; Hollinshead, S. P.; McLay, N. R.; Morgan, K.; Palmer, S. J.; Prince, S. N.; Reynolds, C. D.; Wood, S. D. J. Chem. Soc., Perkin Trans. 1 1993, 431.

88. De la Figuera, N.; Alkorta, I.; García-López, M. T.; Herranz, R.; González-Muñiz, R. Tetrahedron 1995, 51, 7841.

89. Grimes, Jr., J. H.; Angell, Y. M.; Kohn, W. D. Tetrahedron Letters 2003, 44, 3835.

90. (a) Mizsak, A.; Scahill, T. A. J. Am. Chem. Soc. 1984, 106, 1524. (b) Rinehart Jr., K. L.; Kobayashi, J.; Harbour, G. C.; Gilmore, J.; Mascal, M.; Holt, T. G.; Shield, L. S.; Lafargne, F. J. Am. Chem. Soc. 1987, 109, 3378. (c) Lake, R. J.; Brennan, M. M.; Blunt, J. W.; Munro, M. H. G. Tetrahedron Lett. 1988, 29, 2255. (d) Lake, R. J.; Blunt, J. W.; Munro, M. H. G. Aust. J. Chem. 1989, 42, 1201. (e) Balzarini, J.; Scheeren, H. W.; Kruse, C. G. J. Med. Chem. 1992, 35, 3223.

91. (a) Nakagawa, M.; Liu, J.-J.; Ogata, K.; Hino, T. Tetrahedron Lett. 1986, 27, 6087. (b) Nakagawa, M.; Liu, J.-J.; Ogata, K.; Hino, T. J. Chem. Soc., Chem. Commun. 1988, 463. (c) Nakagawa, M.; Liu, J.-J.; Hino, T. J. Am. Chem. Soc. 1989, 111, 2121.

92. (a) Liu, J.-J.; Nakagawa, M.; Hino, T. Tetrahedron 1989, 45, 7729. (b) Liu, J.-J.; Nakagawa, M.; Ogata, K.; Hino, T. Chem. Pharm. Bull. 1991, 39, 1672.

93. Still, I. W.; Strautmanis, J. R. Tetrahedron Lett. 1989, 30, 1041.

94. (a) Liu, J. J.; Hino, T.; Tsuruoka, A.; Harada, N.; Nakagawa, M. J. Chem. Soc., Perkin Trans. 1 2000, 3487. (b) For a review, see: McNulty, J.; Still, I. W. J. Curr. Org. Chem. 2000, 4, 121.

95. (a) Liu, J.-J.; Hino, T.; Nakagawa, M.; Harada, N.; Tsuruoka, A.; Hasegawa, H.; Ma, J.; Hino, T. Heterocycles 1990, 31, 229. (b) Nakagawa, M.; Liu, J. J.; Hino, T. J. Am. Chem. Soc. 1989, 111, 2721.

96. Nakagawa, M.; Liu, J.-J.; Hino, T.; Tsuruoka, A.; Harada, N.; Ariga, M.; Asada, Y. J. Chem. Soc., Perkin Trans. 1 2000, 3477. 
97. van Maarseveen, J. H.; Scheeren, H. W.; De Clercq, E.; Balzarini, J.; Kruse, C. G. Bioorg. Med. Chem. 1997, 5, 955.

98. Ducrot, P.; Rabhi, C.; Thal, C. Tetrahedron 2000, 56, 2683.

99. Myers, A. G.; Kung, D. W.; Zhong, B.; Movassaghi, M.; Kwon, S. J. Am. Chem. Soc. 1999, 121,8401 .

100. McNulty, J; Still, I. W. J. Synth. Commun. 1992, 22, 979.

101.McNulty, J.; Still, I. W. J. Tetrahedron Lett. 1991, 32, 4875.

102.(a) McNulty, J.; Still, I. W. J. J. Chem. Soc., Perkin Trans. 1 1994, 1329. (b) Still, I. W. J.; Strautmanis, J. Can. J. Chem. 1990, 68, 1408.

103. Mahboobi, S.; Wiegrebe, W.; Popp, A. J. Nat. Prod. 1999, 62, 577.

104.(a) Whaley, H. A.; Patterson, E. L.; Dann, M.; Shay, A. J.; Porter, J. N. Antimicrob. Agents Chemother. 1964, 8, 83. (b) He, H.; Shen, B.; Carter, G. T. Tetrahedron Lett. 2000, 41, 2067.

105.(a) Maurer, P. J.; Knudsen, C. G.; Palkowitz, A. D.; Rapoport, H. J. Org. Chem. 1985, 50, 325. (b) Evans, D. A.; Hu, E.; Tedrow, J. S. Org. Lett. 2001, 3, 3133.

106.Ashley, E. R.; Cruz, E. G.; Stoltz, B. M. J. Am. Chem. Soc. 2003, 125, 15000.

107.(a) Reetz, M. T.; Schmitz, A. Tetrahedron Lett. 1999, 40, 2737. (b) Reetz, M. T. Chem. Rev. 1999, 99, 1121.

108.For reviews, see: (a) Arai, T.; Kubo, A. In The Alkaloids; Brossi, A., Ed.; Academic Press: New York, 1983; Vol. 21, Chapter 3. (b) Remers, W. A. The Chemistry of Antitumor Antibiotics; Wiley-Interscience: New York, 1988; Vol. 2, Chapter 3.

109.(a) Martinez, E. J.; Owa, T.; Schreiber, S. L.; Corey, E. J. Proc. Natl. Acad. Sci. U.S.A. 1999, 96, 3496-3501. (b) Danishefsky, S. J.; Zhou, B. U.S. Pat. Appl. 20020025962, Feb 28, 2002. (c) Myers, A. G.; Plowright, A. T. J. Am. Chem. Soc. 2001, 123, 5114.

110.Myers, A. G.; Kung, D. W. J. Am. Chem. Soc. 1999, 121, 10828.

111.(a) Myers, A. G.; Schnider, P.; Kwon, S.; Kung, D. W. J. Org. Chem. 1999, 64, 3322. (b) Myers, A. G.; Yang, B. H.; Kopecky, D. J. Tetrahedron Lett. 1996, 37, 3623.

112. Myers, A. G.; Lanman, B. A. J. Am. Chem. Soc. 2002, 124, 12969.

113. Temme, O.; Taj, S. A.; Andersson, P. G. J. Org. Chem. 1998, 63, 6007.

114.(a) Schultz, A. G.; Liping, P. J. Org. Chem. 1997, 62, 6855. (b) Desmaele, D.; Mekonar, K.; D’Angelo, J. J. Org. Chem. 1997, 62, 3890. (c) Schultz, A. G.; Malachowski, W. P.; You, P. J. Org. Chem. 1997, 62, 1223. (d) Wenkert, E.; Halls, T. D.; Kwart, L. D.; Magnusson, G.; Showalter, H. D. H. Tetrahedron 1981, 37, 4017.

115.(a) Kutney, J. P.; Abdurahman, N.; Le Quesne, P.; Piers, E.; Vlattas, I. J. Am. Chem. Soc. 1966, 88, 3656. (b) Manabu, N.; Nagasawa, H.; Fuji, K. J. Am. Chem. Soc. 1987, 109, 7901.

116.(a) Takano, S.; Chiba, K.; Yonaga, M.; Ogasawara, K. J. Chem. Soc., Chem. Commun. 1980, 616. (b) Takano, S.; Chiba, K.; Yonaga, M.; Ogasawara, K. J. Chem. Soc., Chem. Commun. 1981, 1153.

117.(a) Wenkert, E.; Buckwalter, B. L.; Sathe, S. S. Synth. Commun. 1973, 261. (b) Zenk, P. C.; Wiley: R. A. Chem. Commun. 1984, 695. 
118. Schumacher, R.; Reissig, H. U. Synlett 1996, 1121.

119.(a) Evans, D. A.; Woerpel, K. A.; Hinman, M. M. J. Am. Chem. Soc. 1991, 113, 726. (b) Evans, D. A.; Woerpel, K. A.; Scott, M. J. Angew. Chem., Int. Ed. 1992, 31, 430.

120.(a) Sakai, R.; Higa, T.; Jefford, C. W.; Bernardinelli, G. J. Am. Chem. Soc. 1986, 108, 6404.

(b) Nakamura, H.; Deng, S.; Kobayashi, J.; Ohizumi, Y.; Tomotake, Y.; Matsuzaki, T.; Hirata, Y. Tetrahedron Lett. 1987, 28, 621.

121.Winkler, J. D.; Axten, J. M. J. Am. Chem. Soc. 1998, 120, 6425.

122.(a) Winkler, J. D.; Mazur Bowen, C.; Liotta, F. Chem. Rev. 1995, 95, 2003. (b) Winkler, J. D.; Siegel, M. G.; Stelmach, J. E. Tetrahedron Lett. 1993, 34, 6509. (c) Winkler, J. D.; Stelmach, J.; Siegel, M. G.; Haddad, N.; Axten, J. M.; Dailey, W. P., III. Isr. J. Chem. 1997, $37,47$.

123.Kondo, K.; Shigemori, H.; Kikuchi, Y.; Ishibashi, M.; Sasaki, T.; Kobayashi, J.-I. J. Org. Chem. 1992, 57, 2480.

124.Battersby, A. R.; Burnett, A. R.; Parsons, P. G. J. J. Chem. Soc. 1969, 1187.

125.(a) Patthy-Lukáts, Á.; Kocsis, Á.; Szabó, L. F.; Podányi, B. J. Nat. Prod. 1999, 62, 1492. (b) Patthy-Lukáts, Á.; Beke, Gy.; Szabó, L. F.; Podányi, B. J. Nat. Prod. 2001, 64, 1032.

126.(a) Atta-ur-Rahman; Basha, A. Biosynthesis of Indole Alkaloids; Clarendon Press: Oxford, 1983; pp 45-93. (b) Kapil, R. S.; Brown, R. T. In The Alkaloids; Manske, R. H. F., Rodrigo, R., Eds; Academic Press: New York, 1979; Vol. 18, pp 545-588. (c) Kocsis, Á.; Pál, Z.; Szabó, L.; Tétényi, P.; Varga-Balázs, M. Eur. Pat. Appl. EP 156267, October 2, 1985; Chem. Abstr. 1986, 104, P 149345q.

127. Smith, G. N. Chem. Commun. 1968, 912.

128. Stöckigt, J.; Zenk, M. H. Chem. Commun. 1977, 646.

129.Battersby, A. R.; Burnett, A. R.; Parsons, P. G. J. Chem. Soc. 1969, 1193.

130. Cordell, G. A. Lloydia 1974, 37, 219.

131.(a) De Silva, K. T. D.; Smith, G. N.; Warren, K. E. H. Chem. Commun. 1971, 905. (b) De Silva, K. T. D.; King, D.; Smith, G. N. Chem. Commun. 1971, 908. (c) Blackstock, W. P.; Brown, R. T.; Lee, G. K. Chem. Commun. 1971, 910.

132.Patthy-Lukáts, Á.; Károlyházy, L.; Szabá, L. F.; Podányi, B. J. Nat. Prod. 1997, 60, 69.

133. (a) Brown, R. T. In The Monoterpenoid Indole Alkaloids; Saxton, J. E., Ed.; John Wiley and Sons: New York, 1983; Chapter III, pp 85-96. (b) Bindra, J. S. In The Alkaloids; Manske, R. H. F., Ed.; Academic Press: New York, 1973; Vol. XIV, pp 83-121. (c) Saxton, J. E.. In The Alkaloids; Manske, R. H. F., Ed.; Academic Press: New York, 1965; Vol. VIII, pp 59-91. (d) Saxton, J. E. In The Alkaloids; Manske, R. H. F., Ed.; Academic Press: New York, 1968; Vol. X, pp 521-548. (e) Hibino, S.; Choshi, T. Nat. Prod. Rep. 2001, 18, 66. (f) The Combined Chemical Dictionary on CD-ROM; Chapman and Hall/ CRC, 2001; Version 5: 1

134.(a) Brown, R. T.; Chapple, C. L.; Platt, R. Tetrahedron Lett. 1976, 1401. (b) Brown, R. T.; Platt, R. Tetrahedron Lett. 1976, 2721. (c) Brown, R. T.; Platt, R. Chem. Commun. 1976, 357. 
135.(a) Kawate, T.; Nakagawa, N.; Ogata, K.; Tohru, H. Heterocycles 1992, 33, 801. (b) Czerwinski, K. M.; Cook, J. M. In Advances in Heterocyclic Natural Product Synthesis; Pearson, W. H., Ed.; JAI Press Ltd; London, 1996; Vol. 3, pp 217.

136.(a) Fujii, T.; Ohba, M. In The Alkaloids; Brossi, A., Ed.; Academic Press: New York, 1983; Vol. 22, pp 1-50. (b) Nagakura, N.; Hofle, G.; Coggiola, D.; Zenk, M. H. Planta Med. 1978, 34, 381.

137.Kennard, O.; Roberts, P. J.; Isaacs, N. W.; Allen, F. H.; Motherwell, W. D. S.; Gibson, K. H.; Battersby, A. R. Chem. Commun. 1971, 899.

138.(a) Itoh, A.; Tanahashi, T.; Nakagura, N. Chem. Pharm. Bull. 1989, 37, 1137. (b) Itoh, A.; Tanahashi, T.; Nagakura, N. Phytochemistry 1991, 30, 3117. (c) Itoh, A.; Tanahashi, T.; Nagakura, N. J. Nat. Prod. 1995, 58, 1228.

139.De-Eknamkul, W.; Ounaroon, A.; Tanahashi, T.; Kutchan, T. M.; Zenk, M. H. Phytochemistry 1997, 45, 477.

140.Beke, G.; Szabó, L. F.; Podányi, P. J. Nat. Prod. 2001, 64, 332.

141.Beke, G.; Szabó, L. F.; Podányi, B. J. Nat. Prod. 2002, 65, 649.

142.(a) Angenot, L. Plant Med. Phytother. 1978, 12(2), 123. (b) Bassleer, R.; Depauw-Gillet, M. C.; Massart, B.; Marnette, J.-M.; Wiliquet, P.; Caprasse, M.; Angenot, L. Planta Med. 1982, $45,123$.

143.Lerchner, A.; Carreira, E. M. J. Am. Chem. Soc. 2002, 124, 14826.

144.Cook, G. R.; Beholz, L. G.; Stille, R. G. J. Org. Chem. 1994, 59, 3575.

145.Herdeis, C.; Hubmann, H. P. Tetrahedron: Asymmetry 1992, 3, 1213.

146.Dieter, R. K.; Sharma, R. R. J. Org. Chem. 1996, 61, 4180.

147.For an in-depth discussion, see: Brown, R. T. In Heterocyclic Compounds; Saxon, J. E., Ed.; Wiley-Interscience: New York, 1983; Vol. 25, Part 4, pp 85-97.

148.Burm, B. E. A.; Meijler, M. M.; Korver, J.; Wanner, J. M.; Koomen, G. Tetrahedron 1998, 54, 6135.

149.(a) Rinehart, K. L.; Holt, T. G.; Fregeau, N. L.; Stroh, J. G.; Keifer, P. A.; Sun, F.; Li, L. H.; Martin, D. G. J. Org. Chem. 1990, 55, 4512. (b) Sakai, R.; Rinehart, K. L.; Guan, Y.; Wang, A. H.-J. Proc. Natl. Acad. Sci. U.S.A. 1992, 89, 11456. For a review, see: (c) Rinehart, K. L. Med. Rev. 2000, 20, 1. (c) Takebayashi, Y.; Pourquier, P.; Zimonjic, D. B.; Nakayama, K.; Emmert, S.; Ueda, T.; Urasaki, Y.; Kanzaki, A.; Akiyama, S.; Popescu, N.; Kraemer, K. H.; Pommier, Y. Nat. Med. 2001, 7, 961. (d) Zewail-Foote, M.; Li, V.-S.; Kohn, H.; Bearss, D.; Guzman, M.; Hurley, L. H. Chem. Biol. 2001, 8, 1033.

150. Sakai, R.; Jares-Erijman, E. A.; Manzanares, I.; Silva Elipe, M. V.; Rinehart, K. L. J. Am. Chem. Soc. 1996, 118, 9017.

151.Endo, A.; Yanagisawa, A.; Abe, A.; Tohma, S.; Kan, T.; Fukuyama, T. J. Am. Chem. Soc. 2002, 124, 6552.

152. Corey, E. J.; Gin, D. Y.; Kania, R. S. J. Am. Chem. Soc. 1996, 118, 9202.

153. Buckley, T. F.; Rapoport, H. J. Am. Chem. Soc. 1982, 104, 4446. 
154.Cuevas, C.; Perez, M.; Martin, M. J.; Chicharro, J. L.; Fernandez-Rivas, C.; Flores, M.; Francesch, A.; Gallego, P.; Zarzuelo, M.; Calle, F.; Garcia, J.; Polanco, C.; Rodriguez, I.; Manzanares, I. Org. Lett. 2000, 2, 2545.

155.(a) Menchaca, R.; Martínez, V.; Rodríguez, A.; Rodríguez, N.; Flores, M.; Gallego, P.; Manzanares, I.; Cuevas, C. J. Org. Chem. 2003, 68, 8859. (b) Ikeda, Y.; Idemoto, H.; Hirayama, F.; Yamamoto, K.; Iwao, K.; Asao, T.; Munakata, T. J. Antibiot. 1983, 36, 1279.

156.Zhou, B.; Guo, J.; Danishefsky, S. J. Org. Lett. 2002, 4, 43.

157. Hanessian, S.; Pan, J.; Carnell, A.; Bouchard, H.; Lesage, L. J. Org. Chem. 1997, 62, 465. 158. (a) Roush, W. R.; Michaelides, M. R.; Tai, D. F.; Lesur, B. M.; Chong, W. K. M.; Harris, D. J. J. Am. Chem. Soc. 1989, 111, 2984. (b) Bliard, C.; Herczegh, P.; Olesker, A.; Lukacs, G. J. Carbohydr. Chem. 1989, 8, 103. (c) David, S.; Hanessian, S. Tetrahedron 1985, 41, 643. 


\section{Biographic data of the authors}

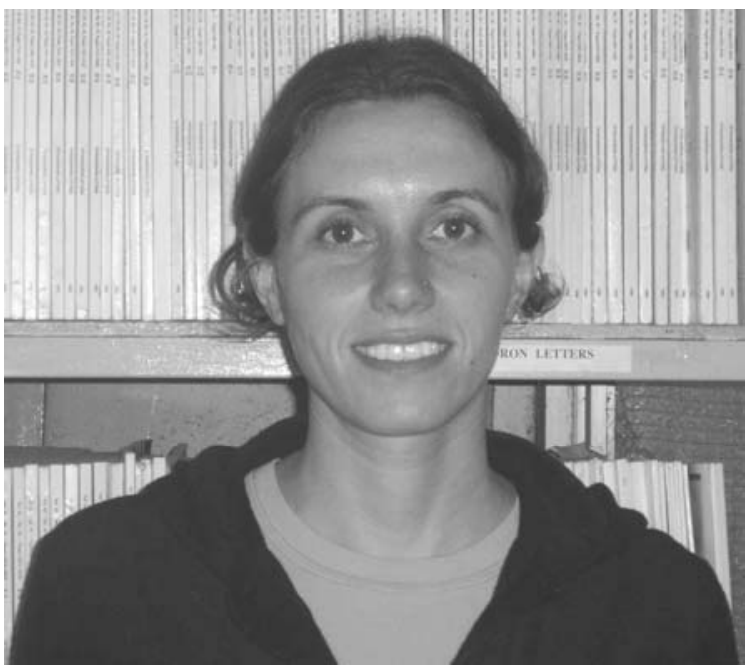

Marcela Amongero was born in Marcos Juarez (Córdoba, Argentina). She is a Biochemist (1999) from the National University of Córdoba (Argentina) and received her BS in Biotechnology from the National University of Rosario in 2004. She recently joined Dr. Kaufman's group and is currently doing research work towards her Ph. D. in Chemical Sciences. Areas of research are asymmetric synthesis and natural products synthesis.

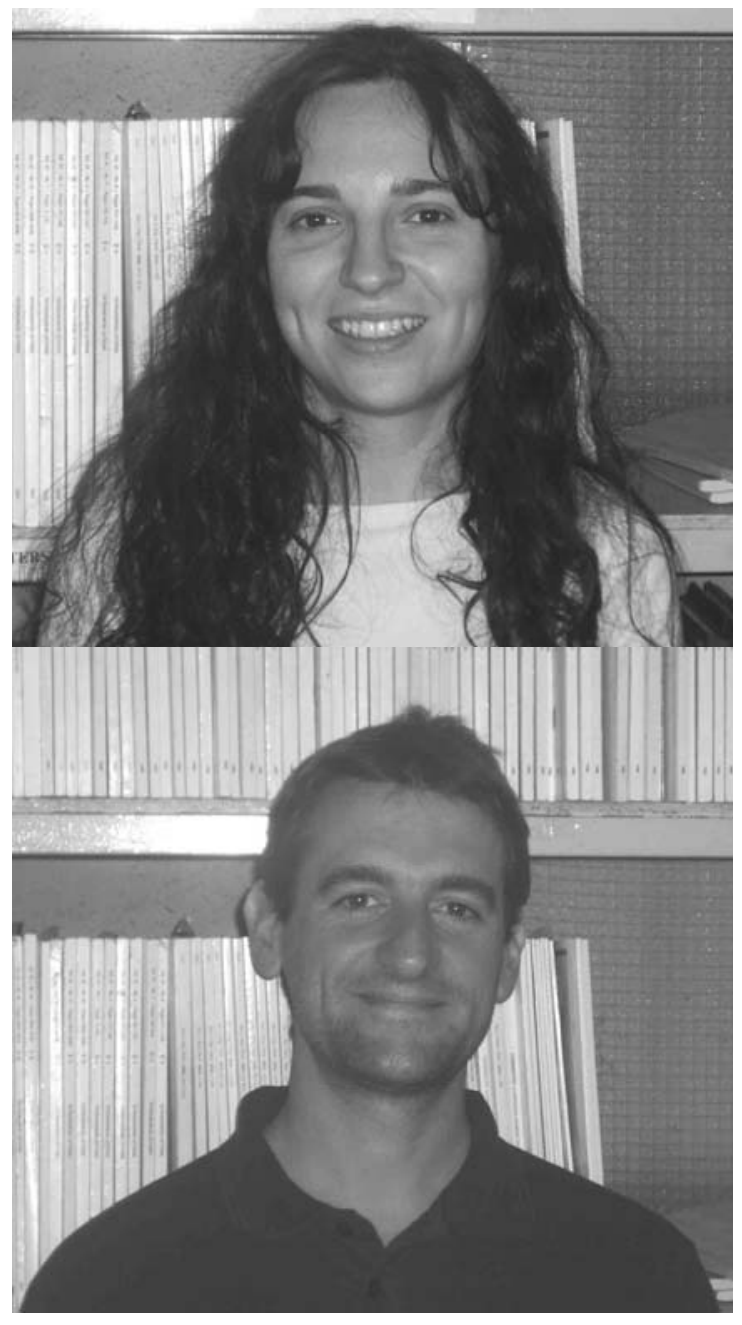

Andrea B. J. Bracca was born in Rosario (Santa $\mathrm{Fe}$, Argentina). She received her $\mathrm{BS}$ in Biotechnology in 2001 from the National University of Rosario (Argentina). She joined Dr. Kaufman's group in 2004 and is currently doing research work towards her Ph. D. in Chemical Sciences. Areas of research are synthesis of heterocyclic natural products.

Enrique L. Larghi was born in Rosario (Santa $\mathrm{Fe}$, Argentina). He received his BS in Chemistry in 1997 from the National University of Rosario (Argentina). Immediately, he started research work at the Universidade Federal de Santa Maria (Brazil) where he received his MSc. degree in 1999 (with Dr. Claudio C. Silveira) and his Ph. D. in 2003 (under Dr. Ademir Farias Morel). After a short experience in the Argentine pharmaceutical industry, he joined joined Dr. Kaufman's group as a postdoctoral fellow. Areas of research are organometalic chemistry and synthesis of heterocyclic natural products. 


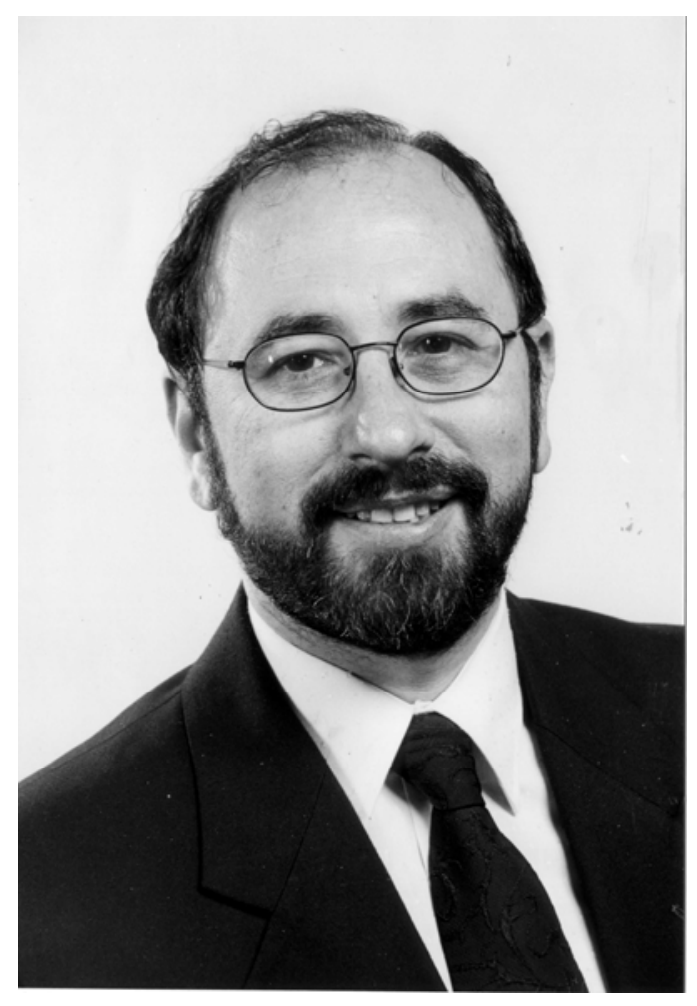

Teodoro S. Kaufman was born near Moises Ville (Santa $\mathrm{Fe}$, Argentina). He graduated as Biochemist (1982) and Pharmacist (1985) from the National University of Rosario (Argentina) and received his $\mathrm{Ph}$. D. in Organic Chemistry from the same University (1987), working with Professor Edmundo A. Rúveda in the synthesis of geochemically interesting terpenoids. From 1987 to 1989 , he was a postdoctoral fellow in the laboratory of Professor Robert D. Sindelar at The University of Mississippi, working on the design and synthesis of analogs of the naturallyoccurring complement inhibitor K-76. In 1990, he became Assistant Research Scientist of the Argentine National Research Council (CONICET) and Assistant Professor at the National University of Rosario. He is now Associate Professor, and Sub-Director of IQUIOS, the Institute of Synthetic Organic Chemistry (Rosario, Argentina), where he heads a small research group as Independent Research Scientist of CONICET. Areas of research are synthetic methodology, asymmetric synthesis and natural products synthesis. The work in his laboratory has been supported by ANPCyT, CONICET, Fundación Antorchas, IFS and TWAS. 